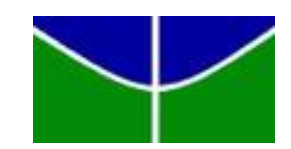

Universidade de Brasília

Departamento de Estatística

\begin{abstract}
Análise de Dados do Senado Federal: construção de um modelo de previsão para o número de sessões e reuniões
\end{abstract}

Taís Bottecchia

Projeto apresentado para obtenção do título de Bacharel em Estatística.

Brasília

2017 
Taís Bottecchia

\section{ANÁLISE DE DADOS DO SENADO FEDERAL: CONSTRUÇÃO DE UM MODELO DE PREVISÃO PARA O NÚMERO DE SESSÕES E REUNIÕES}

Orientador:

Prof. Dr. Eduardo Monteiro de Castro Gomes

Brasília 
2017 


\section{RESUMO}

As despesas previstas com as sessões e reuniões realizadas pelo Senado Federal e Congresso Nacional constam da dotação orçamentária do Senado Federal, estabelecida na Lei Orçamentária Anual, com base no parágrafo $5^{\circ}$ do artigo 165 da Constituição da República Federativa do Brasil de 1988. Com ferramentas estatísticas adequadas é possível estimar o número de sessões e reuniões a serem realizadas pelos referidos órgãos, no decorrer do ano, de forma que o resultado se aproxime da situação real. Uma vez quantificadas as sessões e reuniões, setores interessados podem prever seus custos. Este trabalho teve o propósito de apresentar modelos estatísticos capazes de efetuar tal previsão. Para isso, foram estabelecidos dois objetivos. Primeiramente, a obtenção e organização dos dados foi realizada pela criação de conjuntos de dados, extraídos de fontes de consultas oficiais, com informações referentes às sessões e reuniões realizadas pelo Senado Federal e Congresso Nacional, no período de 2003 a 2016. Para garantir a lisura do procedimento, os dados pesquisados foram submetidos ao processo de confrontamento e validação, sendo selecionados somente aqueles que realmente demonstraram veracidade e relevância. Esses dados serviram de subsídios para chegar ao segundo objetivo, propor modelos de previsão para aferir a estimativa anual dos mencionados eventos. Utilizando os recursos estatísticos de Análise de Regressão Linear e Séries Temporais foi possível criar modelos segmentados de previsão, que geraram resultados parciais. O somatório desses resultados parciais gerou o modelo final capaz de prever, em um único resultado, o número total de sessões e reuniões a serem realizadas pelos órgãos citados.

Palavras-chave: Previsão. Sessões. Reuniões. Senado. Congresso. Dados. Modelos. 


\begin{abstract}
The cost provided during the sessions and reunions of the Federal Senate and Nacional Congress are from Senate estimation, established in the annual Budget Law, based on paragraph 5 article 165 of the Brazilian Constitution from 1988. With the adequate statistical tools is possible to estimate a number of sessions and reunions performed by that courts, during the year, in a way that the results can be almost precise concerning the real situation. Once the sessions and reunions being possible to be counted, the sectors that are interested can predict the costs. That undergraduate thesis aims to present statistical tools that are capable to accomplish that kind of previsions. For this was settled down two objectives. Primarily, the obtainment and organization of the data was accomplished by the creation of data set, extracted from sources of official consultations, with informations of sessions and reunions fulfilled by the Federal Senate and Nacional Congress of Brazil, from 2003 until 2016. Furthermore, to ensure the quality of the procedure, the searched data was submitted to the validation process, being selected just the ones that showed truly and relevance. That data was used to reach the second objective, propose models of previsions to check the annual estimation of the events that was mentioned. Using the statistics resources was possible to create models of previsions, witch created parcial results. The sum of these partial results turned possible the final model capable to predict, in just one result, the totality of sessions and reunions accomplished by the courts mentioned.
\end{abstract}

Keyword Search: Previsions. Sessions. Reunions. Senate. Data. Models. Congress. 


\section{Lista de Figuras}

1 Interpretação geométrica dos parâmetros . . . . . . . . . . . . 11

2 Interpretação geométrica do erro associado . . . . . . . . . . . 11

3 Resíduos heterocedásticos . . . . . . . . . . . . . . . 19

4 Formação de Conjunto de Dados . . . . . . . . . . . . . . 24

5 Sumário do RAP de 2010 - Parte I . . . . . . . . . . . . . . 24

6 Total de sessões realizadas em 2010 . . . . . . . . . . . 25

7 Total de sessões realizadas em 2006 . . . . . . . . . . . 25

8 Mapa de publicações das Atas . . . . . . . . . . . . . . 26

9 Conjunto de Dados Brutos para as reuniões . . . . . . . . . . 27

10 Registro da $4^{\mathrm{a}}$ reunião realizada pela CAS em 2003 . . . . . . 29

11 CPI - RAP de $2010 \ldots \ldots$. . . . . . . . . . . . 29

12 Comissão Temporária de Juristas . . . . . . . . . . . . . . . . 29

13 Registro das Atas por Comissão de uma reunião conjunta . . . 30

14 Registro de Ata republicada . . . . . . . . . . . . . . . . 31

15 Conjunto de Dados Consolidado pelo RAP para as reuniões . . 31

16 Conjunto de Dados Consolidado pelo RAP para as sessões . . 32

17 Web página do Senado Federal . . . . . . . . . . . . . . 33

18 Web página de Relatórios Mensais . . . . . . . . . . . . . . 34

19 Seleção do mês de fevereiro de 2005 . . . . . . . . . . . . . . 34

20 Localização das reuniões . . . . . . . . . . . . . . . . . . . 35

21 Conjunto de Dados consolidados pelo Relatório Mensal . . . . 35

22 Níveis de confiabilidade da informação . . . . . . . . . . . . 36

23 CDC RAP e CDC Relatório Mensal . . . . . . . . . . . . . 37

24 Conjunto Unificado . . . . . . . . . . . . . . . . . . 37

25 CDC RAP menos intersecção . . . . . . . . . . . . . . 38

$2626^{\text {a }}$ reunião realizada pela CMA . . . . . . . . . . . . 38

27 Seleção da data desejada para consulta no DSF . . . . . . . . 39

28 Seleção do Suplemento . . . . . . . . . . . . . . . . . . . . . . 39

29 Apresentação da Ata no DSF . . . . . . . . . . . . . . . . . 40

30 Localização da Ata de reunião . . . . . . . . . . . . . . . . . 42

31 RAP de $2015 \ldots \ldots$. . . . . . . . . . . . . . . . . . . 42

32 Atas disponibilizadas em CD pela Secretaria de Comissões . . 43

33 Ata da $17^{\mathrm{a}}$ reunião . . . . . . . . . . . . . . . . . 43

34 Ata da $18^{\mathrm{a}}$ reunião . . . . . . . . . . . . . . . . . . 43

35 Ata da $19^{\mathrm{a}}$ reunião . . . . . . . . . . . . . . . . . . 44

36 Tabela de confrontamento . . . . . . . . . . . . . 44

37 CDC pelo Relatório Mensal menos intersecção . . . . . . . . . 45

38 Reunião realizada pela CAS - Conjunto de Dados consolidado pelo Relatório Mensal . . . . . . . . . . . . . . . . . . . 45 
39 CD disponibilizado pela Secretaria de Comissões - Atas . . . . 45

40 CD disponibilizado pela Secretaria de Comissões - Pauta . . . 46

41 Levantamento das pastas das Atas . . . . . . . . . . . . 46

42 Conjunto de Dados consolidado pelo Relatório Mensal . . . . . 47

43 Página web do DSF . . . . . . . . . . . . . . . . . 48

44 Página web do DSF - Sessão Legislativa Ordinária . . . . . . . 49

45 Página web do DSF - Sessão Legislativa Extraordinária . . . . 49

46 Página web do DSF - Sessão Legislativa Extraordinária . . . . 50

47 Número de reuniões realizadas por Comissões Permanentes . . 53

48 Eleições . . . . . . . . . . . . . . . . . . . . . . . . . 54

49 Análise de resíduos - Homocedasticidade . . . . . . . . . 55

50 Gráfico de Probabilidade Normal dos Resíduos . . . . . . . . . 56

51 Número de reuniões realizadas por Subcomissões, por ano . . . 56

52 Número de reuniões x Número de Subcomissões . . . . . . . . 57

53 Análise de resíduos - Homocedasticidade . . . . . . . . . . . 59

54 Gráfico de Probabilidade Normal dos Resíduos . . . . . . . . . 59

55 Número de reuniões de Comissões Temporárias realizadas por ano ............................ 60

56 Número de Comissões Temporárias x Número de reuniões . . . 61

57 Gráfico de Probabilidade Normal dos Resíduos . . . . . . . . . 62

58 Análise de resíduos - Homocedasticidade . . . . . . . . . . 63

59 Gráfico de Probabilidade Normal dos Resíduos . . . . . . . . . 64

60 Número de sessões plenárias por ano . . . . . . . . . . . . . . 66

61 Número de sessões realizadas por ano x número de sessões previstas por ano . . . . . . . . . . . . . . 67

62 Análise de resíduos - Homocedasticidade . . . . . . . . . 70

63 Gráfico de Probabilidade Normal dos resíduos . . . . . . . . . 70

64 Sessões Conjuntas . . . . . . . . . . . . . . . . . . 71

65 FAC e FACP do processo . . . . . . . . . . . . . . . 72

66 Análise de resíduos - Correlograma . . . . . . . . . . . 73

67 Previsão para 2015 e 2016 x Valores reais de 2015 e 2016 . . . 73

68 Anos x Percentual dos resíduos . . . . . . . . . . . . 75 


\section{Lista de Tabelas}

1 Variáveis do CDC pelo RAP para reuniões . . . . . . . . . . . 28

2 Variáveis do CDC pelo RAP para sessões plenárias e conjuntas 32

3 Variáveis do CDC pelo Relatório Mensal . . . . . . . . . . . . 33

4 Análise do número de reuniões para a CMA . . . . . . . . . . 41

5 Quantitativo de sessões plenárias . . . . . . . . . . . 50

6 Tabela Comparativa . . . . . . . . . . . . . . . 51

7 Teste t . . . . . . . . . . . . . . 55

8 Teste de significância de Shapiro-Wilk . . . . . . . . . . 56

9 Teste t . . . . . . . . . . . . . . . . 58

10 Teste de significância de Shapiro-Wilk . . . . . . . . . . . . . 59

11 Tabela comparativa entre Arquimedes e RAP . . . . . . . . . 60

12 Teste de significância de Shapiro-Wilk . . . . . . . . . . . . 62

13 Erro Quadrático Médio . . . . . . . . . . . . . . . . 62

14 Testet . . . . . . . . . . . . . . . . 63

15 Teste de significância de Shapiro-Wilk . . . . . . . . . . . 64

16 Tabela Comparativa . . . . . . . . . . . . . . . 65

17 Número de sessões plenárias não-realizadas . . . . . . . . . . . 67

18 Sessões plenárias realizadas em 28/10/2009 . . . . . . . . . . . 68

19 Teste t . . . . . . . . . . . . . . . . . 69

20 Teste de significância de Shapiro-Wilk . . . . . . . . . . . . 70

21 Modelos Parciais . . . . . . . . . . . . . . . . 74 


\section{Sumário}

1 INTRODUÇÃO $\quad 8$

2 REVISÃO LITERÁRIA $\quad 10$

2.1 Regressão Linear . . . . . . . . . . . . . . . . . . . . . . . . 10

2.1.1 Regressão Linear Simples . . . . . . . . . . . . . . . . . 10

2.1.2 Regressão Linear Múltipla . . . . . . . . . . . . . . . . . 14

2.1.3 Variáveis Indicadoras . . . . . . . . . . . . . . . . 16

2.2 Inferência . . . . . . . . . . . . . . . . . . . . 16

2.2.1 Teste de hipótese . . . . . . . . . . . . . . . . . 16

2.2.2 Teste t para coeficientes de regressão . . . . . . . . . 17

2.2.3 Teste de Significância Global . . . . . . . . . . . . . . 17

2.2 .4 Análise de resíduos . . . . . . . . . . . . . . . . . . 18

2.2.5 Homocedasticidade . . . . . . . . . . . . . . . 18

2.2.6 Normalidade . . . . . . . . . . . . . . . . . . 18

2.2.7 Violação de suposições . . . . . . . . . . . . . . . . . 19

2.3 Séries Temporais . . . . . . . . . . . . . . . . . . . . 19

2.3.1 Processo de Médias móveis . . . . . . . . . . . . . . 21

3 METODOLOGIA 23

3.1 Conjunto de Dados Brutos (CDB) . . . . . . . . . . . . 23

3.1.1 Conjunto de Dados Brutos para as sessões . . . . . . . 24

3.1.2 Conjunto de Dados Brutos para as reuniões . . . . . . 26

3.2 Conjunto de Dados consolidado (CDC) pelo RAP . . . . . . . 27

3.2.1 Conjunto de Dados consolidado pelo RAP para as reuniões . . . . . . . . . . . . . . . 27

3.2.2 Conjunto de Dados consolidado pelo RAP para sessões plenárias e conjuntas . . . . . . . . . . . . 31

3.3 Conjunto de Dados consolidado pelo Relatório Mensal para reuniões realizadas pelas Comissões Permanentes . . . . . . . . 32

3.4 Validação . . . . . . . . . . . . . . . . . . . . . 35

3.4.1 Validação das reuniões realizadas pelas Comissões Permanentes .................. 36

3.4.2 Validação das reuniões realizadas pelas Comissões Temporárias . . . . . . . . . . . . . . . . 47

3.4.3 Validação do Conjunto de Dados consolidado pelo RAP para as sessões plenárias ou conjuntas . . . . . . . . . . 48 
4 RESULTADOS

4.1 Reuniões realizadas por Comissões Permanentes . . . . . . . . 52

4.2 Reuniões realizadas por Subcomissões das Comissões Permanentes ....................... 56

4.3 Reuniões realizadas por Comissões Temporárias . . . . . . . . 59

4.4 Sessões Plenárias . . . . . . . . . . . . . . . . . . . 64

4.5 Sessões Conjuntas . . . . . . . . . . . . . . . . . . . 70

4.6 Modelo Final . . . . . . . . . . . . . . . . . . . . . . 74

5 CONCLUSÃO $\quad 76$

6 REFERÊNCIAS $\quad 78$

$\begin{array}{lll}7 & \text { GLOSSÁRIO } & 79\end{array}$ 


\section{INTRODUÇÃO}

A Secretaria-Geral da Mesa (SGM) do Senado Federal fornece anualmente à Coordenação de Planejamento e Acompanhamento Orçamentário a previsão do número de sessões plenárias e reuniões a serem realizadas pelo Senado Federal e do número de sessões conjuntas a serem realizadas pelo Congresso Nacional, no decorrer do ano. Os custos estimados com a realização desses eventos constam da dotação orçamentária do Senado Federal, estabelecida na Lei Orçamentária Anual, com base no parágrafo $5^{\circ}$ do artigo 165 da Constituição da República Federativa do Brasil de 1988. O setor de Coordenação de Estatísticas, Pesquisa e Relatórios Legislativos é responsável, junto à SGM, pelo levantamento desses valores. Por se tratar de uma previsão, torna-se necessário adotar critérios com embasamento estatístico para aproximar a previsão da situação real.

Visando a esse propósito, primeiramente, foi necessário consolidar informações referentes às sessões e reuniões do Senado Federal e do Congresso Nacional realizadas no período de 2003 a 2016, em conjuntos de dados. Nesse processo, foram utilizadas as seguintes fontes de consulta: Relatórios da Presidência (RAP), Relatórios Mensais da atividade legislativa, Diários do Senado Federal, Atas e Pautas disponibilizadas pela Secretaria de Comissões e o programa Arquimedes.

Durante a organização dos dados, observaram-se controvérsias entre informações extraídas de fontes de consultas diferentes. Algumas fontes apresentaram maior número de sessões ou reuniões do que outras. Destaca-se que o maior conflito se deu em anos anteriores a 2012. Dessa forma, foi necessário criar mecanismos de validação a fim de aumentar a confiabilidade dos dados coletados.

Determinados dados foram consolidados manualmente em planilhas eletrônicas. Tal tarefa se deu pelo fato de os registros compreendidos nos Diários do Senado Federal, nos Relatórios da Presidência e nos Relatórios Mensais da atividade legislativa não serem disponibilizados de forma padronizada, impedindo a transferência automatizada para arquivos de outro formato. Acrescenta-se a tal esforço, o contratempo de os dados se encontrarem dispersos, exigindo maior empenho na pesquisa. A pesquisa dos dados constantes dessas fontes de informações se deu com o auxílio e acompanhamento dos servidores do Senado.

A partir da criação e organização dos conjuntos de dados, passou-se à fase da análise descritiva para identificar e descobrir prováveis causas relacionadas às observações coletadas. Esse procedimento foi adotado com o número total de reuniões realizadas por Comissões Permanentes, reuniões realizadas por 
Subcomissões, reuniões realizadas por Comissões Temporárias, sessões plenárias do Senado Federal e sessões conjuntas do Congresso Nacional. Para prever o número de sessões Conjuntas foi empregado o modelo de Médias Móveis e para prever os demais eventos (reuniões realizadas por Comissões Permanentes, por Comissões Temporárias, por Subcomissões ou por sessões Plenárias) foi utilizado modelo de Regressão Linear.

Desta forma, chegou-se ao modelo individual de previsão para cada tipo de sessão e de reunião. Esses modelos geraram resultados parciais. O resultado final consiste da somatória dos resultados parciais.

O trabalho foi estruturado em 7 sessões. A seção 1 trata da presente introdução. A seção 2 aborda a Revisão Literária, onde menciona os modelos estatísticos empregados. A seção 3 cita a Metodologia utilizada para a consolidação dos conjuntos de dados e o processo de validação. A seção 4 apresenta os Resultados com a proposta dos modelos segmentados e do modelo final de previsão do número de reuniões e sessões. A seção 5 relata a conclusão final do trabalho. As seções 6 e 7 apresentam, respectivamente, as Referências de consulta e o Glossário de termos utilizados. 


\section{REVISÃO LITERÁRIA}

Buscando estimar o número de sessões e reuniões a serem realizadas pelo Senado Federal e pelo Congresso Nacional, foram utilizados modelos estatísticos de Regressão Linear e Médias Móveis.

Nos tópicos 3.1 e 3.2 será abordada a teoria do modelo de Regressão Linear com referência nos livros (Wooldridge 2005) [1] e (Moretin,Toloi 1969) [3]. O modelo de Séries Temporais descrito no tópico 3.3 com referência no livro (Charnet 1999) [2].

\section{$2.1 \quad$ Regressão Linear}

A análise de regressão linear consiste em averiguar a existência de uma relação entre uma variável dependente (resposta) com uma ou mais variáveis independentes (explicativas). Em outras palavras, permite obter uma equação que tente explicar o comportamento de uma variável dependente, quando atribuídos valores casuais à(s) variável(is) independente(s).

Tal método utiliza dados observados para prever comportamentos futuros e apontar variáveis que realmente interferem na análise estatística de um padrão de comportamento percebido. Desta forma, a regressão linear pode ter como objetivo a predição e a identificação de variáveis relevantes.

Quando o modelo apresenta somente uma variável independente (explicativa) é denominado de modelo de regressão linear simples; quando apresenta mais de uma variável independente, é denominadado de regressão linear múltipla.

\subsubsection{Regressão Linear Simples}

De acordo com (Wooldridge 2005) [1], o modelo de regressão linear simples é dado por:

$$
Y_{i}=\beta_{0}+\beta_{1} x_{i}+\varepsilon_{i}, \quad \text { para } i=1, \ldots, n
$$

Sendo:

$Y_{i}$ : valor da variável resposta para o i-ésimo elemento da amostra;

$x_{i}$ : valor da variável explicativa para o i-ésimo elemento da amostra;

$\beta_{0}$ e $\beta_{1}$ : são os parâmetros desconhecidos;

$\varepsilon_{i}$ : erro aleatório.

O parâmetro $\beta_{0}$ representa o ponto em que a reta regressora corta o eixo $\mathrm{Y}$ quando o valor de $\mathrm{x}$ é igual a zero. Devido à linearidade do modelo, o 
parâmetro $\beta_{1}$ representa o aumento de $\beta_{1}$ unidades em y quando x aumenta uma unidade.

Geometricamente, $\beta_{0}$ representa o intercepto e $\beta_{1}$ representa o coeficiente angular da reta com relação ao eixo x, representados na Figura 1:

Figura 1: Interpretação geométrica dos parâmetros

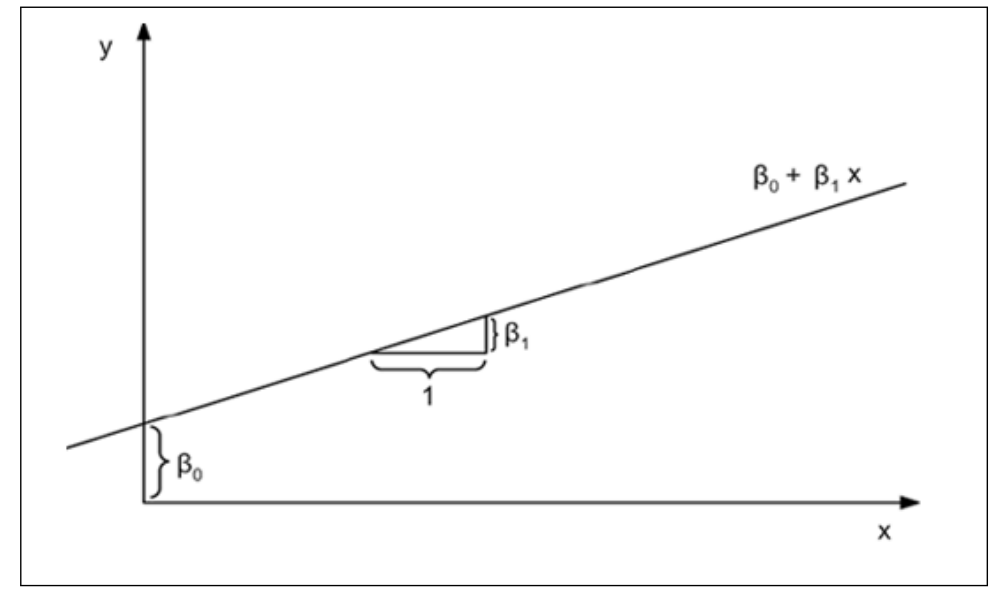

Por sua vez, erro aleatório $\left(\varepsilon_{i}\right)$ representa os fatores não observáveis, ou seja, corresponde a outros fatores não enumerados no modelo que afetam $Y$. A variável $\varepsilon$ é dada por:

$$
\varepsilon_{i}=y_{i}-\left(\beta_{0}+\beta_{1} x_{i}\right)
$$

Graficamente, $\varepsilon_{i}$ é o erro associado à distância entre o valor observado $Y_{i}$ e o correspondente ponto na curva, do modelo proposto, para o mesmo elemento da amostra i de $x_{i}$, conforme apresentado na Figura 2.

Figura 2: Interpretação geométrica do erro associado

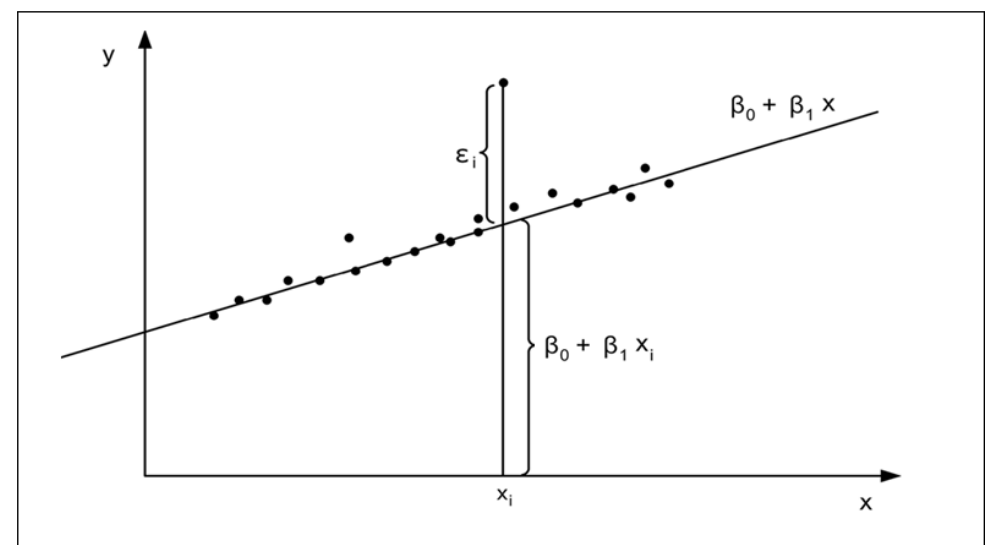


Para estimar os parâmetros $\beta_{0}$ e $\beta_{1}$ será utilizado o método dos Mínimos Quadrados, que consiste em adotar os estimadores que minimizam a soma de quadrados dos erros, ou seja, que minimizam a soma de quadrados dos desvios entre os valores estimados e os valores observados na amostra, dado na equação 3:

$$
\sum_{i=1}^{n} \varepsilon_{i}^{2}=\sum_{i=1}^{n}\left[Y_{i}-\beta_{0}-\beta_{1} X_{i}\right]^{2}
$$

Para adotar o modelo, tem-se como pressuposto que, na população, $\varepsilon$ tem média zero e é não-correlacionado com x. Portanto, parte-se do princípio que:

1. $E(\varepsilon)=0$

2. A covariânvia entre $\mathrm{x}$ e $\varepsilon$ é zero

$$
\operatorname{Cov}(x, \varepsilon)=E(x \varepsilon)=0
$$

Dado $E(e)=0$

$$
\begin{array}{r}
E\left(y_{i}\right)=E\left(\beta_{0}+\beta_{1} x_{i}+\varepsilon_{i}\right) \\
=\beta_{0}+\beta_{1} x_{i}+E\left(\varepsilon_{i}\right) \\
=\beta_{0}+\beta_{1} x_{i}
\end{array}
$$

Para encontrar as estimativas dos parâmetros, é necessário obterem-se as derivadas parciais da Equação 3 em relação a $\beta_{0}$ e $\beta_{1}$ e igualá-las a zero:

$$
\begin{gathered}
\frac{\partial L\left(\beta_{0}, \beta_{1}\right)}{\partial \beta_{0}}=-2 \sum_{i=1}^{n}\left(Y_{i}-\beta_{0}-\beta_{1} x_{i}\right)=0 \\
\mathrm{e} \frac{\partial L\left(\beta_{0}, \beta_{1}\right)}{\partial \beta_{1}}=-2 \sum_{i=1}^{n}\left(Y_{i}-\beta_{0}-\beta_{1} x_{i}\right) x_{i}=0
\end{gathered}
$$

Simplificando as equações 5 e 6, obtém-se o sistema expresso:

$$
\left\{\begin{array}{c}
n \widehat{\beta}_{0}+\widehat{\beta}_{1} \sum_{i=1}^{n} x_{i}=\sum_{i=1}^{n} Y_{i} \\
\widehat{\beta}_{0} \sum_{i=1}^{n} x_{i}+\widehat{\beta}_{1} \sum_{i=1}^{n} x_{i}^{2}=\sum_{i=1}^{n} x_{i} Y_{i} .
\end{array}\right.
$$

Resolvendo o sistema, os parâmetros são dados por:

$$
\widehat{\beta}_{0}=\bar{Y}-\widehat{\beta}_{1} \bar{x}
$$




$$
\widehat{\beta}_{1}=\frac{\sum_{i=1}^{n}\left(x_{i}-\bar{x}\right)\left(Y_{i}-\bar{Y}\right)}{\sum_{i=1}^{n}\left(x_{i}-\bar{x}\right)^{2}}=\frac{\sum_{i=1}^{n}\left(x_{i}-\bar{x}\right) Y_{i}}{\sum_{i=1}^{n}\left(x_{i}-\bar{x}\right) x_{i}}
$$

Os valores de $\widehat{\beta}_{0}$ e $\widehat{\beta}_{1}$ determinados são chamados estimadores de Mínimos Quadrados Ordinários (MQO).

Assim, o modelo de regressão linear simples ajustado é expresso por:

$$
\widehat{y}_{i}=\widehat{\beta}_{0}+\widehat{\beta}_{1} x_{i}
$$

Sendo $\widehat{y}_{i}$ o valor previsto para y quando $X=x_{i}$.

Há um valor estimado para cada observação na amostra. O resíduo de MQO associado a cada observação i, $\widehat{\varepsilon_{i}}$, é a diferença entre $y_{i}$ e seu valor estimado $\left(\widehat{y}_{i}\right)$, representado na equação:

$$
\widehat{\varepsilon_{i}}=y_{i}-\widehat{y_{i}}
$$

Se $\widehat{\varepsilon_{i}}$ é positivo, a reta subestima $y_{i}$; se $\widehat{\varepsilon_{i}}$ é negativo, a reta superestima $y_{i}$. O caso ideal para a observação i é quando $\widehat{\varepsilon_{i}}=0$, mas em geral, isso dificilmente ocorre.

Para a construção do modelo de regressão linear utilizaram-se como suposições a existência de homocedasticidade e a ausência de autocorrelação do erro:

SUPOSIÇÃO 1 Homocedasticidade

Os erros $\varepsilon_{i}$ são variáveis aleatórias com variância constante

$$
\operatorname{Var}\left(\varepsilon \mid x_{1}, \ldots, x_{p}\right)=\sigma^{2}
$$

Esse pressuposto assegura que a média condicional de $Y$ possui a mesma precisão para os diferentes elementos da variável X.

SUPOSIÇÃO 2 Ausência de autocorrelação no erro

$$
\operatorname{Cov}\left(\varepsilon_{i}, \varepsilon_{j}\right)=0 \text { para } i \neq j
$$

O pressuposto de ausência de autocorrelação ou correlação serial no termo de erro assegura que não existe uma relação sistemática entre o termo de erro e a variável dependente $(Y)$. 


\subsubsection{Regressão Linear Múltipla}

O modelo de regressão linear múltipla se difere do modelo de regressão linear simples por considerar duas ou mais variáveis explicativas, sendo definido por:

$$
Y_{i}=\beta_{0}+\beta_{1} x_{i 1}+\beta_{2} x_{i 2}+\ldots+\beta_{p} x_{i p}+e_{i}, \quad i=1, \ldots, n
$$

$Y_{i}$ representa o valor da variável resposta na observação $i, \quad i=1, \ldots, n$; $x_{i 1}, x_{i 2}, \ldots, x_{i p}$ são valores conhecidos da i-ésima observação das $\mathrm{p}$ variáveis explicativas;

$\beta_{0}, \beta_{1}, \beta_{2}, \ldots, \beta_{p}$ são parâmetros ou coeficientes da regressão;

$e_{i}, \quad i=1, \ldots, n$ são os erros aleatórios

Os parâmetros $\beta_{j}, \quad j=1, \ldots, p$, representam o aumento na variável $Y$, quando a variável $X_{j}, \quad j=1, \ldots, p$ sofre um acréscimo unitário, mantendo todas as outras variáveis constantes. O parâmetro $\beta_{0}$ corresponde ao intercepto do plano de regressão.

Da mesma forma que explicitado no modelo de regressão linear simples, para estimar os parâmetros $\beta_{j}$ será utilizado o método dos Mínimos Quadrados. Ou seja, também será necessário obter as derivadas parciais da Equação 12 em relação aos $\beta_{j}$ e iguala-las a zero:

$$
\sum_{i=1}^{n} \varepsilon_{i}^{2}=\sum_{i=1}^{n}\left[Y_{i}-\beta_{0}-\beta_{1} x_{i 1}-\beta_{2} x_{i 2}-\ldots-\beta_{p} x_{i p}\right]^{2}
$$

$\left\{\begin{array}{c}\frac{\partial L}{\partial \beta_{0}}=-2 \sum_{i=1}^{n}\left[Y_{i}-\beta_{0}-\beta_{1} x_{i 1}-\beta_{2} x_{i 2}-\cdots-\beta_{p} x_{i p}\right]=0, \\ \frac{\partial L}{\partial \beta_{1}}=-2 \sum_{i=1}^{n}\left[Y_{i}-\beta_{0}-\beta_{1} x_{i 1}-\beta_{2} x_{i 2}-\cdots-\beta_{p} x_{i p}\right]=0, \quad j=1,2, \ldots, p . \\ \vdots \\ \frac{\partial L}{\partial \beta_{j}}=-2 \sum_{i=1}^{n}\left[Y_{i}-\beta_{0}-\beta_{1} x_{i 1}-\beta_{2} x_{i 2}-\cdots-\beta_{p} x_{i p}\right] x_{j i}=0,\end{array}\right.$

Para facilitar o cálculo das estimativas dos parâmetros, expressa-se o modelo na forma matricial: 


$$
Y=\left[\begin{array}{c}
Y_{1} \\
Y_{2} \\
\vdots \\
Y_{n}
\end{array}\right] \quad, \quad X=\left[\begin{array}{ccccc}
1 & x_{11} & x_{12} & \ldots & x_{1 p} \\
1 & x_{21} & x_{22} & \ldots & x_{2 p} \\
\vdots & \vdots & \vdots & \ddots & \vdots \\
1 & x_{n 1} & x_{n 2} & \ldots & x_{n p}
\end{array}\right] \quad, \quad \beta=\left[\begin{array}{c}
\beta_{0} \\
\beta_{1} \\
\vdots \\
\beta_{p}
\end{array}\right] \quad \text { e } \varepsilon=\left[\begin{array}{c}
\varepsilon_{1} \\
\varepsilon_{2} \\
\vdots \\
\varepsilon_{n}
\end{array}\right]
$$

$Y$ é um vetor $n \times 1$ cujos componentes correspondem às n respostas; $X$ é uma matriz de dimensão $n \times(p+1)$ denominada matriz do modelo; $\beta$ é um vetor $(p+1) \times 1$ cujos elementos são os coeficientes de regressão $\varepsilon$ é um vetor de dimensão $n \times 1$ cujos componentes são os erros

Em conformidade com (Wooldridge 2005) [1], supondo que a matriz $\left(X^{\prime} X\right)$ tenha inversa, ou seja, tenha determinante diferente de zero e seja não singular, conclui-se que os parâmetros $\beta_{j}, \quad j=0, \ldots, p$ são dados pelo vetor:

$$
\widehat{\beta}=\left(X^{\prime} X\right)^{-1} X^{\prime} Y
$$

Sendo,

$E(\widehat{\beta})=\beta \quad, \operatorname{Cov}(\widehat{\beta})=\sigma^{2}\left(X^{\prime} X\right)^{-1}+\beta \beta^{\prime}-\beta \beta^{\prime}=\sigma^{2}\left(X^{\prime} X\right)^{-1}$ e $\widehat{\sigma^{2}}=\frac{(y-X \widehat{\beta})^{\prime}(y-X \widehat{\beta})}{n-p-1}$

Conclui-se que o modelo de regressão linear ajustado e o vetor de resíduos são respectivamente:

$$
\begin{gathered}
\widehat{Y}=X \widehat{\beta} \\
\varepsilon=Y-\widehat{Y}
\end{gathered}
$$

Para calcular os parâmetros $\widehat{\beta}_{j}$, além das suposições 1 e 2 , deve-se considerar suposição 3:

SUPOSIÇÃO 3 Ausência de multicolinearidade

Não há relação linear perfeita entre as variáveis explicativas $(\mathrm{X})$. Ou seja:

$$
\operatorname{posto}(X)=p
$$

Esse pressuposto garante que a matriz $\left(X^{\prime} X\right)^{-1}$ exista. Caso posto $(X)<$ $p$, a matriz $\left(X^{\prime} X\right)^{-1}$ é singular, impossibilitando a estimação dos parâmetros. 


\subsubsection{Variáveis Indicadoras}

Uma forma de introduzir variáveis qualitativas em modelos de regressão linear consiste na utilização de variáveis indicadoras, frequentemente chamadas de binárias ou dicotômicas, uma vez que assumem apenas um de dois valores, em geral 0 ou 1, para indicar a ausência ou a presença de determinada característica.

Assim, uma variável Indicadora, I, pode ser descrita da seguinte maneira:

$$
I=\left\{\begin{array}{c}
0, \text { se a característica não estiver presente } \\
1, \text { se a caracrerística estiver presente }
\end{array}\right.
$$

Neste caso, $\widehat{\beta}_{j}$ representa a diferença entre os valores $\widehat{y_{i}}$ calculados para o grupo que apresenta determinada característica e para o outro que não a apresenta.

\subsection{Inferência}

Para inferir sobre os parâmetros estimados $\widehat{\beta}_{j}$, é necessário assumir que $\varepsilon$ seja normalmente distribuído, com média zero e variância $\sigma^{2}: \varepsilon \sim N\left(0, \sigma^{2}\right)$, conforme segue:

SUPOSIÇÃO 4 Os erros têm distribuição normal

O erro populacional $\varepsilon$ é condicionalmente independente das variáveis explicativas $x_{i}, x_{2}, \ldots, x_{k}$ e normalmente distribuído, com média zero e variância $\sigma^{2}: \varepsilon \sim N\left(0, \sigma^{2}\right)$

Assumida a suposição $4, \widehat{\beta}_{j}$ terá distribuição assintótica normal dada por $\widehat{\beta}_{j} \sim N\left(\beta_{j}, \operatorname{Var}\left(\widehat{\left.\beta_{j}\right)}\right)\right.$. Conhecida essa distribuição, é possível realizar testes de hipóteses para determinar se o modelo estimado é adequado.

\subsubsection{Teste de hipótese}

Teste de hipótese é o recurso que especifica se deve aceitar ou rejeitar uma alegação sobre a população, de acordo com as informações fornecidas pela amostra de dados.

Tal teste analisa hipóteses complementares sobre determinada população que, para fins de conceito, são denominadas de hipótese nula e hipótese alternativa. A hipótese nula é a pressuposição que é colocada à prova. Em geral, indica uma igualdade a ser contestada. A hipótese alternativa contém os pressupostos que serão aceitos na medida em que há evidências para a rejeição da hipótese nula. 
Para a aplicação do teste de hipótese, é necessário estipular um determinado nível de significância $\alpha$, denominado probabilidade do erro do tipo I. Tal nível corresponde à probabilidade de rejeição da hipótese nula, quando ela é verdadeira. Para o estudo dos modelos apresentados, adotou-se $\alpha$ igual a $5 \%$, significando que a probabilidade assumida para o erro do tipo I é de 0,05 .

Definido o nível de significância, calcula-se o p-valor para averiguar se há evidências de rejeição da hipótese nula. $\mathrm{O}$ p-valor corresponde à probabilidade de encontrar um valor da estatística de teste mais extremo que o valor apurado pelo nível de significância. Caso o p-valor seja inferior ao nível de significância estabelecido, há evidências para rejeitar a hipótese nula.

Para fazer inferência a respeito dos parâmetros estimados pelo modelo de regressão linear, pode-se realizar o teste t para coeficientes de regressão e o teste de significância global.

\subsubsection{Teste $\mathrm{t}$ para coeficientes de regressão}

O Teste t para coeficientes de regressão verifica se determinada variável explicativa influencia a variável resposta de forma significante. No caso da regressão linear múltipla, o teste analisa individualmente cada variável explicativa, mantendo as demais constantes.

As hipóteses são definidas por:

$$
\begin{aligned}
& H_{0}: \beta_{j}=0 \\
& H_{1}: \beta_{j} \neq 0
\end{aligned}
$$

Se há evidências para rejeitar $H_{0}, x_{j}$ tem efeito sobre $\widehat{Y}$, mantendo as outras variáveis constantes.

Para calcular a estatística de teste do Teste t, vide informações do livro (Wooldridge 2005) [1].

\subsubsection{Teste de Significância Global}

O teste de significância global verifica a adequabilidade do conjunto de parâmetros de um modelo de regressão linear múltipla ao verdadeiro modelo populacional.

Para o referido teste, as hipóteses são definidas por:

$$
\begin{gathered}
H_{0}: \beta_{1}=\beta_{2}=\ldots=\beta_{p}=0 \\
H_{1}: \beta_{j} \neq 0 \text { para qualquer } j=1, \ldots, p
\end{gathered}
$$


Se há evidências para rejeitar $H_{0}$, conclui-se que há contribuição significativa de uma ou mais variáveis regressoras no estudo de Y.

Para calcular a estatística de teste do Teste de Significância Global, vide informações do livro (Wooldridge 2005) [1].

\subsubsection{Análise de resíduos}

A análise dos Resíduos é o conjunto de técnicas adotadas para investigar a adequabilidade de um modelo de regressão linear, simples ou múltipla, com base nos resíduos.

Conforme já mencionado, o resíduo $(\widehat{\varepsilon})$ é dado pela diferença entre a variável resposta observada $\left(Y_{i}\right)$ e a variável resposta estimada $\left(\widehat{Y}_{i}\right)$, isto é:

$$
\widehat{\varepsilon}=Y_{i}-\widehat{Y}_{i}=Y_{i}-\widehat{\beta}_{0}-\widehat{\beta}_{1} x_{1 i}-\cdots-\widehat{\beta}_{p} x_{p i} \quad i=1, \ldots, n .
$$

Uma vez ajustado o modelo, deseja-se que os resíduos tenham as seguintes propriedades:

1. $\operatorname{Var}\left(\varepsilon_{i}\right)=\sigma^{2}$ (constante);

2. $\varepsilon_{i} \sim N\left(0, \sigma^{2}\right)$ (normalidade);

3. Modelo é linear;

\subsubsection{Homocedasticidade}

Para testar a existência de homocedasticidade serão realizadas as análises gráficas apresentadas na Figura 49. Caso os pontos estejam distribuídos aleatoriamente em torno do zero sem uma tendência aparente, a suposição de homocedasticidade não é violada.

Se o gráfico dos resíduos detectar alguma tendência, comprova-se a existência de heterocedasticidade. Assim, deve-se mudar a forma funcional por meio de transformações das variáveis. Na Figura 3, podem-se notar algumas representações gráficas que indicam a existência de um comportamento sistemático:

\subsubsection{Normalidade}

A suposição de normalidade pode ser verificada por meio da análise do gráfico de probabilidade normal, apresentado na Figura 50. Se os pontos estiverem distribuídos próximos à reta, a suposição de normalidade não é violada. Tal pressuposto também é verificado por intermédio do teste de Shapiro-Wilk. Para o referido teste, as hipóteses são definidas por: 

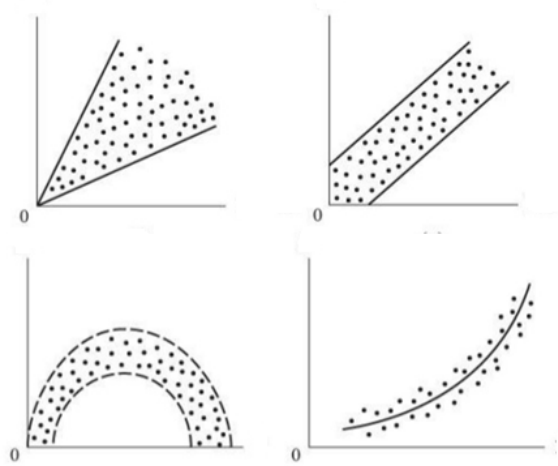

Figura 3: Resíduos heterocedásticos

$H_{0}$ : A amostra provém de uma população Normal

$H_{1}$ : A amostra não provém de uma população Normal

Se não há evidências para rejeitar $H_{0}$, conclui-se que a suposição não é contrariada. Para mais informações, vide o livro (Thode 2002) [4].

\subsubsection{Violação de suposições}

Se após a análise de resíduos constatar-se a violação de uma ou mais suposições, algumas vezes é possível amenizar esse problema fazendo transformações pertinentes na variável resposta $Y$, que irão gerar modelos de regressão diferentes. No trabalho em questão foram utilizadas as transformações raiz quadrática $(\sqrt{Y})$, Box-Cox (vide livro (Samohyl 2009) [5]) e logarítmica $(\log (Y))$, empregadas para estabilizar a variância.

Quando for necessário definir o melhor modelo de regressão, será selecionado aquele que possuir menor Erro Quadrático Médio (EQM). Esse valor será calculado conforme segue na Equação 19:

$$
E Q M=\sum_{t=1}^{n} \frac{e_{t}^{2}}{n}
$$

\subsection{Séries Temporais}

Série temporal é um conjunto de observações coletadas em intervalos uniformes de tempo. Diferentemente da regressão linear, os dados são depen- 
dentes entre si, criando padrões não aleatórios. Para este trabalho, as séries temporais serão empregadas para fazer predições.

É uma suposição comum, em muitas técnicas de séries temporais, que os dados sejam fracamente estacionários, ou seja, assumindo y(t) uma série temporal, a função deve seguir as seguintes propriedades:

1. $E(y(t))=\mu(t)=\mu$

$\mathrm{y}(\mathrm{t})$ deve ter média constante

2. $\operatorname{Var}(y(t))<\infty$

$\mathrm{y}(\mathrm{t})$ deve ter variância finita

3. $\gamma\left(t_{1}, t_{2}\right)=\operatorname{cov}\left(y\left(t_{1}\right), y\left(t_{2}\right)\right)$ é função de $|\tau|=\left|t_{1}-t_{2}\right|$

Covariância entre $z\left(t_{1}\right)$ e $z\left(t_{2}\right)$ depende somente de $\tau$

Para verificar a estacionariedade da série, deve-se observar a representação gráfica dos dados sequencialmente ao longo do tempo. Por meio da análise gráfica, é possível delinear padrões do comportamento, como tendências de crescimento (ou decrescimento), sazonalidade e observações discrepantes. Também pode-se averiguar a estacionaridade da série realizando o teste KPSS (vide (Charnet 1999) [2]). Caso o comportamento não seja estacionário, deverão ser empregadas transformações numéricas na amostra.

Para identificar um modelo, são empregadas as funções de autocorrelação (FAC) e autocorrelação parciais (FACP) estimadas a partir da amostra disponível. A FAC apresenta o desenvolvimento de $\mathrm{Y}(\mathrm{t})$ ao longo do tempo. Ela mostra o quão forte o valor observado atualmente está correlacionado com os valores observados no passado. Por sua vez, a FACP dá a correlação entre a variável no instante t e uma de suas defasagens, retirados os efeitos das outras defasagens. Por intermédio da comparação gráfica destas funções com os comportamentos esperados teóricos, obtém-se a ordem do modelo a ser utilizado.

Outro método aplicado na fase de identificação se baseia na mensuração do Critério de Informação Bayesiano (BIC). Este é um critério matemático que confronta as funções de log-verossimilhança com penalidades atreladas ao número de parâmetros do modelo. A combinação das funções e penalidades que resultar no menor BIC indica o modelo mais adequado. Para adotar esse critério de seleção, alguns modelos submetidos a análise devem ser determinados e estimados. Assim, é possível fazer a comparação dos BICs calculados. 
Uma vez identificado o melhor modelo capaz de distinguir padrões que estejam presentes nas observações, é necessário verificar se os resíduos estimados se comportam como ruído branco, ou seja, uma sequência de erros aleatórios de média zero e variância constante na qual segue distribuição normal $\varepsilon \sim N\left(0, \sigma_{\varepsilon}^{2}\right)$. Essa verificação é feita analisando a funcão de autocorrelação (FAC) e a função autocorrelação parcial (FACP) dos coeficientes dos resíduos do modelo e realizando o teste de Box-Pierce (vide livro (Charnet 1999) [2])

É possível que o modelo identificado se ajuste bem aos dados usados na estimação, porém não produza boas previsões. Dessa forma, é comum a separação da amostra em dois grupos, sendo um de Controle e outro de Teste. O grupo de Controle é utilizado para a estimação do modelo e será empregado com dados pesquisados no período de 2003 a 2014. O grupo de Teste é usado para calcular o erro associado à previsão e será empregado com os dados pesquisados no período de 2015 a 2016. Quanto menor o erro, melhor o modelo de previsão.

\subsubsection{Processo de Médias móveis}

Um modelo de médias móveis resulta da combinação dos ruídos brancos $\varepsilon$ do período com aqueles ocorridos em períodos anteriores. Assim, um modelo de médias móveis de ordem q ou MA(q) é definido por:

$$
\widetilde{X_{t}}=\varepsilon_{t}-\theta_{1} \varepsilon_{t-1}-\ldots-\theta_{q} \varepsilon_{t-q}
$$

Sendo:

$\widetilde{X_{t}}=X_{t}-\mu$

$\theta_{1}, \ldots, \theta_{q}$ os parâmetros que descrevem como $X_{t}$ se relaciona com os valores de $\varepsilon_{t-i}$ para $\mathrm{i}=1,2, \ldots, \mathrm{q}$

$\varepsilon_{t}$ um ruído branco, ou seja, uma variável com média zero, variância constante e não correlacionada:

$$
E\left(\varepsilon_{t}\right)=0, \quad \operatorname{Var}\left(\varepsilon_{t}\right)=\sigma_{a}^{2}, \quad \operatorname{Cor}\left(\varepsilon_{t}, \varepsilon_{s}\right)=0, s \neq t
$$

O modelo MA(q) dado pela equação 20 pode ser reescrito como em 21, utilizando o operador de defasagem B.

$$
\left.1-{ }_{1} B-\theta_{2} B^{2}-\ldots-\theta_{q} B^{q}\right) \varepsilon_{t}=\theta(B) \varepsilon_{t}=\widetilde{X_{t}}
$$

O software R foi utilizado ara análise do processo, identificação do modelo, verificação de seu ajustamento e previsão. 
As funções acf e pacf foram empregadas afim de analisar a função de autocorrelação e a função de autocorrelação parcial do modelo, respectivamente.

Por meio do pacote forecast, aplicou-se a função auto.arima para identificação do modelo estacionário ARIMA com menor BIC. Tal seleção foi feita por stepwise e a estacionariedade foi verificada pelo teste KPSS. Vale ressaltar que os parâmetros do modelo foram estimados por máxima verossimilhança.

Para verificação do ajustamento, isto é, análise dos resíduos, aplicou-se o teste de Box-Pierce por meio da função box.test.

Uma vez selecionado o modelo, utilizou-se a função forecast para previsão.

Para mais informações, vide livro (Charnet 1999) [2]. 


\section{METODOLOGIA}

A metodologia utilizada partiu da observação sistemática de eventos e da comprovação dos resultados obtidos.

Por meio da observação direta de dados existentes em fontes de consultas oficiais, foi possível criar variáveis para montar Conjuntos de Dados distintos, que serão disponibilizados aos usuários.

Contudo, durante a compilação dos dados, observaram-se controvérsias entre informações extraídas de fontes de consultas diferentes. Algumas fontes apresentaram maior número de sessões ou reuniões do que outras. Destacase que o maior conflito se deu em anos anteriores a 2012. Dessa forma, foi necessário criar mecanismos de validação a fim de aumentar a confiabilidade dos dados coletados.

Determinados dados foram consolidados manualmente em planilhas eletrônicas. Tal tarefa se deu pelo fato de os registros compreendidos nos Diários do Senado Federal, nos Relatórios da Presidência e nos Relatórios Mensais da atividade legislativa, não serem disponibilizados de forma padronizada, impedindo a transferência automatizada para arquivos de outro formato. Acrescenta-se a tal esforço, o contratempo de os dados se encontrarem dispersos, exigindo maior empenho na pesquisa.

A metodologia foi dividida em quatro tópicos: Conjunto de Dados Brutos (CDB), Conjunto de Dados consolidado (CDC) pelo Relatório da Presidência (RAP), Conjunto de Dados consolidado (CDC) pelo Relatório Mensal da atividade legislativa e Validação.

O primeiro apresenta a criação do CDB para as sessões e para as reuniões. O segundo, a montagem do CDC pelo RAP para as reuniões, sessões plenárias e conjuntas. O terceiro, apresenta a constituição do CDC pelo Relatório Mensal da atividade legislativa para as reuniões das Comissões Permanentes. O quarto tópico, trata da validação do quantitativo de reuniões e sessões registradas nos conjuntos criados.

\subsection{Conjunto de Dados Brutos (CDB)}

Foi criado um Conjunto de Dados Brutos, tanto para sessões, quanto para reuniões, que serviu de alicerce para a criação do Conjunto de Dados conso-

lidados. As informações inseridas nesse Conjunto de Dados foram retiradas do Relatório da Presidência(RAP), no período de 2003 a 2016. 


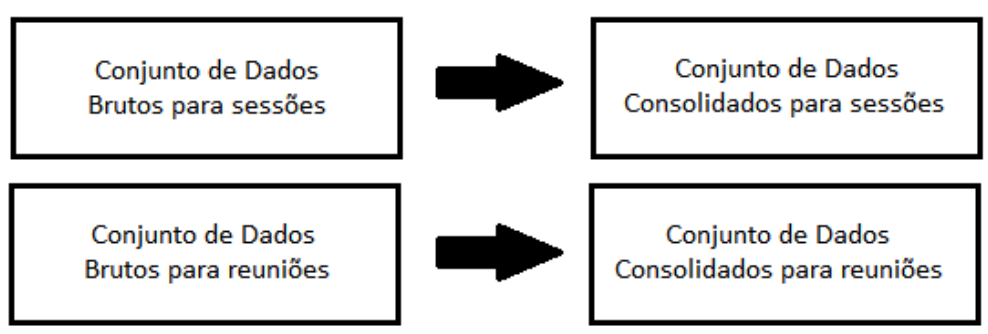

Figura 4: Formação de Conjunto de Dados

\subsubsection{Conjunto de Dados Brutos para as sessões}

Na parte I do RAP, foram obtidas informações acerca das sessões plenárias. A Figura 5 ilustra o texto, tomando-se como exemplo o RAP referente ao ano de 2010.

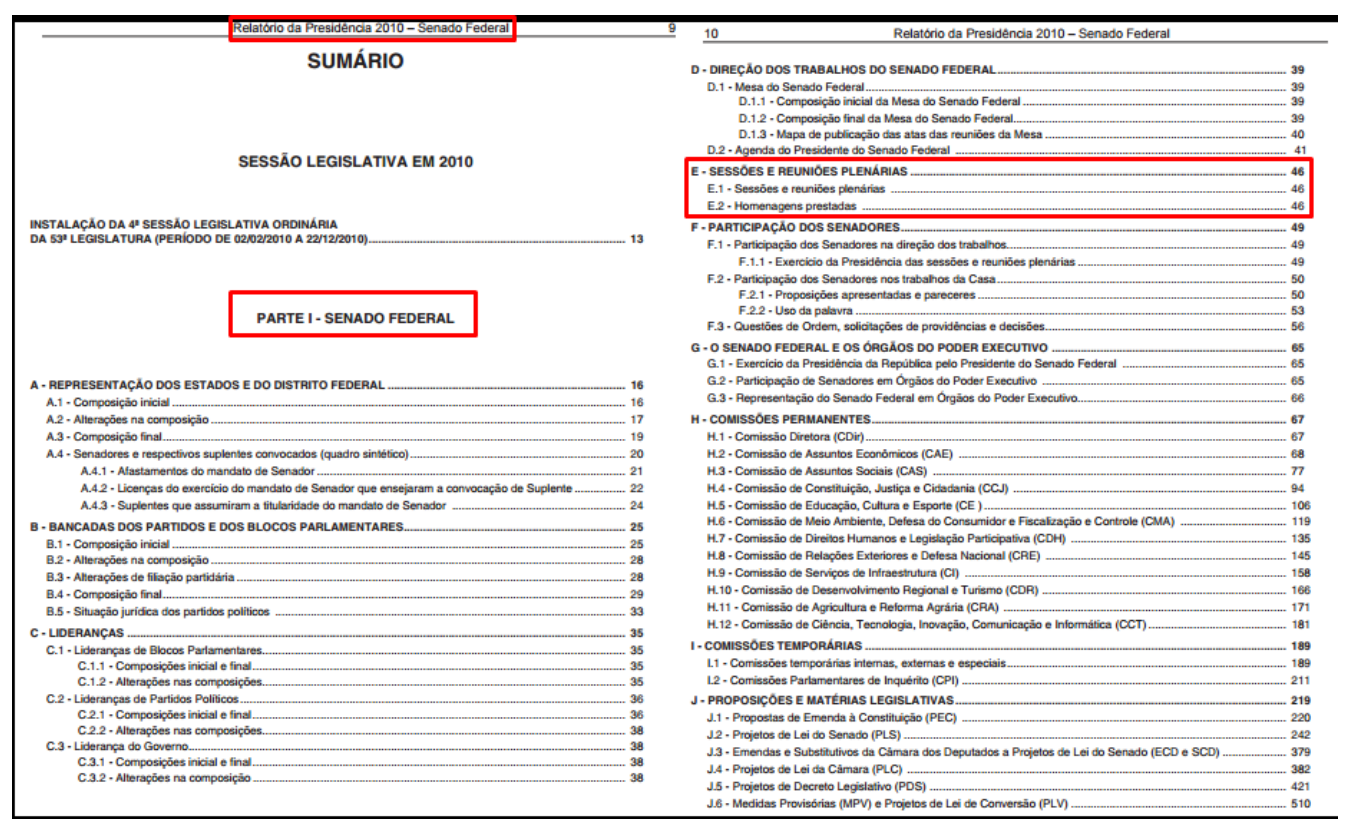

Figura 5: Sumário do RAP de 2010 - Parte I

Acessando o tópico "Sessões e reuniões Plenárias", encontrou-se o quantitativo de sessões plenárias realizadas durante o ano, separado por Sessões Legislativas Ordinárias e Extraordinárias.

Quando ocorreu somente a Sessão Legislativa Ordinária no ano pesquisado, o quantitativo procurado constava diretamente no campo "Total de sessões realizadas", conforme ilustrado na Figura 6: 


\section{E.1 - SESSŌES E REUNIŌES PLENÁRIAS}

Durnte a 4 Sessao Legislativa Ondinaria da $53^{\circ}$ Legislatura, o Senado Federal fez realizar 217 (duzentas e dezessete) sessces. lendo realizado a primeira em $Q 2$ de fevereiro de $2010 \mathrm{e}$ a útima em 22 de dezembro de 2010 .

As delberaches legislafivas do Senado estiveram scbrestadas por Medidas Provisorias, nos iermos do art $62,6^{\circ}$ da Constituiclo Federal, em 86 (cinquenta e seis) das sessoes plentrias deiberativas realizadas; sendo que em 14 (calorze) destas deixou de haver deliberacaso sobre qualquer materia legislativa.

\begin{tabular}{|c|c|}
\hline Sessces Realizadas & Total \\
\hline Sessbes Delberativas Ordinarias & 90 \\
\hline Sessces Delberativas Extraordinarias & 25 \\
\hline Sessbes Nao Deliberativas & 91 \\
\hline Sestces Especiais & 9 \\
\hline Sessdes para Entrega de Premiaclo & 2 \\
\hline Total de Sessobes Realizadas & 217 \\
\hline
\end{tabular}

\begin{tabular}{|c|c|}
\hline Sessóes Plenárias provistas e nåo realizadas & Total \\
\hline 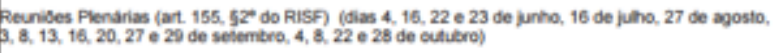 & 17 \\
\hline 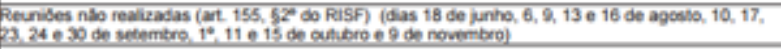 & 14 \\
\hline Total & 31 \\
\hline
\end{tabular}

Figura 6: Total de sessões realizadas em 2010

Quando ocorreu mais de uma Sessão Legislativa no ano pesquisado, foi somado o número total de sessões plenárias, apresentado em cada Sessão Legislativa, conforme ilustrado na Figura 7:

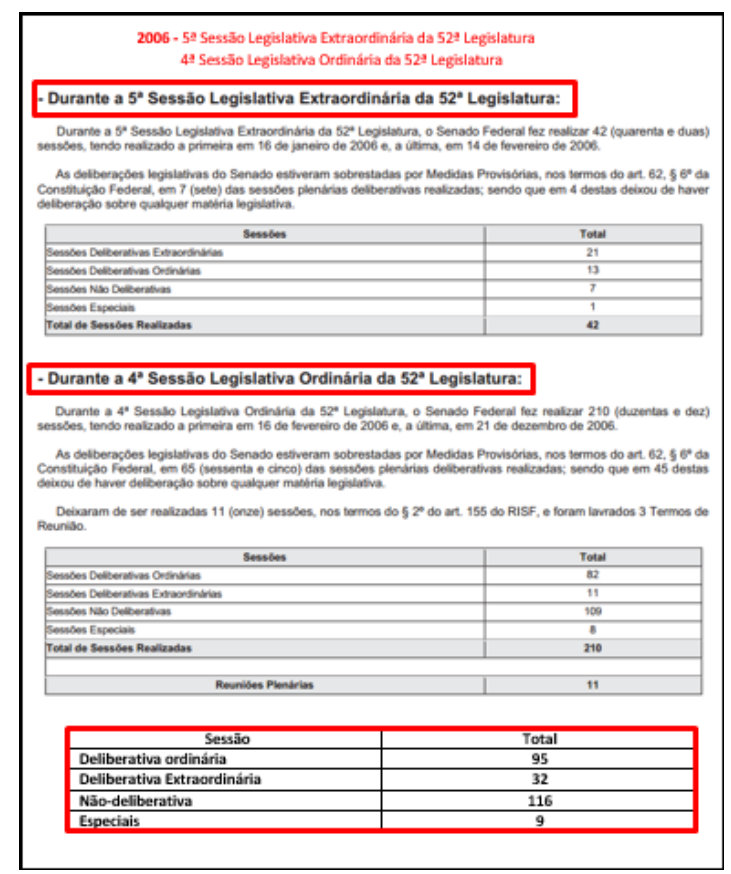

Figura 7: Total de sessões realizadas em 2006

Para obter o quantitativo de sessões conjuntas, realizadas num determi- 
nado ano, foi seguido o mesmo procedimento.

Esses dados reunidos constituíram o Conjunto de Dados Brutos para as sessões.

\subsubsection{Conjunto de Dados Brutos para as reuniões}

Acessando cada tipo de Comissão, seja permanente ou temporária, foi possível encontrar o mapa de publicações das Atas das reuniões realizadas nas Sessões Legislativas. Isso pode ser observado na Figura 8:

Relatório da Presidência 2010 - Senado Federal

81

- Atas de reuniões realizadas na $4^{\mathrm{a}}$ Sessão Legislativa Ordinária da $53^{\mathrm{a}}$ Legislatura:

\begin{tabular}{|c|c|c|c|c|}
\hline \multirow{2}{*}{ Reunião } & \multirow{2}{*}{ Resumo } & \multirow{2}{*}{ Data } & \multicolumn{2}{|c|}{ Publicaçăo no DSF } \\
\hline & & & Dia & Página \\
\hline $1^{a}$ & $\begin{array}{l}\text { Extraordinária } \\
\text { Apreciaçăo de matérias }\end{array}$ & $03 / 02$ & $\begin{array}{c}02 / 07 / 2010 \\
\text { Supl. } \\
\text { Volume I }\end{array}$ & 336 \\
\hline $2^{a}$ & $\begin{array}{l}\text { Extraordinária } \\
\text { Apreciaçăo de matérias }\end{array}$ & $10 / 02$ & $\begin{array}{c}\text { 02107/2010 } \\
\text { Supl. } \\
\text { Volume I }\end{array}$ & 363 \\
\hline $3^{a}$ & \begin{tabular}{|l|} 
Extraordinária \\
Apreciaçăo de matérias
\end{tabular} & $24 / 02$ & $\begin{array}{c}02 / 07 / 2010 \\
\text { Supl. } \\
\text { Volume I }\end{array}$ & 379 \\
\hline $4^{a}$ & 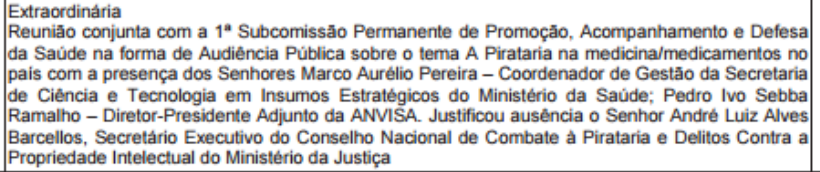 & $25 / 02$ & $\begin{array}{c}02 / 07 / 2010 \\
\text { Supl. } \\
\text { Volume I. }\end{array}$ & 396 \\
\hline $5^{a}$ & $\begin{array}{l}\text { Extraordinária } \\
\text { Apreciaçăo de Matérias }\end{array}$ & $03 / 03$ & $\begin{array}{c}02 / 07 / 2010 \\
\text { Supl. } \\
\text { Volume I }\end{array}$ & 410 \\
\hline $6^{a}$ & $\begin{array}{l}\text { Extraordinária } \\
\text { Apreciação de Matérias }\end{array}$ & $10 / 03$ & $\begin{array}{c}02 / 07 / 2010 \\
\text { Supl. } \\
\text { Volume I } \\
\end{array}$ & 424 \\
\hline $7^{a}$ & $\begin{array}{l}\text { Extraordinária } \\
\text { Apreciaçăo de Matérias }\end{array}$ & $17 / 03$ & $\begin{array}{c}02 / 07 / 2010 \\
\text { Supl. } \\
\text { Volume I } \\
\end{array}$ & 453 \\
\hline $8^{a}$ & $\begin{array}{l}\text { Extraordinária } \\
\text { Apreciação de Matérias }\end{array}$ & $24 / 03$ & $\begin{array}{c}\text { 02/07/2010 } \\
\text { Supl. } \\
\text { Volume I }\end{array}$ & 456 \\
\hline
\end{tabular}

Figura 8: Mapa de publicações das Atas

De posse dessas informações, foi criado o Conjunto de Dados Brutos para as reuniões, conforme segue no modelo dado pela Figura 9: 


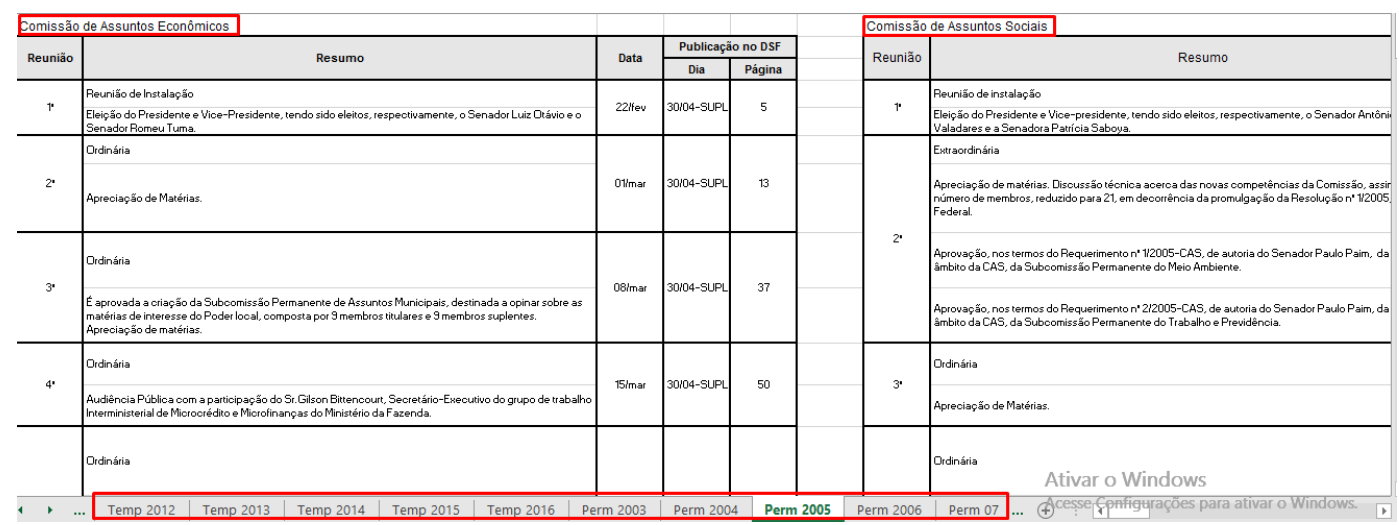

Figura 9: Conjunto de Dados Brutos para as reuniões

\subsection{Conjunto de Dados consolidado (CDC) pelo RAP}

Uma vez montado o Conjunto de Dados Bruto (CDB), foi elaborado o Conjunto de Dados Consolidado pelo RAP, que permite acessar as informações desejadas de forma rápida e concisa. Isso não era possível anteriormente, pelo fato de as informações estarem difundidas em diversos documentos, dificultando a busca. Ressalta-se que o referido Conjunto foi elaborado no formato xlsx, que facilita o manuseio dos dados. Anteriormente, as informações eram extraídas dos Relatórios da Presidência, publicados na extensão pdf.

\subsubsection{Conjunto de Dados consolidado pelo RAP para as reuniões}

No que se refere às reuniões das Comissões, o $\mathrm{CDC}$ foi alimentado, de forma não automatizada, pelas informações contidas no CDB, segundo as variáveis definidas na Tabela 1: 
Tabela 1: Variáveis do CDC pelo RAP para reuniões

\begin{tabular}{l|l}
\hline Variável & Descrição \\
\hline Ano & Ano em que foi realizada a reunião, no período \\
& de 2003 a 2016 \\
Comissão & Nome da comissão discriminada no RAP \\
Sigla & Sigla da comissão discriminada no RAP \\
Tipo & Permanente ou temporária \\
Natureza & Ordinária, Extraordinária, Conjunta, Temporá- \\
& ria, Parlamentar de Inquérito (CPI) e Jurista \\
Número sequencial & Número de série da reunião registrada na Ata \\
Data & Data em que a reunião ocorreu \\
Documento de publicação & Documento em que a Ata da reunião foi publi- \\
& cada \\
Número de publicação & Número do Diário do Senado Federal (DSF) \\
Data de publicação & Data em que a Ata foi publicada no DSF \\
Página & Página do DSF em que foi publicada a Ata \\
Resumo & Informativo breve a respeito do que foi discri- \\
Observações & minado na reunião \\
Indicadora de Conjunta & Pontos a serem destacados \\
Indicadora de duplicação & Impedir dupla contagem de reuniões conjuntas \\
\hline
\end{tabular}

A variável "natureza", na Comissão Permanente, foi empregada para classificar as reuniões em ordinárias, extraordinárias e conjuntas. Nas situações que, num mesmo evento, determinada reunião foi classificada como Conjunta Ordinária e Conjunta Extraordinária, desprezaram-se os termos "ordinária"e "extraordinária"e todas reuniões passaram a ser consideradas somente como conjunta, a fim de evitar erro de mensuração.

A título de ilustração, segue, na Figura 10, um extrato do "Mapa de publicação de Atas de reuniões"do RAP de 2003, referente à $4^{\mathrm{a}}$ reunião da Comissão de Assuntos Sociais, onde ocorreu o encontro de uma reunião de natureza "conjunta extraordinária"com outra de natureza "conjunta ordinária": 


\begin{tabular}{|c|c|c|c|c|}
\hline \multirow{2}{*}{ Reuniăo } & \multirow{2}{*}{ Natureza } & \multirow{2}{*}{ Data } & \multicolumn{2}{|c|}{ Publicação no DSF } \\
\hline & & & Dia & Página \\
\hline $1^{\mathrm{a}}$ & $\begin{array}{c}\text { Extraordinária } \\
\text { Eleição do Presidente e Vice-Presidente da Comissâo } \\
\text { para o biênio 2003/2004 }\end{array}$ & $19 / 02$ & $1 \% 7-$ SUPL & 00314 \\
\hline $2^{a}$ & $\begin{array}{c}\text { Extraoordinária } \\
\text { Apreciaçăo de requerimentos } \\
\end{array}$ & $13 / 03$ & $1 \% 7-$ SUPL & 00316 \\
\hline $3^{\mathrm{a}}$ & $\begin{array}{c}\text { Extraordinária } \\
\text { Apreciação de matérias legislativas }\end{array}$ & $20 / 03$ & $1 \% 7-$ SUPL & 00324 \\
\hline $4^{a}$ & $\begin{array}{l}\text { Extraordinária } \\
\text { (conjunta com a 6 } 6^{\mathrm{a}} \text { Ordinária da CCJ) } \\
\text { Audiência Pública com a presença do Senhor Ministro } \\
\text { Extraordinário de Segurança Alimentar e Combate à } \\
\text { Fome, Ministro José Francisco Graziano da Silva. }\end{array}$ & $26 / 03$ & $1 \% 7-$ SUPL & 00333 \\
\hline
\end{tabular}

Figura 10: Registro da $4^{\mathrm{a}}$ reunião realizada pela CAS em 2003

A variável "natureza", nas Comissões Temporárias, seguiu a seguinte proposta de classificação: "Parlamentar de Inquérito (CPI)", "Jurista" e "Temporária".

Tiveram a natureza Parlamentar de Inquérito (CPI) aquelas comissões que apresentaram a nomenclatura "Parlamentar de Inquérito" explícita em seu texto:

\section{I.2.3 - COMISSÃO PARLAMENTAR DE INQUÉRITO AMAZÔNIA * \\ Finalidade: Comissão Parlamentar de Inquérito, criada nos termos do Requerimento $\mathrm{n}^{\circ} 572$, de 2009, de autoria do Senador Mozarildo Cavalcanti e outros Senhores Senadores, composta por onze titulares e sete suplentes, para investigar, no prazo de cento e oitenta dias, os seguintes fatos a respeito da Amazônia: 1) conflito referente à demarcação da reserva indigena Raposa Serra do Sol e outras; 2) recentes denúncias de falta de assistência à saúde indigena; 3) áreas indigenas nos Estados de Roraima, Amazonas, Pará e Mato Grosso, cujos territórios chegam a $57 \%, 21 \%, 20 \%$ e 30\%, respectivamente, das áreas territoriais desses Estados; 4) problemas envolvendo a soberania nacional nas áreas de fronteira: tráfico internacional, terrorismo, guerrilhas, vigilância das fronteiras ete; 5) falta de condiçôes de sustentabilidade das comunidades indigenas já integradas às comunidades não indigenas; 6) alegado aumento do desmatamento da floresta; 7) recrudescimento da aquisição de terras por parte de estrangeiros; 8) questões fundiárias e ambientais.}

Figura 11: CPI - RAP de 2010

De forma idêntica, tiveram a natureza "jurista" as comissões que apresentaram a nomenclatura "juristas", conforme ilustrado na Figura 12.

\section{I.1.4 - Comissão de Juristas criada pelo RQS 227/2008 com a finalidade de elaborar Projeto de Código de Processo Penal}

Figura 12: Comissão Temporária de Juristas

Tiveram a natureza "Temporária" todas as demais Comissões Temporárias que, por exclusão, não tiveram a natureza "CPI" ou "Jurista".

Cabe mencionar que, no site do Senado Federal, não foram encontradas as naturezas propostas (CPI, Jurista e Temporária) para as Comissões. Apenas foram encontrados os termos: Comissão Temporária Interna ou Comissão Temporária Externa. Estas denominações não foram adotadas, porque não acrescentaram informações pertinentes ao estudo. 
A variável "Indicadora de Conjunta", tem a seguinte função:

$$
I_{x}(\theta)=\left\{\begin{array}{l}
1, \text { se computa a reunião } \\
0, \text { caso contrário }
\end{array}\right.
$$

Ela foi utilizada para corrigir distorções de mensuração, quando mais de uma Comissão participou da mesma reunião. A título de ilustração, apresenta-se a Figura 13, extraída do "Mapa de publicação de Atas de reuniões do RAP"de 2010.

\begin{tabular}{|c|c|c|c|c|c|}
\hline \multirow[t]{2}{*}{ Comissão } & \multirow[t]{2}{*}{ Reunião } & \multirow[t]{2}{*}{ Resumo } & \multirow[t]{2}{*}{ Data } & $\begin{array}{l}\text { Publicação } \\
\text { DSF }\end{array}$ & \\
\hline & & & & Dia & Página \\
\hline $\begin{array}{l}\text { Comissão de Assuntos } \\
\text { Econômicos (CAE) }\end{array}$ & $19 \mathrm{a}$ & $\begin{array}{l}\text { Reunião Conjunta com as seguintes comissões: } \\
\text { CCJ, CAS e CE } \\
\text { Apreciação de matérias }\end{array}$ & $19 / 05$ & $\begin{array}{c}02 / 05 / 2010 \\
\text { Supl. }\end{array}$ & 443 \\
\hline $\begin{array}{l}\text { Comissão de Assuntos } \\
\text { Sociais (CAS) }\end{array}$ & $21^{\mathrm{a}}$ & $\begin{array}{l}\text { Reunião Conjunta com as seguintes comissões: } \\
\text { CCJ, CAE e CE } \\
\text { Apreciação de matérias }\end{array}$ & $19 / 05$ & $\begin{array}{c}02 / 05 / 2010 \\
\text { Supl. } \\
\text { Volume I }\end{array}$ & 744 \\
\hline $\begin{array}{l}\text { Comissão de Constituiç̃ao, } \\
\text { Justiça e Cidadania (CCJ) }\end{array}$ & $22^{\mathrm{a}}$ & $\begin{array}{l}\text { Reunião Conjunta com as seguintes comissões: } \\
\text { CAE, CAS e CE } \\
\text { Apreciação de matérias }\end{array}$ & $19 / 05$ & $\begin{array}{c}02 / 05 / 2010 \\
\text { Supl. } \\
\text { Volume II }\end{array}$ & 1231 \\
\hline $\begin{array}{l}\text { Comissão de Educação, } \\
\text { Cultura e Esporte (CE) }\end{array}$ & $20 \mathrm{a}$ & $\begin{array}{l}\text { Reunião Conjunta com as seguintes comissões: } \\
\text { CCI, CAS e CAE } \\
\text { Apreciação de matérias }\end{array}$ & $19 / 05$ & $\begin{array}{c}02 / 05 / 2010 \\
\text { Supl. }\end{array}$ & 443 \\
\hline
\end{tabular}

Figura 13: Registro das Atas por Comissão de uma reunião conjunta

Pode ser observado que no dia 19/05, quatro Comissões (CAE, CAS, CCJ e CE) participaram da mesma reunião. O registro dessa reunião poderia ter sido realizado quatro vezes, causando erro de mensuração. Para evitar problemas dessa espécie, foi criada a variável "Indicadora de conjunta", que considerou as reuniões conjuntas como uma única, independentemente do registro ser realizado mais de uma vez.

De forma idêntica, a variável "Indicadora de Duplicidade" tem a seguinte função:

$$
I_{x}(\theta)=\left\{\begin{array}{l}
1, \text { se computa a reunião } \\
0, \text { caso contrário }
\end{array}\right.
$$

Esta também foi utilizada para corrigir distorções de mensuração, quando ocorreu a republicação de uma determinada Ata. A título de ilustração, apresenta-se a Figura 14, extraída do "Mapa de publicação de Atas de reuniões do RAP"de 2010, que trata da republicação: 


\begin{tabular}{|c|c|c|c|c|}
\hline \multirow{2}{*}{ Reunião } & \multirow{2}{*}{ Resumo } & \multirow{2}{*}{ Data } & \multicolumn{2}{|c|}{ Publicação DSF } \\
\hline & & & Dia & Página \\
\hline \multirow[t]{3}{*}{$14^{\mathrm{a}}$} & $\begin{array}{l}\text { Reunião Conjunta com as seguintes comissões: CCJ, CAS e } \\
\text { CMA. } \\
\text { Realização de audiência pública para instruir o Substitutivo } \\
\text { da Câmara dos Deputados ao Projeto de Lei do Senado nº } \\
354 \text { de } 1989 \text {, que "institui a política nacional de resíduos } \\
\text { sólidos; } \\
\text { altera a Lei no } 9.605 \text {, de } 12 \text { de fevereiro de 1998; e dá outras } \\
\text { providências", com a presença da Sra. Izabella Mônica Vieira } \\
\text { Teixeira, Ministra de Estado do Meio Ambiente; da Sra. Nadja } \\
\text { Limeira Araújo, Gerente de Projetos da Gerência de } \\
\text { Resíduos Sólidos da Secretaria Nacional de Saneamento } \\
\text { Ambiental; do Sr. Rafael Lucchesi, Diretor de Operações da } \\
\text { Confederação Nacional das Indústrias - CNl; }\end{array}$ & \multirow[t]{3}{*}{$05 / 05$} & $\begin{array}{l}\text { 02/06/2010 } \\
\text { Supl. }\end{array}$ & \multirow{3}{*}{$\begin{array}{l}315 \\
147\end{array}$} \\
\hline & $\begin{array}{l}\text { do Sr. Edison Castro Martins, Técnico em Meio Ambiente da } \\
\text { Confederação Nacional dos Municípios; do Sr. Newton de } \\
\text { Lima Azevedo, Vice-Presidente da Associação Brasileira da } \\
\text { Infraestrutura e Indústria de Base - ABDIB; }\end{array}$ & & $\begin{array}{l}\text { Republicada } \\
02 / 07 / 2010 \\
\text { Supl. }\end{array}$ & \\
\hline & $\begin{array}{l}\text { do Sr. Carlos Roberto Vieira da Silva Filho, Diretor Executivo } \\
\text { da Associação Brasileira de Empresas de Limpeza Pública e } \\
\text { Resíduos Especiais - Abrelpe; e do Sr. Ronei Alves da Silva, } \\
\text { representante do Movimento Nacional dos Catadores de } \\
\text { Materiais Recicláveis - MNCR. }\end{array}$ & & & \\
\hline
\end{tabular}

Figura 14: Registro de Ata republicada

Observa-se que no dia 02/07/2010 ocorreu a republicação da Ata, emitida no dia 02/06/2010. Esse fato pode gerar erro de mensuração, ao considerar a ocorrência de duas reuniões distintas, cada uma com sua respectiva Ata. Para evitar problemas dessa espécie, foi criada a variável "Indicadora de Duplicidade" para dirimir erros com a republicação da Ata.

Compilados todos os dados mencionados anteriormente, criou-se o Conjunto de Dados Consolidado pelo RAP para as reuniões, conforme o modelo apresentado na Figura 15:

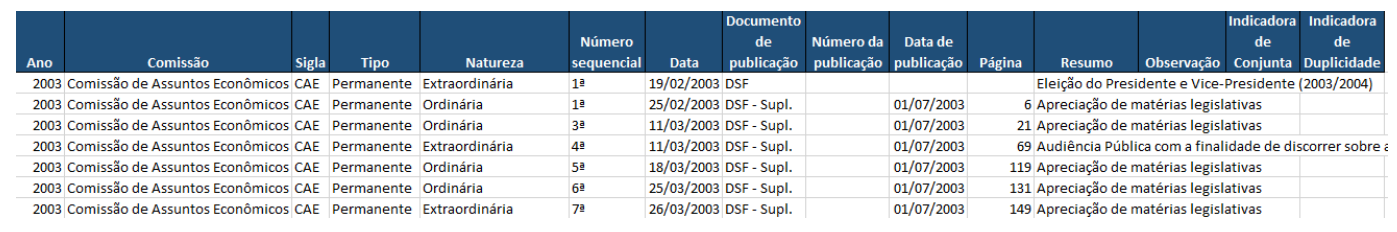

Figura 15: Conjunto de Dados Consolidado pelo RAP para as reuniões

\subsubsection{Conjunto de Dados consolidado pelo RAP para sessões ple- nárias e conjuntas}

No que se refere às sessões, o CDC foi alimentado, de forma não automatizada, pelas informações contidas no CDB, segundo as variáveis definidas na tabela 2: 
Tabela 2: Variáveis do CDC pelo RAP para sessões plenárias e conjuntas

\begin{tabular}{l|l}
\hline Variável & Descrição \\
\hline Ano & $\begin{array}{l}\text { Ano em que foi realizada a reunião, no período } \\
\text { de } 2003 \text { a } 2016\end{array}$ \\
Tipo de sessão & $\begin{array}{l}\text { Deliberativa, não deliberativa, especial, debate } \\
\text { temático, entrega de premiação, matérias legis- } \\
\text { lativas e solene. }\end{array}$ \\
Classificação & Plenária ou Conjunta \\
Natureza & Ordinária, extraordinária, conjunta ou especial \\
Quantitativo & Total de sessões realizadas no ano \\
\hline
\end{tabular}

Segue, na Figura 16, o modelo de Conjunto de Dados Consolidado pelo RAP para as sessões, conforme mencionado anteriormente:

\begin{tabular}{|l|llr|}
\hline Ano & \multicolumn{1}{|c}{ Tipo de Sessão } & \multicolumn{1}{c}{ Natureza } & Quantitativo \\
\hline 2003 Deliberativa & Plenária & Ordinária & 127 \\
2003 Deliberativa & Plenária & Extraordinária & 2 \\
2003 Não-deliberativa & Plenária & & 82 \\
\hline 2003 Especial & Plenária & Ordinária & 4 \\
\hline 2004 Deliberativa & Plenária & Extraordinária & 89 \\
\hline 2004 Deliberativa & Plenária & & 15 \\
\hline 2004 Não-deliberativa & Plenária & & 101 \\
\hline 2004 Especial & Plenária & Ordinária & 1 \\
\hline 2005 Deliberativa & Plenária & Extraordinária & 110 \\
\hline 2005 Deliberativa & Plenária & & 15 \\
2005 Não-deliberativa & Plenária & & 86 \\
2005 Especial & Plenária & & 14 \\
\hline
\end{tabular}

Figura 16: Conjunto de Dados Consolidado pelo RAP para as sessões

\subsection{Conjunto de Dados consolidado pelo Relatório Men- sal para reuniões realizadas pelas Comissões Per- manentes}

Além do Relatório da Presidência, o Relatório Mensal também foi utilizado como fonte de dados secundários para a quantificação de reuniões realizadas por Comissões Permanentes.

Assim, foi criado um Conjunto de Dados consolidado pelo Relatório Mensal, com informações do período de 2005 a 2008, que permitirá ao usuário acessar as informações desejadas de forma rápida e concisa. Isso não era 
possível anteriormente, pelo fato de as informações estarem difundidas em diversos documentos, dificultando a busca.

O CDC pelo Relatório Mensal foi alimentado, de forma não automatizada, segundo as variáveis definidas na Tabela 3:

Tabela 3: Variáveis do CDC pelo Relatório Mensal

\begin{tabular}{l|l}
\hline Variável & Descrição \\
\hline Ano & $\begin{array}{l}\text { Ano em que foi realizada a reunião, no período } \\
\text { de } 2005 \text { a } 2008\end{array}$ \\
Nome da comissão discriminada no Relatório \\
Mensal \\
Sigla \\
Sigla da comissão discriminada no Relatório \\
Mensal \\
Natureza & $\begin{array}{l}\text { Permanente } \\
\text { Data }\end{array}$ \\
Documento de publicação \\
Página & $\begin{array}{l}\text { Data em que a reunião ocorreu } \\
\text { Relatório Mensal }\end{array}$ \\
& $\begin{array}{l}\text { Página do Relatório Mensal em que a reunião } \\
\text { foi registrada }\end{array}$ \\
\hline
\end{tabular}

Para obter informações acerca das reuniões, foi necessário realizar a consulta mês a mês para todo o período desejado.

A título de exemplo, cita-se o registro das reuniões realizadas pela CAS, referente ao mês de fevereiro de 2005. Para isso foi necessário:

1. Acessar a página de "Relatórios Mensais" da Web página do Senado Federal.

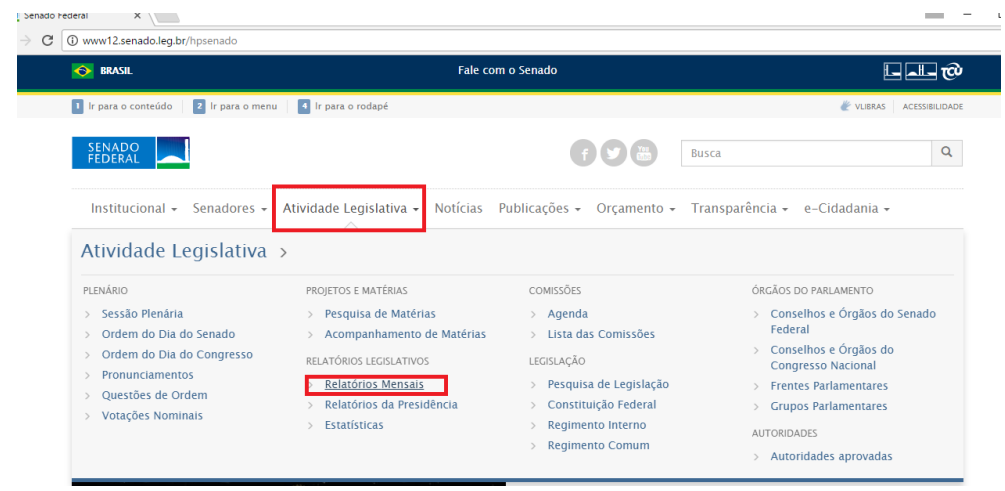

Figura 17: Web página do Senado Federal 
2. Selecionar o ano 2005

\begin{tabular}{|c|c|c|}
\hline \multirow{16}{*}{$\begin{array}{l}\text { O Relatório Mensal da Atividade Legislativa } \\
\text { consolida informaçōes referentes a sessões e } \\
\text { reuniões plenárias, matérias legislativas } \\
\text { deliberadas e atuação das comissōes, entre } \\
\text { outros, no âmbito do Senado Federal e do } \\
\text { Congresso Nacional. }\end{array}$} & Relatórios Mensais de 2017 & Relatórios Mensais de outros anos \\
\hline & Q 02 - Relatório de Fevereiro de 2017 & $E 2000$ \\
\hline & Q 03 - Relatório de Março de 2017 & $\approx 2001$ \\
\hline & Q 04 - Relatório de Abril de 2017 & $=2002$ \\
\hline & Q 05 - Relatório de Maio de 2017 & E 2003 \\
\hline & & $=2004$ \\
\hline & Listagens descritivas & $E 2006$ \\
\hline & & $=2007$ \\
\hline & Matérias legislativas do Senado Federal & $\boldsymbol{E} 2008$ \\
\hline & & $=2009$ \\
\hline & Licenças e missôes & $\approx 2010$ \\
\hline & Audiências públicas e matérias nas comissões & E 2011 \\
\hline & & E 2012 \\
\hline & Matérias legislativas do Congresso Nacional & $=2013$ \\
\hline & Normas promulgadas & $=2015$ \\
\hline & & E 2016 \\
\hline
\end{tabular}

Figura 18: Web página de Relatórios Mensais

3. Efetuar o download do arquivo referente à Resenha de fevereiro de 2005

Relatórios Mensais de outros anos

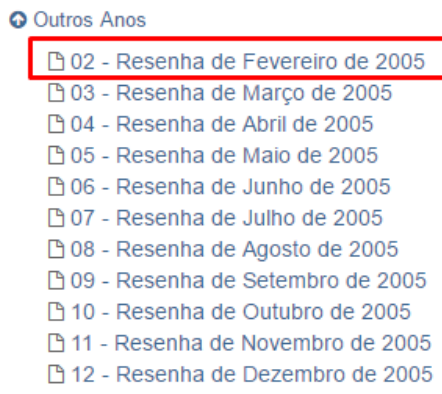

Figura 19: Seleção do mês de fevereiro de 2005

4. Localizar a CAS e os registros das suas respectivas reuniões, conforme ilustrado na Figura 20: 


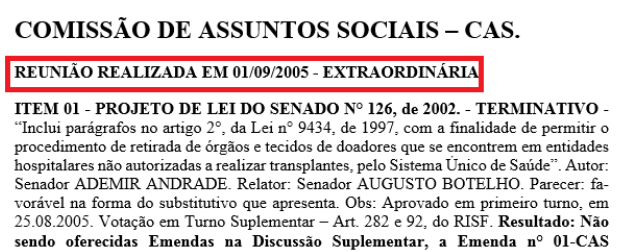

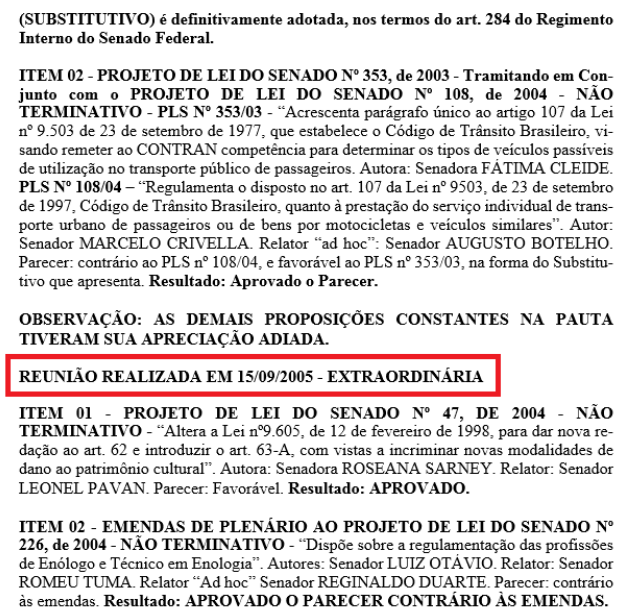

às emendas. Resultado: APROVADO O PARECER CONTRARIO ÁS EMENDAS.

Figura 20: Localização das reuniões

Uma vez localizadas as reuniões, as informações foram transcritas para o Conjunto de Dados consolidado pelo Relatório Mensal, como segue:

\begin{tabular}{||r|l|l|l|l|l|}
\hline Ano $\quad$ Comissão & Sigla & Tipo & Natureza & Data & Document Página \\
\hline 2005 Comissão de Assuntos Sociais & CAS & Permaner Conjunta & $01 / 09 / 2005$ & Resenha & 60 \\
\hline 2005 Comissão de Assuntos Sociais & CAS & Permaner Conjunta & $15 / 09 / 2005$ & Resenha & 61 \\
\hline
\end{tabular}

Figura 21: Conjunto de Dados consolidados pelo Relatório Mensal

\subsection{Validação}

"Dados" são informações coletadas em fontes de consulta diversas, que fornecem subsídios ao estudo e à análise estatística. Neste tópico, os estudos foram focados nos dados "reunião" e "sessão".

Validar é o ato de apurar se determinado dado é verdadeiro. Para esse trabalho, a validação se deu pelo confrontamento das informações extraídas do RAP e do Relatório Mensal com as informações obtidas das seguintes fontes de consulta: Diário do Senado Federal, programa Arquimedes, Atas e Pautas disponibilizadas pela Secretaria de Comissões. Esse confrontamento é necessário para checar se as informações apresentadas, tanto no CDC pelo RAP quanto no CDC pelo Relatório Mensal, são realmente verdadeiras. Essa é a essência do processo de validação.

Contudo, ressalta-se que o processo de validação se deu de forma diferenciada para as Comissões Permanentes, Comissões Temporárias, Sessões Plenárias e Conjuntas. 
O Diário do Senado Federal contém informações confiáveis sobre o registro de todas as reuniões realizadas pelo Senado, fato que não deu margem a erros no processo de validação.

O programa Arquimedes contém informações confiáveis, porém só possui registro de dados a partir do ano de 2013 no que se refere às Comissões.

As Atas são documentos elaborados pelas Comissões, onde constam os assuntos discutidos nas reuniões. De outra forma, confirmam a existência de determinada reunião. Possuem alta confiabilidade. Contudo, a Secretaria de Comissões não disponibilizou todas as Atas para esse estudo.

As Pautas já possuem menos confiabilidade, uma vez que só apresentam os assuntos a serem debatidos nas reuniões. Logo, poderá ocorrer o cancelamento de uma determinada reunião, após a emissão da Pauta. Assim, as Pautas são somente um indicativo de que determinada reunião possa ter ocorrido.

Para o fim de visualização dos diferentes níveis de confiabilidade da informação, apresenta-se o fluxograma na Figura 22 que mostra, do topo para a base, o grau decrescente de confiabilidade dos documentos utilizados como fonte de consulta.

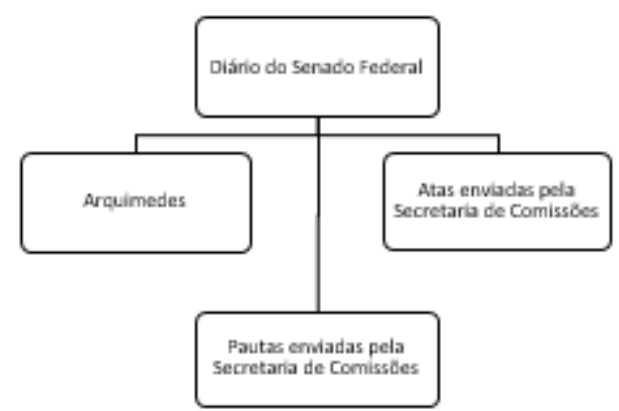

Figura 22: Níveis de confiabilidade da informação

\subsubsection{Validação das reuniões realizadas pelas Comissões Perma- nentes}

O processo de validação das reuniões realizadas pelas Comissões Permanentes, no período de 2003 a 2004, deveria ser feito manualmente, com consulta ao Diário do Senado Federal. Como, no decorrer do trabalho em curso, não houve tempo suficiente para executar tal tarefa, essas reuniões foram consideradas validadas. 
Para a validação das reuniões realizadas pelas Comissões Permanentes, no período 2005 a 2008, foram consultados os registros efetuados no Conjunto de Dados consolidado pelo RAP e pelo Relatório Mensal. Contudo, ocorreu de uma mesma reunião estar registrada em ambos os Conjuntos. Isso permitiu que, ao executar o levantamento da quantidade de reuniões realizadas, a mesma reunião fosse quantificada duas vezes. Para evitar tal erro, foi criado um terceiro Conjunto de Dados, utilizando-se o software R, que abarcou os registros dos Conjuntos citados anteriormente. Com a criação desse novo Conjunto de Dados foi possível identificar e evitar que determinada reunião, registrada tanto no Conjunto de Dados consolidado pelo RAP, quanto no Conjunto de Dados consolidado pelo Relatório Mensal, fosse duplamente quantificada. Esse terceiro Conjunto de dados foi denominado de "Conjunto Unificado".

As Figuras 23 e 24 ilustram a interação de dados entre os três Conjuntos. Na primeira, as duas circunferências representam os Conjuntos Consolidados pelo RAP e pelo Relatório Mensal respectivamente. A intersecção simula a área de redundância, onde pode ocorrer de uma única reunião estar registrada tanto num, quanto noutro Conjunto. O Conjunto Unificado é representado, na segunda figura, pela área contínua das duas circunferências superpostas.

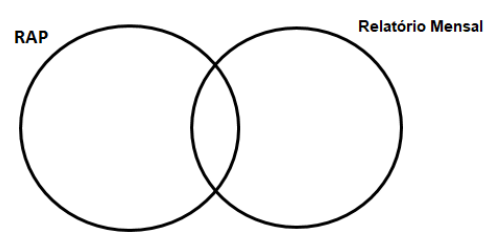

Figura 23: CDC RAP e CDC Relatório Mensal

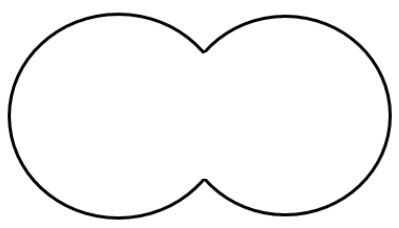

Figura 24: Conjunto Unificado

\subsubsection{Validação das reuniões registradas no Conjunto de Dados consolidado pelo RAP, excluindo-se a área de intersecção com o Relatório Mensal}




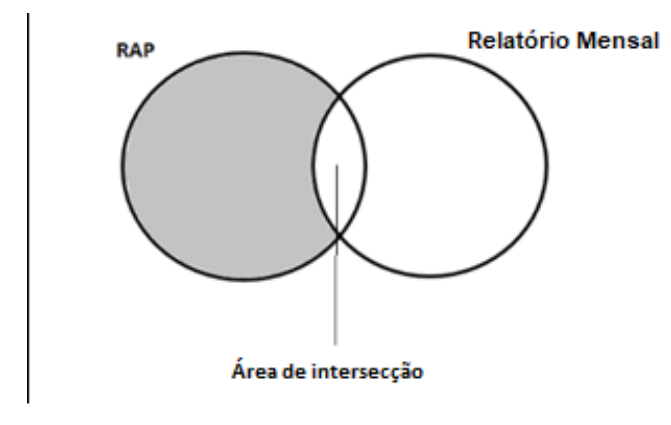

Figura 25: CDC RAP menos intersecção

Primeiramente, vale ressaltar que os registros das Reuniões das Subcomissões, efetuados no Conjunto de Dados consolidado pelo RAP, não fizeram parte do processo de validação, uma vez que não possuem fonte de consulta para comparação. Tal fato não causou viés significativo no quantitativo de reuniões realizadas, já que o número de registros é bem reduzido.

Para confrontar e, consequentemente, validar os dados inseridos no Conjunto consolidado pelo RAP, foi necessário buscar informações no Diário do Senado Federal e nas Atas enviadas pela Secretaria de Comissões.

A título de exemplo, procura-se validar a $26^{a}$ reunião da CMA registrada no Conjunto de Dados consolidado pelo RAP.

Por meio dos dados inseridos nos campos "Documento de Publicação", "Data da Publicação" e "Página" é possível localizar, no DSF, a reunião que se deseja auferir.

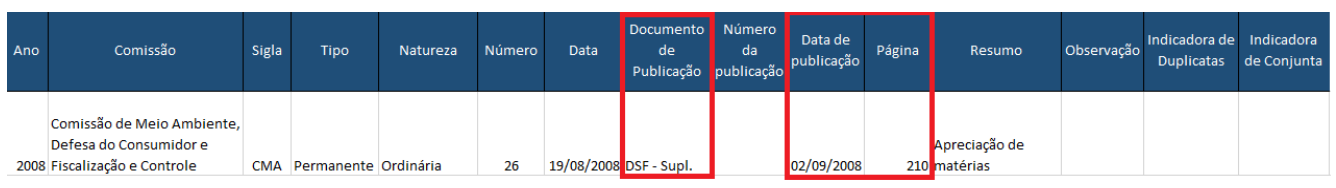

Figura 26: $26^{\mathrm{a}}$ reunião realizada pela CMA

De acordo com as informações destacadas, o registro da $26^{\mathrm{a}}$ reunião se encontra na página 210 do Suplemento do Diário do Senado Federal (DSF Supl.), publicado em 02/09/2008.

Após a localização dessa reunião, basta entrar no site do DSF e realizar a pesquisa, conforme pode ser visto nas Figuras 27, 28 e 29: 


\section{Diários}

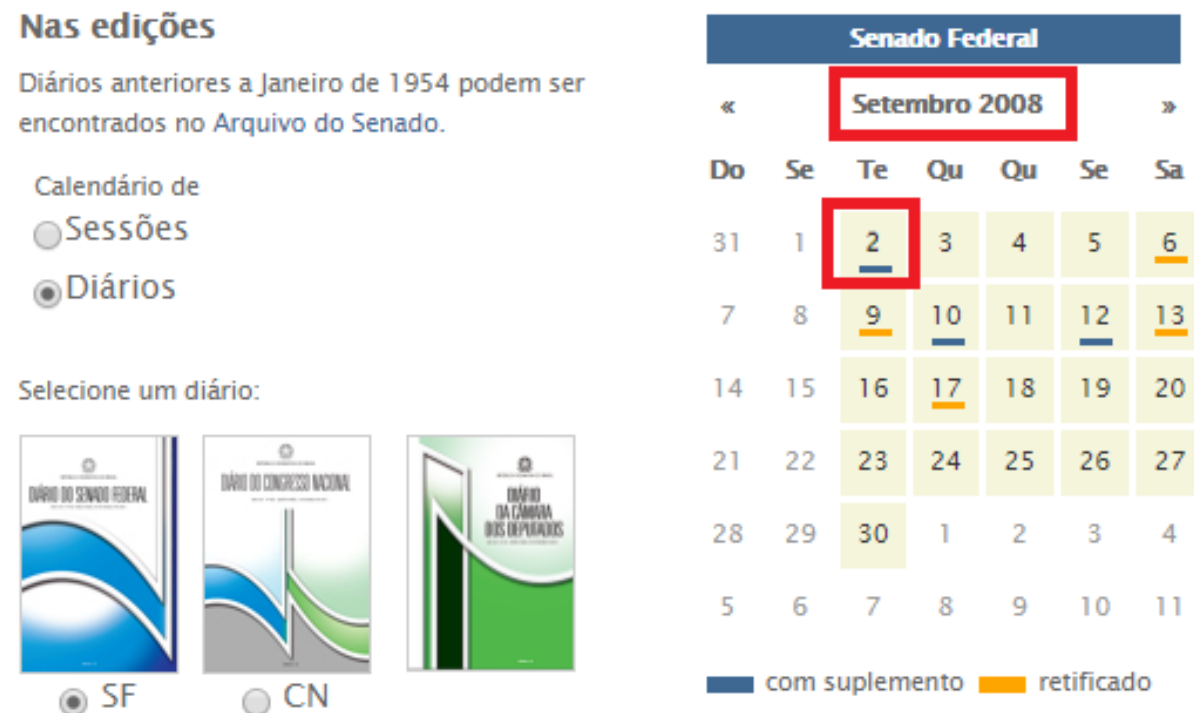

Figura 27: Seleção da data desejada para consulta no DSF

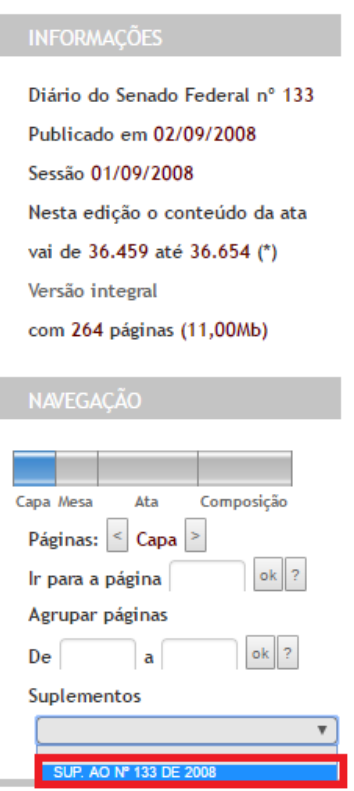

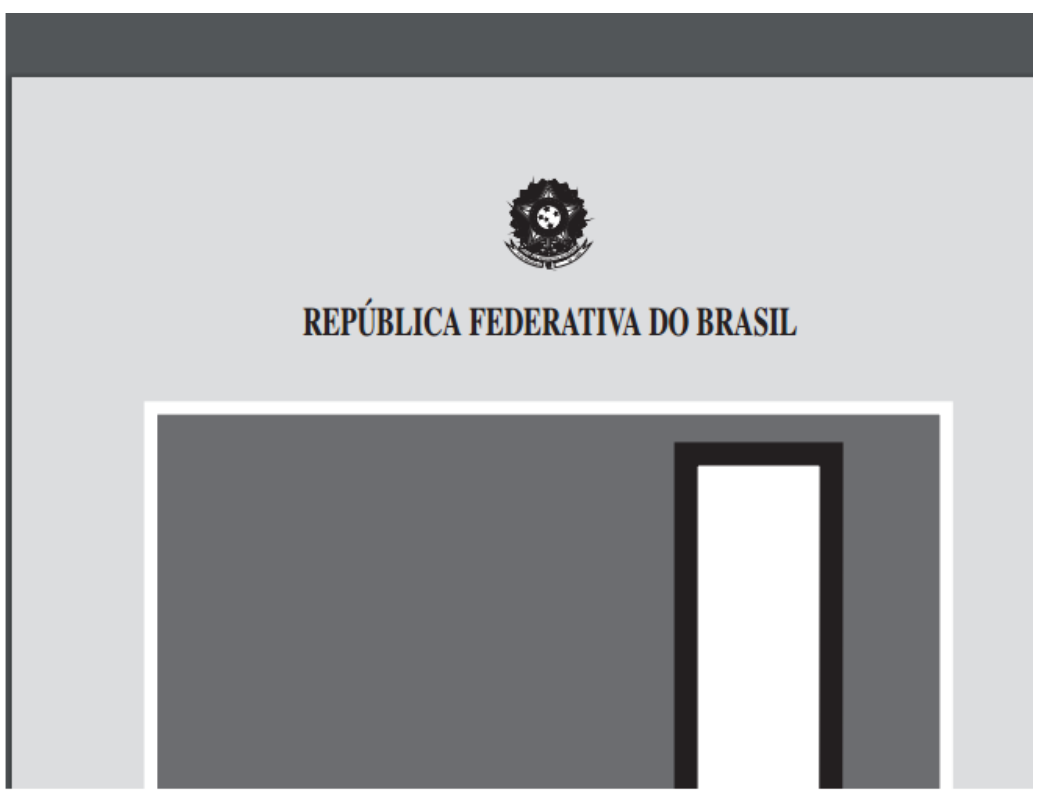

Figura 28: Seleção do Suplemento 

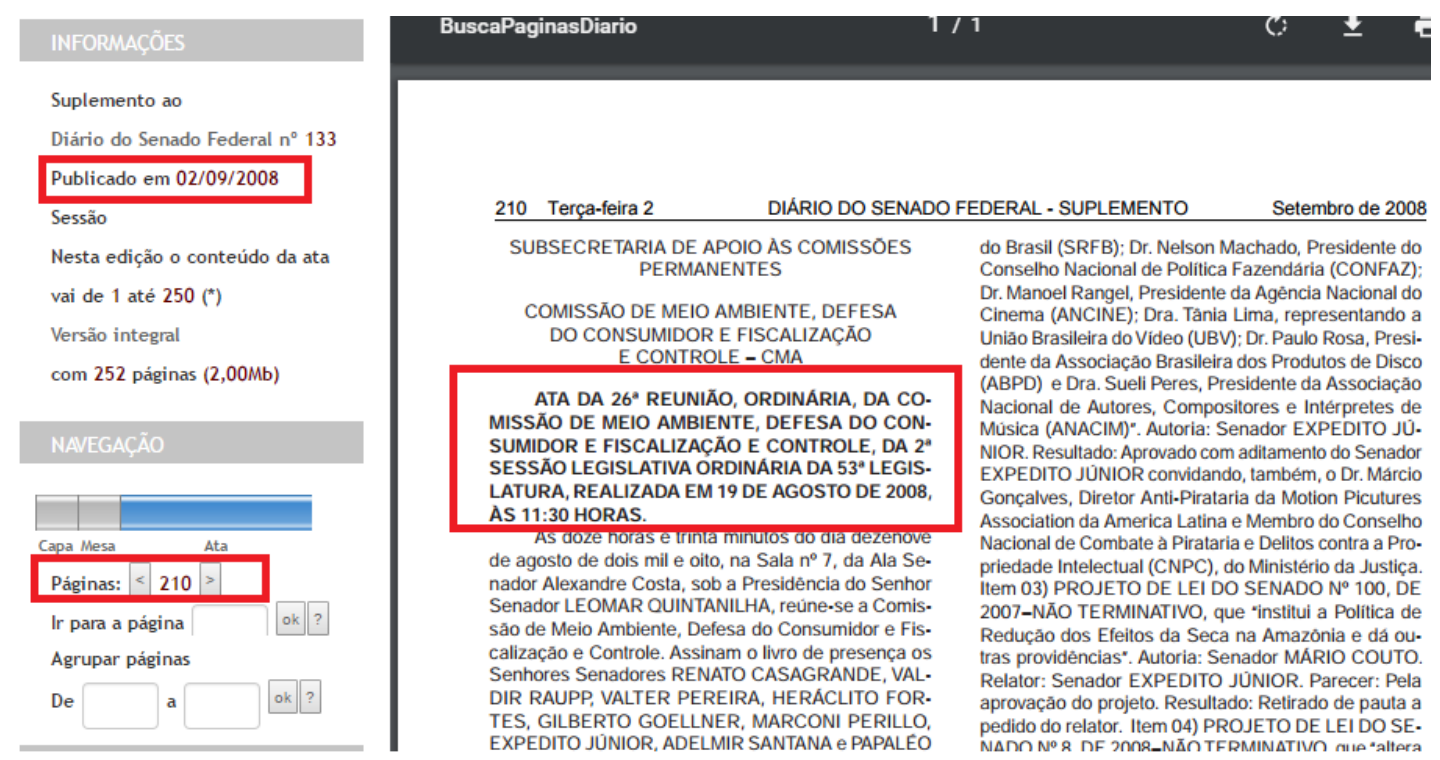

Figura 29: Apresentação da Ata no DSF

Localizada a reunião, a informação foi considerada verdadeira e o dado validado. Caso a reunião não fosse encontrada, a informação seria desconsiderada e excluída do Conjunto de Dados Consolidado pelo RAP.

Quanto à numeração ordinal das reuniões, há de se mencionar que a ordem serial, muitas vezes, não coincidiu com o número real de reuniões realizadas anualmente. Ocorreu de a última reunião realizada em um determinado ano possuir certa ordem numérica que não coincidiu com a ordem numérica apresentada na fonte de pesquisa. Constatou-se, na verdade, que foram realizadas menos reuniões do que a ordem sequencial descrita na fonte documental.

Toma-se, como exemplo, a tabela 4 referente a "Análise do número de reuniões para a CMA", que apresenta o número ordinal da última reunião realizada no ano. Observa-se que nos anos de 2005, 2006 e 2007, tal número não expressa o quantitativo de reuniões realmente realizadas. Ocorreu a perda sequencial da numeração ao pular de um número para outro mais à frente. Isso induz ao erro, quando se considera que a ordem sequencial coincide com o número real de reuniões realizadas. Para sanar esse problema, foi feita uma análise para cada Comissão, averiguando-se e informando-se quais reuniões foram omitidas, conforme apresentado no campo "situação" da referida tabela. 
Tabela 4: Análise do número de reuniões para a CMA

\begin{tabular}{l|l|l|l}
\hline Ano & $\begin{array}{c}\text { Número da última } \\
\text { reunião no RAP }\end{array}$ & $\begin{array}{c}\text { Quantitativo } \\
\text { de reuniões }\end{array}$ & \multicolumn{1}{c}{ Situação } \\
\hline 2005 & 21 & 18 & Não há registros da $17^{\mathrm{a}}, 18^{\mathrm{a}}$ e $19^{\mathrm{a}}$ reunião \\
2006 & 8 & 7 & Não há registro da $4^{\mathrm{a}}$ reunião \\
2007 & 37 & 35 & Não há registros da $1^{\mathrm{a}}$ e $18^{\mathrm{a}}$ reunião \\
2008 & 36 & 36 & Não há registros faltosos \\
2009 & 46 & 46 & Não há registros faltosos \\
2010 & 35 & 35 & Não há registros faltosos \\
2011 & 60 & 50 & Não há registros faltosos \\
2012 & 55 & 47 & Não há registros faltosos \\
2013 & 47 & 30 & Não há registros faltosos \\
2014 & 30 & 59 & Não há registros faltosos \\
2015 & 59 & 21 & Não há registros faltosos \\
2016 & 21 & \multicolumn{2}{c}{} \\
\hline
\end{tabular}

Para suprir a falta do registro de reuniões, buscou-se o registro destas nas Atas disponibilizadas, em CD, pela Secretaria de Comissões. O acesso às referidas Atas se deu da seguinte forma:

1. Localizou-se, no CD, o nome da Comissão que se desejava pesquisar;

2. Selecionou-se o item Atas e o ano;

Depois, foram apresentadas, em ordem cronológica, todas as reuniões realizadas no ano selecionado.

Dessa forma, foi possível apurar as reuniões que deixaram de ser registradas no RAP devido ao salto que houve na ordem sequencial. 


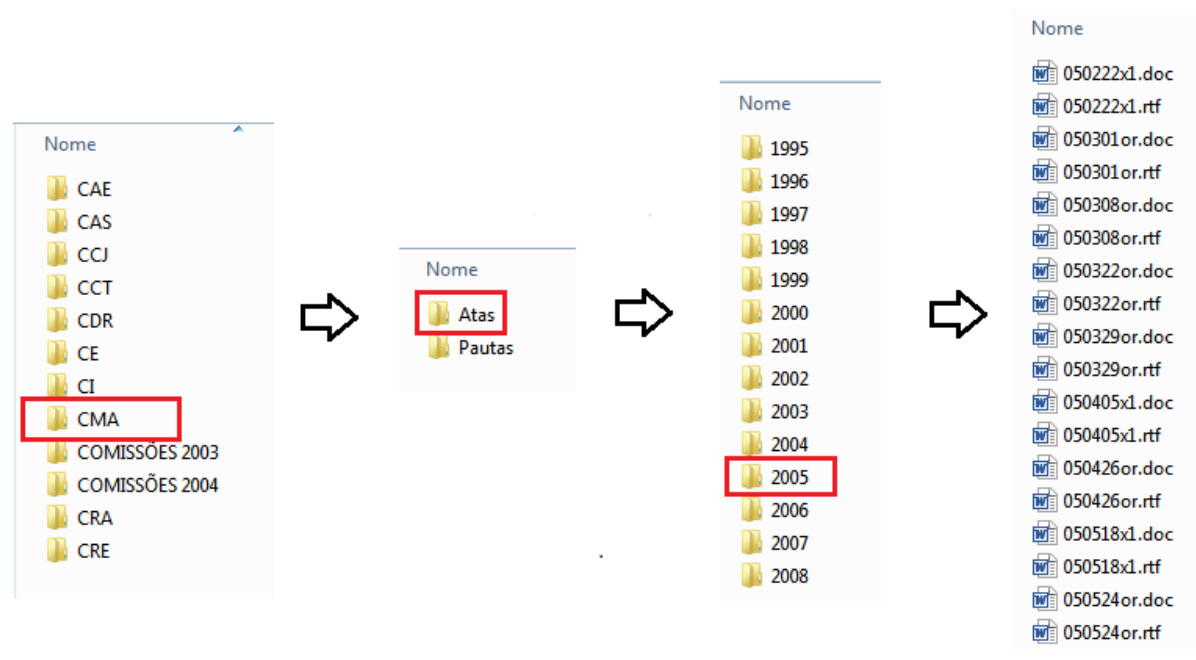

Figura 30: Localização da Ata de reunião

Também foi possível agilizar as pesquisas, nas Atas, sobre as reuniões que não foram registradas no Relatório da Presidência. Para isso, verificou-se, no RAP, o espaço temporal entre duas reuniões. Esse período de vacância serviu como parâmetro de busca.

Por exemplo, acessando-se o RAP de 2005, representado na Figura 31, observou-se que a $16^{\text {a }}$ reunião foi realizada no dia 30/06. A reunião seguinte, registrada como a $20^{a}$ reunião, foi realizada no dia 13/09.

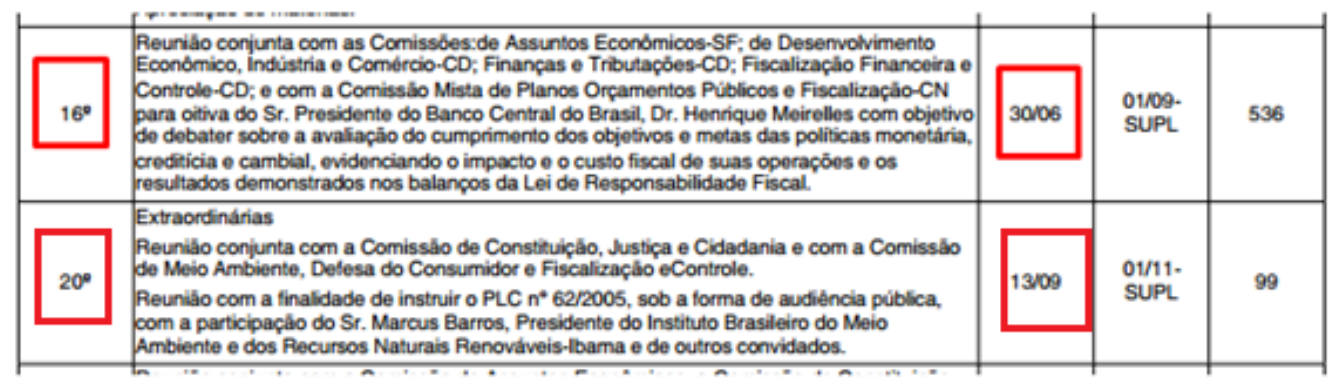

Figura 31: RAP de 2015

Ocorreu um salto sequencial da $16^{\mathrm{a}}$ para a $20^{\mathrm{a}}$ reunião, gerando dúvidas sobre a ocorrência das reuniões intermediárias. Como a $16^{\mathrm{a}}$ e a $20^{\mathrm{a}}$ reunião possuíam o registro da data de realização, foi possível concentrar a procura, nas Atas, por reuniões ocorridas no período de 30/06 a 13/09, conforme demonstrado na Figura 32: 


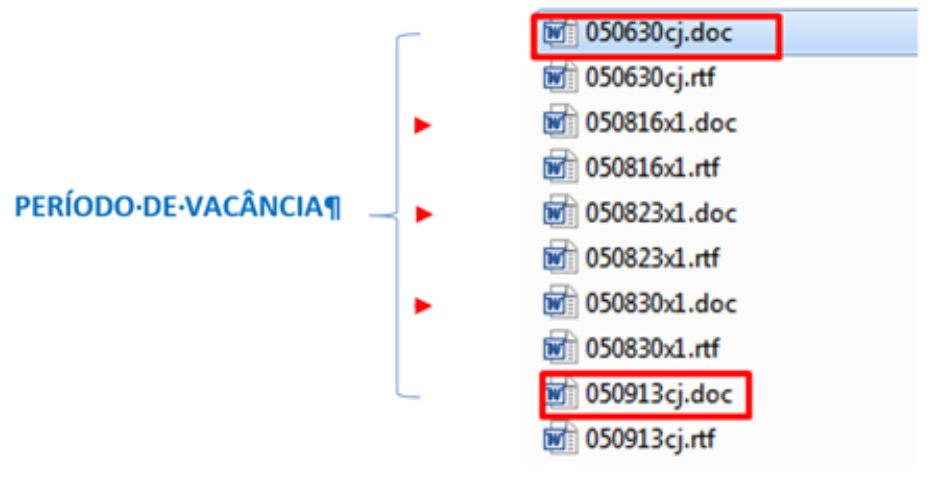

Figura 32: Atas disponibilizadas em CD pela Secretaria de Comissões

Abrindo-se os documentos datados em 16/08/2005, 23/08/2005 e 30/08/2005, foi possível ver as reuniões que faltavam no registro do RAP $\left(17^{\mathrm{a}}, 18^{\mathrm{a}}\right.$ e $\left.19^{\mathrm{a}}\right)$ :

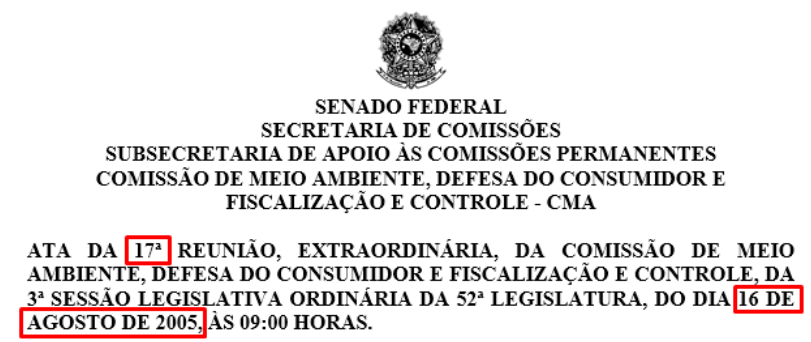

Figura 33: Ata da $17^{\mathrm{a}}$ reunião

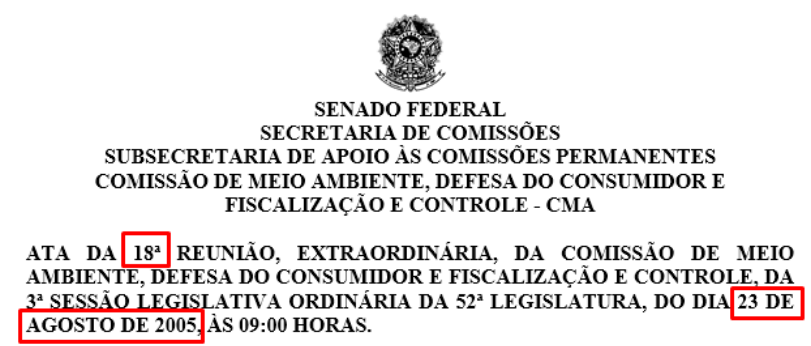

Figura 34: Ata da $18^{\mathrm{a}}$ reunião 


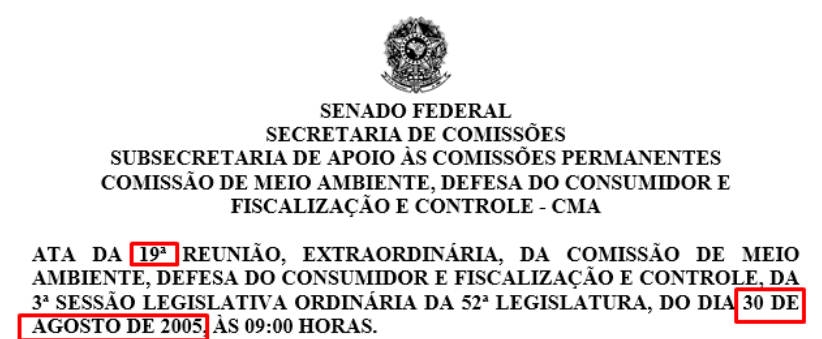

Figura 35: Ata da $19^{a}$ reunião

As reuniões ausentes no RAP, mas presentes nas Atas, foram adicionadas no Conjunto Unificado. Contudo, antes de adicionar tais registros, foi verificado se essas reuniões já tinham sido registradas no Relatório Mensal. Para isso, foi criada a tabela de confrontamento representada na Figura 36, onde foi possível visualizar o registro das reuniões, tanto nas Atas, quanto nos Relatórios Mensais. Caso o registro de determinada reunião já constasse no Relatório Mensal, não seria necessário adicioná-las ao Conjunto Unificado, pelo simples fato de terem sido inseridas.

\begin{tabular}{|c|c|c|c|c|c|c|c|}
\hline $\begin{array}{l}\text { Ano } \\
2005\end{array}$ & $\begin{array}{l}\text { Comissão } \\
\text { Comissão de Meio Am }\end{array}$ & $\begin{array}{l}\text { Reuniao Natureza } \\
17 \text { Extraordinária }\end{array}$ & $\begin{array}{l}\text { Data } \\
16 / 08 / 2005\end{array}$ & \multicolumn{2}{|c|}{ Documen' Número.1 Data.1 } & Página & Observaç̧̂́ PRESENTE NA RESENHA \\
\hline 2005 & Comissão de Meio Am & 19 Extraordinária & $30 / 08 / 2005$ & 5 Ata & & & SIM \\
\hline
\end{tabular}

Figura 36: Tabela de confrontamento

Ressalta-se que CAE e a CDH não possuem registros de Atas em 2005 e 2006. Nesse caso, as Atas foram substituídas pelas Pautas de reuniões, a fim de apurar possíveis omissões no RAP.

Concluiu-se, assim, o processo de validação das reuniões registradas no Conjunto de Dados consolidado pelo RAP.

\subsubsection{Validação das reuniões registradas no Conjunto de Dados consolidado pelo Relatório Mensal, excluindo-se a área de intersec- ção com o RAP.}




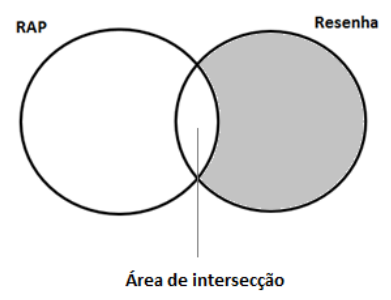

Figura 37: CDC pelo Relatório Mensal menos intersecção

Para confrontar e, consequentemente, validar os dados inseridos no Conjunto consolidado pelo Relatório Mensal, foi necessário buscar informações nas Atas e nas Pautas disponibilizadas pela Secretaria de Comissões.

A título de exemplo, procurou-se validar a reunião realizada pela CAS em 01/09/2005, registrada no Conjunto de Dados consolidado pelo Relatório Mensal.

Por meio dos dados inseridos nos campos "Comissão" e "Data" foi possível localizar nas Atas ou nas Pautas, disponibilizadas em CD, a reunião que se desejava auferir, conforme segue nas Figuras 38 e 39:

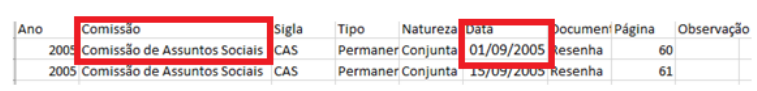

Figura 38: Reunião realizada pela CAS - Conjunto de Dados consolidado pelo Relatório Mensal

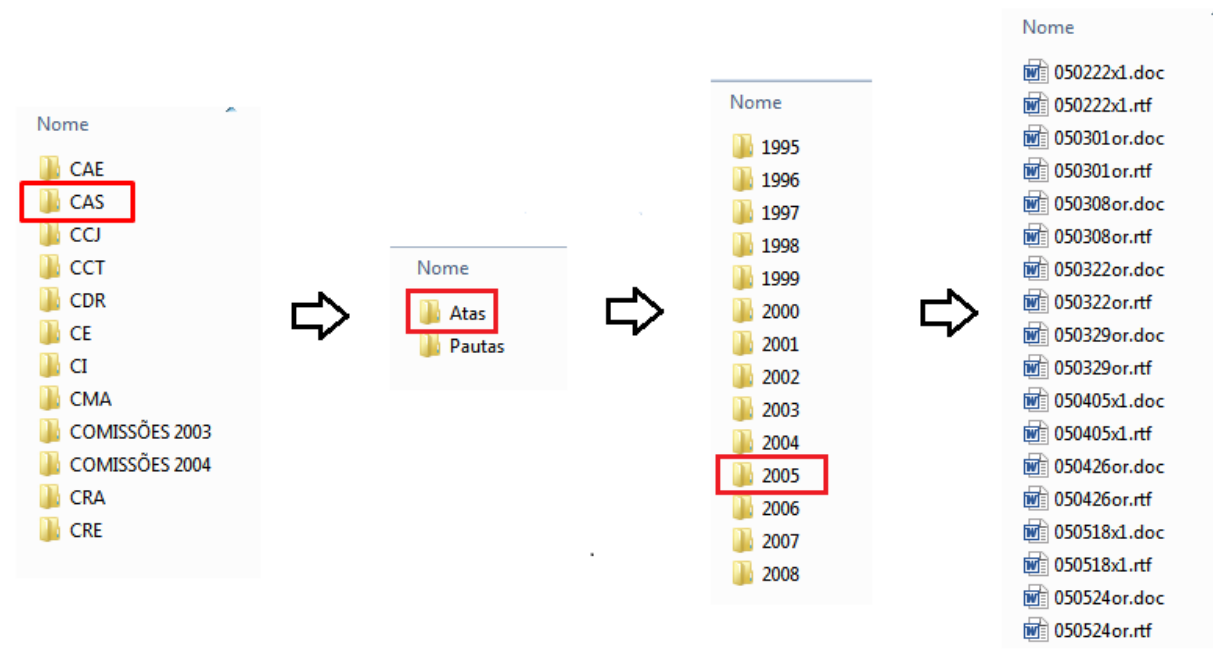

Figura 39: CD disponibilizado pela Secretaria de Comissões - Atas 
Caso a pasta de Atas das reuniões não estivesse disponível ou a reunião não fosse encontrada, seria verificada a existência da Pauta da reunião, conforme segue na Figura 40 no que se refere a CDR:

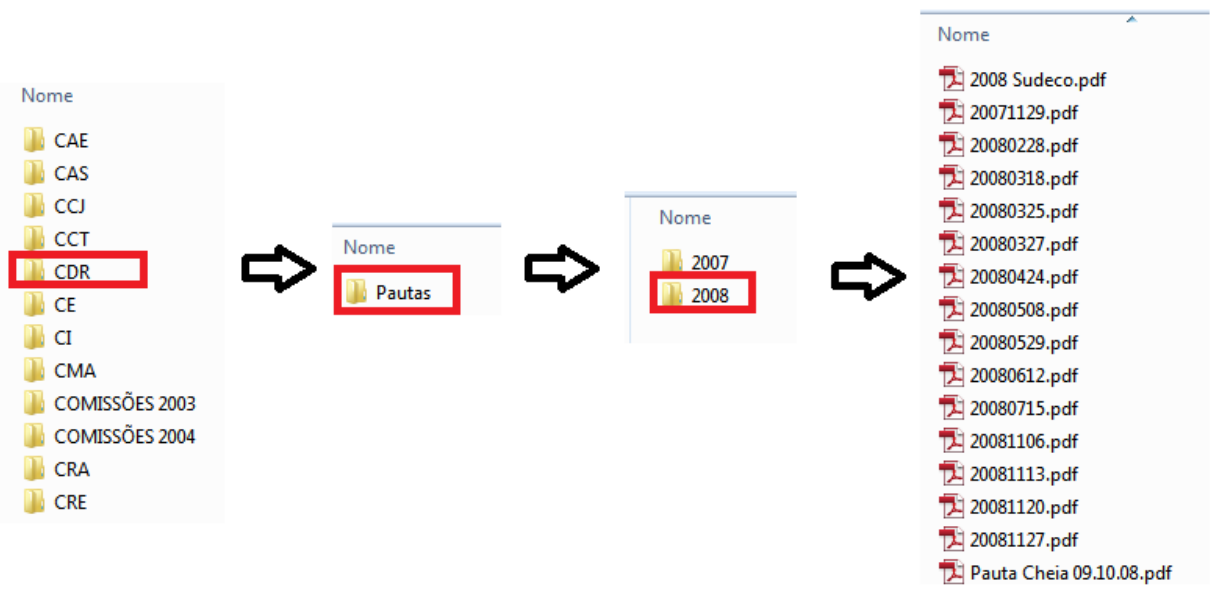

Figura 40: CD disponibilizado pela Secretaria de Comissões - Pauta

Para efeitos de validação dos dados do Conjunto consolidado pelo Relatório Mensal, as Pautas tiveram o mesmo grau de confiabilidade das Atas.

As reuniões disponibilizadas na pasta de Atas ou Pautas foram consideradas verdadeiras e, consequentemente, validadas. De outra forma, as reuniões que não possuíam registro na pasta de Atas ou Pautas foram excluídas do Conjunto de Dados Consolidado pelo Relatório Mensal.

Quando não houve pasta de Atas e Pautas, não foi possível validar as informações. Nessa hipótese, por limitação das fontes de consulta, os dados foram considerados verdadeiros.

Para melhor compreensão, segue a Figura 41 que apresenta o levantamento das pastas das Atas ou Pautas disponibilizadas pela Secretaria de Comissões, no período de 2003 a 2008:

\begin{tabular}{|l|l|l|l|l|l|l|l|l|l|l|l|l|l|}
\cline { 2 - 11 } \multicolumn{1}{l|}{} & CAE & CAS & CCJ & CE & CMA & CDH & CRE & CI & CDR & CRA & CCT & CFC & CLP \\
\hline 2003 & & & & & & & & & & & & & \\
\hline 2004 & & & & & & & & & & & & & \\
\hline 2005 & & & & & & & & & & & & \\
\hline 2006 & & & & & & & & & & & & \\
\hline 2007 & & & & & & & & & & & \\
\hline 2008 & & & & & & & & & & & & \\
\hline
\end{tabular}

Figura 41: Levantamento das pastas das Atas 
As células em branco indicam que as Atas ou Pautas das reuniões foram disponibilizadas. As células em vermelho indicam que as Atas ou Pautas não foram disponibilizadas e as células em preto indicam a inexistência de Atas ou Pautas pelo fato de a comissão não existir na época (ex.: CCT criada após o ano de 2007) ou pelo fato de a comissão ter sido extinta ou incorporada a outra Comissão (ex.: CFC e CLP).

Realizado o levantamento das informações sobre as reuniões registradas nas Atas e nas Pautas, essas foram transportadas para os campos "Natureza", "Número Sequencial", "Observação" e "Possui Ata/Pauta" do Conjunto de Dados consolidado pelo Relatório Mensal.

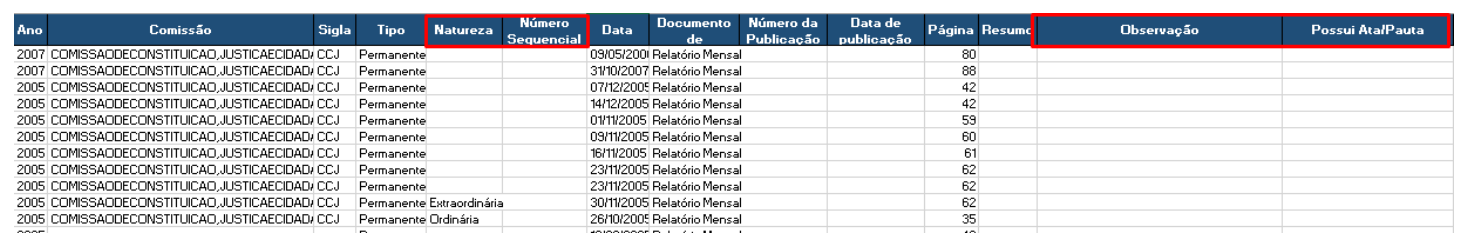

Figura 42: Conjunto de Dados consolidado pelo Relatório Mensal

Concluiu-se assim o processo de validação do Conjunto de Dados consolidado pelo Relatório Mensal.

\subsubsection{O emprego do Conjunto Unificado no processo de valida- ção}

Os registros do Conjunto Unificado são provenientes dos Conjuntos consolidados pelo RAP e pelo Relatório Mensal. Como esses registros já foram validados anteriormente, não foi necessário revalidá-los.

O Conjunto Unificado foi empregado como recurso de validação para eliminar possíveis erros, no que se refere à numeração sequencial das reuniões. Trata-se de uma revisão final dos dados cadastrados nos Conjuntos consolidados.

Considerando a hipótese das pastas de as Atas possuírem mais registros de reuniões do que o Conjunto Unificado, esses registros seriam transportados para o referido Conjunto.

\subsubsection{Validação das reuniões realizadas pelas Comissões Tempo- rárias}

Somente as reuniões realizadas pelas Comissões Temporárias, no período de 2013 a 2016, registradas no Conjunto de Dados consolidado pelo RAP, passaram pelo processo de validação. De outra forma, utilizou-se o programa 
Arquimedes para validar e complementar com dados o Conjunto consolidado pelo RAP.

\subsubsection{Validação do Conjunto de Dados consolidado pelo RAP para as sessões plenárias ou conjuntas}

Para a validação do quantitativo de sessões realizadas no período de 2003 a 2016, presentes no Conjunto de Dados Consolidados pelo RAP, foi consultado o Diário do Senado Federal.

Uma vez que as sessões são numeradas e registradas no DSF de forma sequencial, independentemente de sua natureza, o quantitativo de sessões ocorridas numa Sessão Legislativa ${ }^{1}$ é evidenciado pela numeração ordinal da última sessão realizada. Isso pode ser observado no exemplo a seguir:

A Figura 43 apresenta a web página do Diário do Senado Federal do dia 23 de dezembro de 2009. Trata-se do registro da $259^{a}$ sessão deliberativa ordinária correspondente à última sessão da Sessão Legislativa Ordinária, realizada no ano de 2009. Logo, o quantitativo de sessões realizadas, neste ano, correspondeu a 259 sessões.

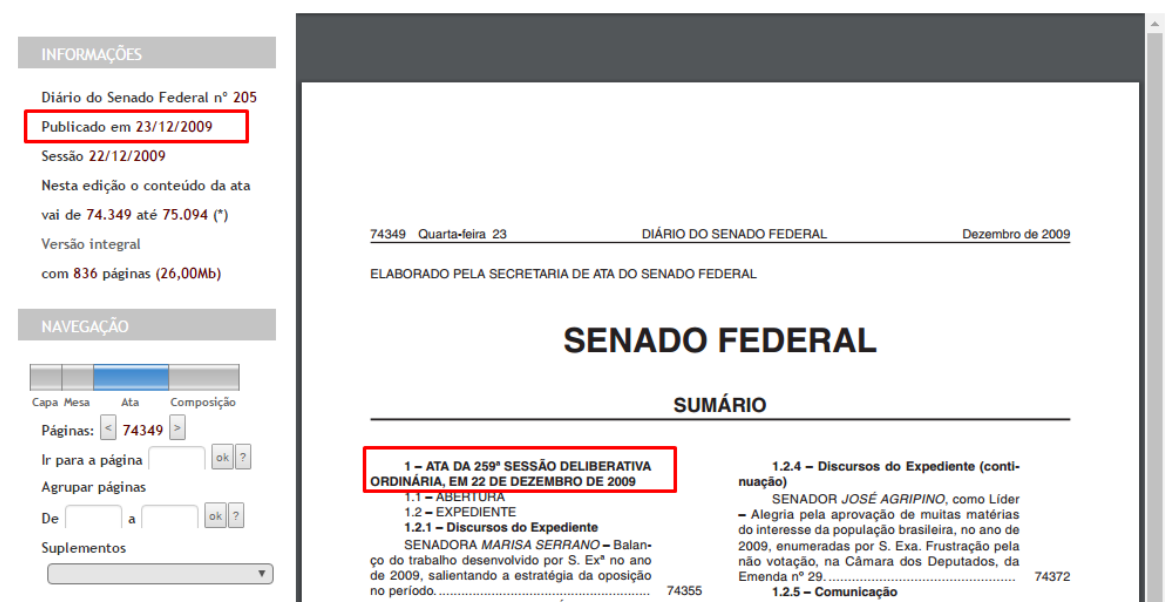

Figura 43: Página web do DSF

Contudo, em determinados anos ocorreram Sessões Legislativas Ordinárias e Extraordinárias. Nesses casos, o quantitativo de sessões no ano correspondeu à soma das sessões realizadas numa e noutra Sessão Legislativa, conforme se pode observar:

\footnotetext{
${ }^{1}$ As sessões correspondem ao período do dia em que os senadores se reunem para discutir e apreciar matérias legislativas, fazer homenagens, debater questões relevantes de interesse nacional, dentre outras atividades legislativas. Já as Sessões Legislativas correspondem ao ano legislativo.
} 
1. A Figura 44 apresenta a web página do Diário do Senado Federal do dia 16 de dezembro de 2004. Trata-se do registro da $182^{\mathrm{a}}$ sessão deliberativa ordinária, correspondente a última sessão plenária da Sessão Legislativa Ordinária, realizada no ano de 2004. Logo, o quantitativo de sessões realizadas pela Sessão Legislativa Ordinária corresponderá a 182 sessões.

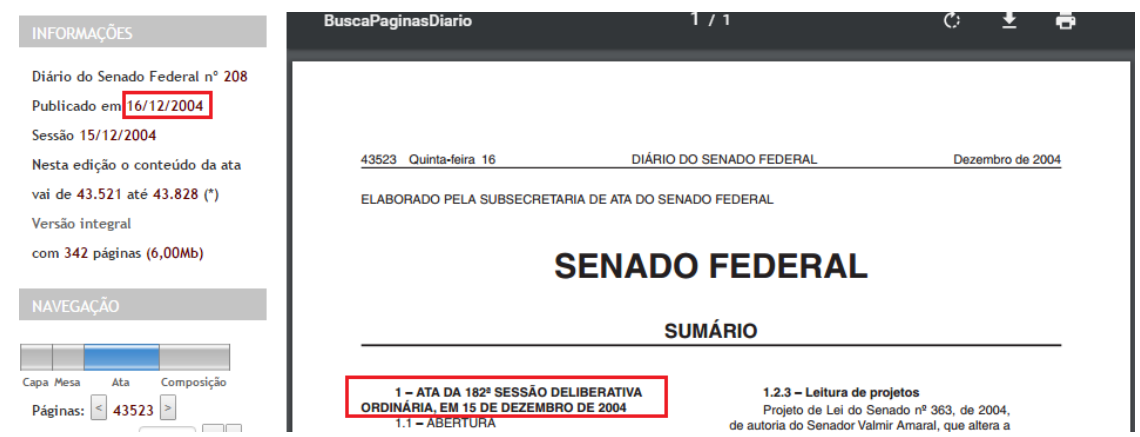

Figura 44: Página web do DSF - Sessão Legislativa Ordinária

2. As Figuras 45 e 46 apresentam, respectivamente, a $20^{\mathrm{a}}$ e a $4^{\mathrm{a}}$ sessão realizada nas Sessões Legislativas Extraordinárias no ano de 2004. Trata-se dos registros das últimas sessões plenárias realizadas.

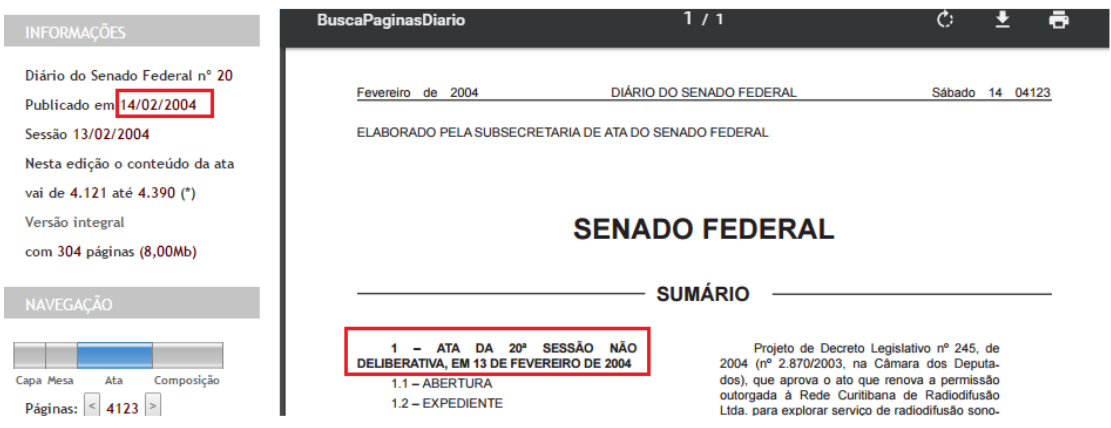

Figura 45: Página web do DSF - Sessão Legislativa Extraordinária 


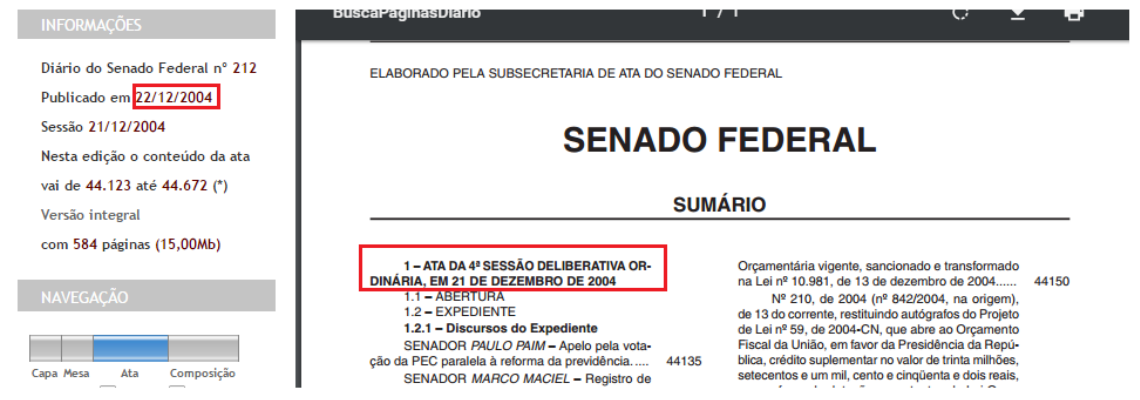

Figura 46: Página web do DSF - Sessão Legislativa Extraordinária

3. Logo, o total de sessões plenárias realizadas no ano de 2004, pelas Sessões Legislativas Ordinária e Extraordinária, será de 206.

Tabela 5: Quantitativo de sessões plenárias

\begin{tabular}{l|l|l}
\hline \multicolumn{1}{c|}{ Sessão Legislativa } & \multicolumn{1}{|c|}{ Ano } & \multicolumn{1}{c}{ Total de sessões plenárias } \\
& & \\
\hline Ordinária & 2004 & 182 \\
Extraordinária & 2004 & 20 \\
Extraordinária & 2004 & 4 \\
\hline \multicolumn{2}{c}{ Total } & 206 \\
\hline
\end{tabular}

Para concluir o processo de validação do Conjunto de Dados consolidado pelo RAP para as sessões, compararam-se as informações obtidas do DSF, no que se refere ao total de sessões realizadas num determinado ano, com as informações das sessões registradas no Conjunto consolidado pelo RAP, referentes ao mesmo ano.

Tais dados foram inseridos numa tabela comparativa, conforme ilustrado abaixo, que facilitou a visualização de congruências e possíveis divergências entre os dados registrados no DSF e o Conjunto de Dados consolidado para as sessões plenárias. 
Tabela 6: Tabela Comparativa

\begin{tabular}{c|c|c}
\hline Ano & $\begin{array}{c}\text { Número de sessões } \\
\text { plenárias contidas no RAP }\end{array}$ & $\begin{array}{c}\text { Número de sessões } \\
\text { plenárias contidas no DSF }\end{array}$ \\
\hline 2003 & 215 & 215 \\
2004 & 206 & 206 \\
$\cdot$ & $\cdot$ & $\cdot$ \\
$\cdot$ & $\cdot$ & $\cdot$ \\
$\cdot$ & $\cdot$ & $\cdot$ \\
2016 & 197 & 197 \\
\hline
\end{tabular}




\section{RESULTADOS}

Uma vez validados e quantificados os dados, em um Conjunto de consulta, realizou-se a análise do comportamento de variáveis para identificar causas e prever o número de sessões e reuniões.

Nesse sentido, a Análise Descritiva é uma excelente ferramenta de interpretação, pois trata da análise exploratória de dados com a finalidade de identificar e descobrir prováveis causas para o comportamento das séries, por meio de medidas de posição, de dispersão e análise gráfica.

Tal ferramenta foi empregada para a análise do quantitativo de reuniões realizadas pelo Senado Federal e sessões realizadas pelo Senado e Congresso Nacional, visando ampliar o entendimento sobre o processo de quantificação de dados.

Para cada tipo de reunião ou sessão foi proposto um modelo individual que levou a um resultado parcial. O número total de sessões e reuniões realizadas pelo Senado Federal e pelo Congresso Nacional, que é o resultado final requerido, será dado pela soma dos resultados parciais.

Para prever o número de sessões Conjuntas - sessoesconj, foi utilizado modelo de Médias Móveis, e para os demais eventos (reuniões realizadas por Comissões Permanentes - reuperm, por Comissões Temporárias - reutemp, por Subcomissões - reusub ou sessões Plenárias - sessoesplen) foi utilizado modelo de regressão linear.

Ao estimar os modelos parciais reuperm, reusub, reutemp e sessoesplen, a suposição de independência condicional dos erros foi violada. Contudo, os testes apresentaram resultados satisfatórios.

Buscou-se centralizar a previsão do número total de reuniões e sessões realizadas, por ano, em um único modelo estatístico. Todavia, tal modelo não demonstrou ser adequado pelo fato de apresentar o Erro Quadrático Médio maior do que a soma dos resultados dos modelos parciais. Assim, o modelo final compreende o somatório dos resultados auferidos pelos modelos parciais, já mencionados anteriormente.

\subsection{Reuniões realizadas por Comissões Permanentes}

No ano de 2005, o Senado Federal emitiu uma Resolução que aparentemente aumentou o número de reuniões realizadas pelas comissões Permanentes. Trata-se da Resolução No 1 de 22/02/2005, que cria no Senado Federal a Comissão de Agricultura e Reforma Agrária - CRA, e altera a denominação e atribuições das Comissões Permanentes. As Comissões CMA, CRA, CDR e CDH passaram a constar no RISF e as antigas CFC e CLP deixaram de constar, por força de medida resolutiva. 
Isso foi observado na série temporal projetada para o número de reuniões realizadas por Comissões Permanentes, a partir do ano de 2006, apresentada na Figura 47.

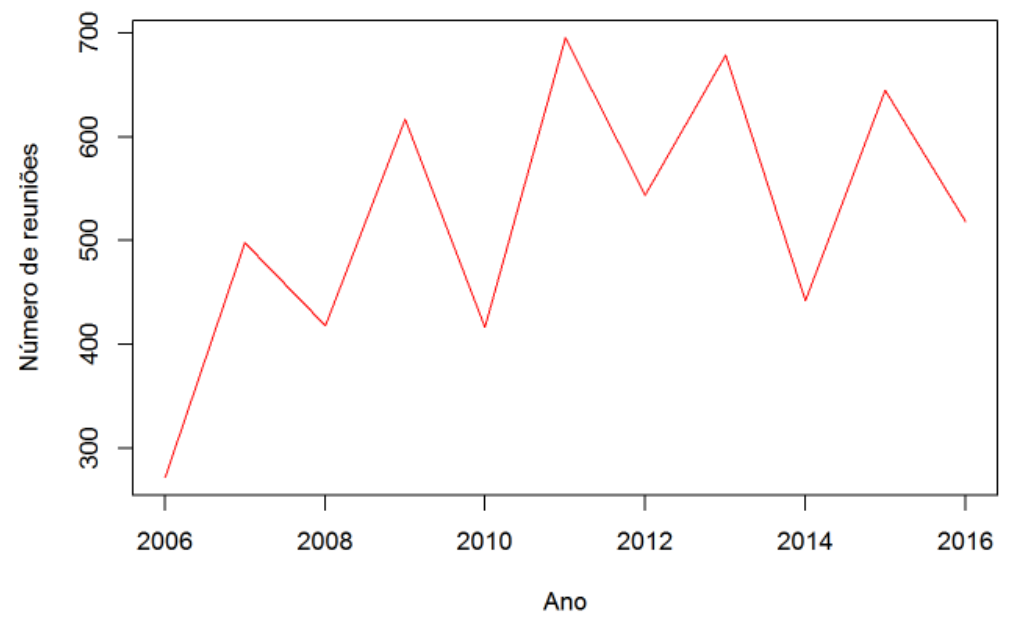

Figura 47: Número de reuniões realizadas por Comissões Permanentes

Analisando o gráfico acima, deparou-se com o número reduzido de reuniões realizadas nos anos de 2003 e 2004. A epígrafe da Resolução $N^{\circ} 1$, de 2005, menciona a alteração de atribuições das Comissões Permanentes.

Dedutivamente, foi possível chegar ao entendimento de que a diferença do quantitativo de reuniões, a partir de 2005, foi devida às alterações implementadas pela referida Resolução.

Outra possível razão pela qual o gráfico evidenciou o número reduzido de reuniões em 2003 e 2004 foi o fato de cinquenta e cinco por cento das comissões existentes não terem passado pelo processo de validação, devido à ausência de Atas e Pautas como fonte de consulta. A título de ilustração, menciona-se que, no ano de 2003, a CCJ só teve o registro de uma única reunião.

Em 2006, o número de reuniões permaneceu baixo, ao comparar com os anos seguintes. Presume-se que isso tenha ocorrido devido ao período de adaptação às mudanças do Regimento Interno.

Já o comportamento periódico do gráfico provavelmente tenha sido motivado pelos anos eleitorais. Atualmente, no Brasil, ocorrem eleições gerais (Presidente da República, Vice-Presidente, Deputado Federal, Governador, Vice-Governador e Deputado Estadual) e municipais (Prefeito, Vice-Prefeito e Vereadores ) a cada quatro anos. Para o cargo de senador, as eleições são realizadas também a cada quatro anos, sendo que há renovação parcial das 
vagas do cargo, alternando entre $1 / 3$ e $2 / 3$ da composição da Casa, por força de dispositivo constitucional ( $\mathrm{CF}$, art.46, $\left.\S 2^{\circ}\right)$.

Considerando-se que as eleições municipais são intercaladas e defasadas das eleições gerais, por período de dois anos consecutivos, conclui-se que a cada biênio ocorre um escrutínio. Isso pode ser demonstrado na linha temporal que segue na Figura 48.

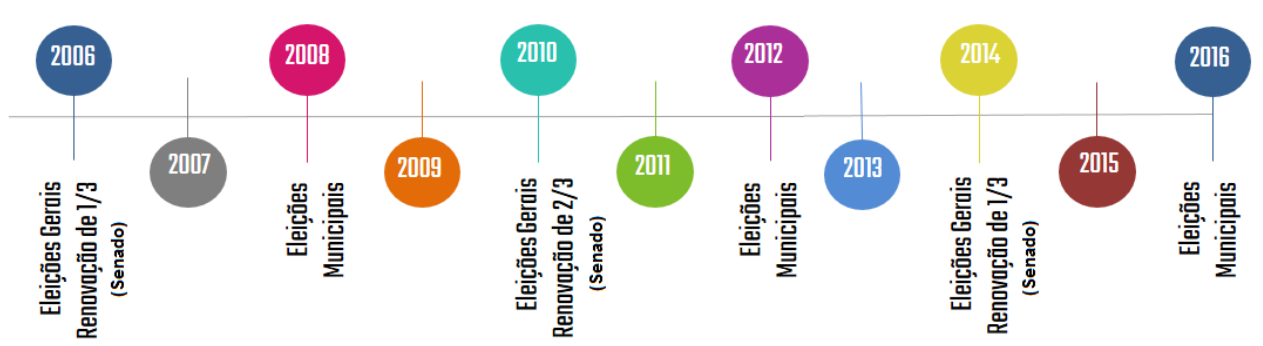

Figura 48: Eleições

Tal fato possivelmente possa corroborar o comportamento periódico do gráfico, ao se considerar que o decaimento do número de reuniões coincide com os anos de eleições gerais ou municipais.

Já a tendência crescente da série apresentada na Figura 47 pode ser atribuída à prática de transmissão ao vivo pela TV Senado das reuniões realizadas pelas Comissões Permanentes, iniciada em 2009.

Tendo em vista os resultados obtidos pela análise descritiva, foi elaborado um modelo de Regressão, conforme a equação 11, no qual a variável resposta é dada pelo número de reuniões realizadas pelas Comissões Permanentes (reuperm), e as variáveis explicativas são definidas por:

$$
\begin{aligned}
& \text { anoeleitoral }=\left\{\begin{array}{r}
0, \text { se não é ano eleitoral } \\
1, \text { se é ano eleitoral }
\end{array}\right. \\
& t v=\left\{\begin{array}{c}
0, \text { se não há transmissão pela TV } \\
1, \text { se há transmissão pela TV }
\end{array}\right.
\end{aligned}
$$

Aplicando-se o método de Mínimos Quadrados Ordinários descrito na Seção 2.1.2 descrito na Equação 11, obtém-se o seguinte modelo estimado:

$$
\text { reuperm }=510,88-172,31 \text { anoeleitoral }+144,91 \text { tv }
$$

Para testar se as variáveis explicativas realmente influenciaram na variável resposta, foi realizado o Teste $t$, por meio do qual concluiu-se que ambas 
as variáveis independentes são estatisticamente significantes. Isso pode ser facilmente observado na tabela 7 :

Tabela 7: Teste $\mathrm{t}$

\begin{tabular}{l|c|c|c}
\hline Parâmetro & Estatística teste & P-valor & Conclusão \\
\hline$\widehat{\beta}_{\text {anoeleitoral }}$ & $-4,97$ & 0,001 & Há evidências para rejeitar $H_{0}$ \\
$\widehat{\beta}_{t v}$ & 3,74 & 0,005 & Há evidências para rejeitar $H_{0}$ \\
\hline
\end{tabular}

Analisando conjuntamente todos os parâmetros, ou seja, realizando o Teste de significância global, obteve-se a estatística de teste equivalente a 22,65 e p-valor igual a 0,005. Dessa forma, também pôde-se concluir que a contribuição é estatisticamente diferente de zero.

Para testar o pressuposto de homocedasticidade do erro, foi feita a análise gráfica da Figura 49:

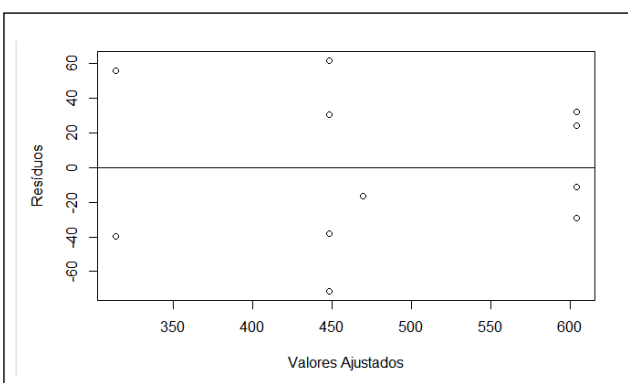

(a) Resíduos x Valores ajustados

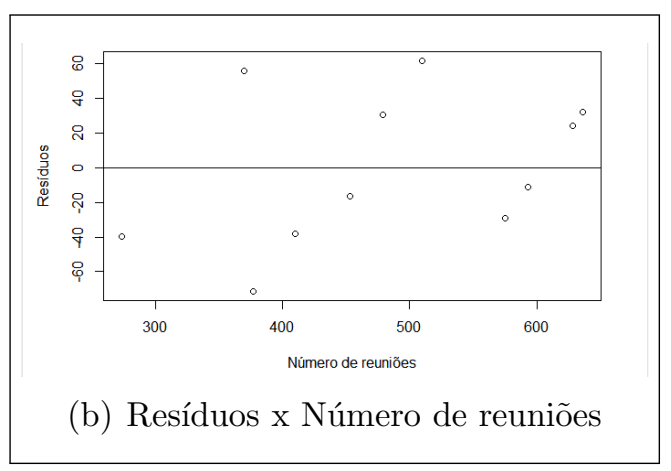

Figura 49: Análise de resíduos - Homocedasticidade

Nota-se que os pontos estão distribuídos aleatoriamente em torno do zero, ou seja, não há uma tendência aparente. Assim, a suposição de homocedasticidade não foi violada.

Observando-se o gráfico da Probabilidade Normal dos Resíduos, representado na Figura 50, há evidências de que a distribuição dos erros é normal, uma vez que os pontos encontram-se próximos à reta. Tal hipótese é confirmada pelo resultado obtido no teste de significância de Shapiro-Wilk, apresentado na Tabela 8: 


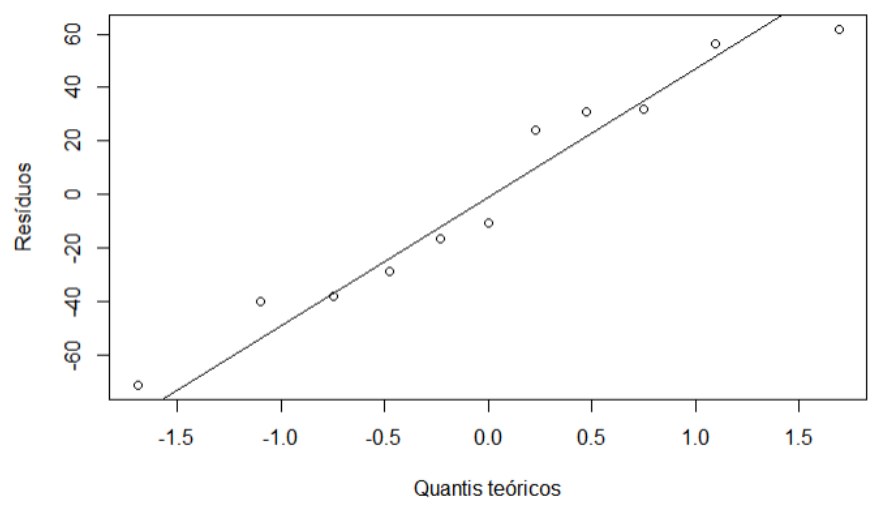

Figura 50: Gráfico de Probabilidade Normal dos Resíduos

Tabela 8: Teste de significância de Shapiro-Wilk

\begin{tabular}{c|c|c}
\hline Estatística teste & P-valor & Conclusão \\
\hline 0,94 & 0,52 & Não há evidências para rejeitar normalidade \\
\hline
\end{tabular}

\subsection{Reuniões realizadas por Subcomissões das Comis- sões Permanentes}

A representação da série temporal para o número de reuniões realizadas por Subcomissões é dada pela Figura 51:

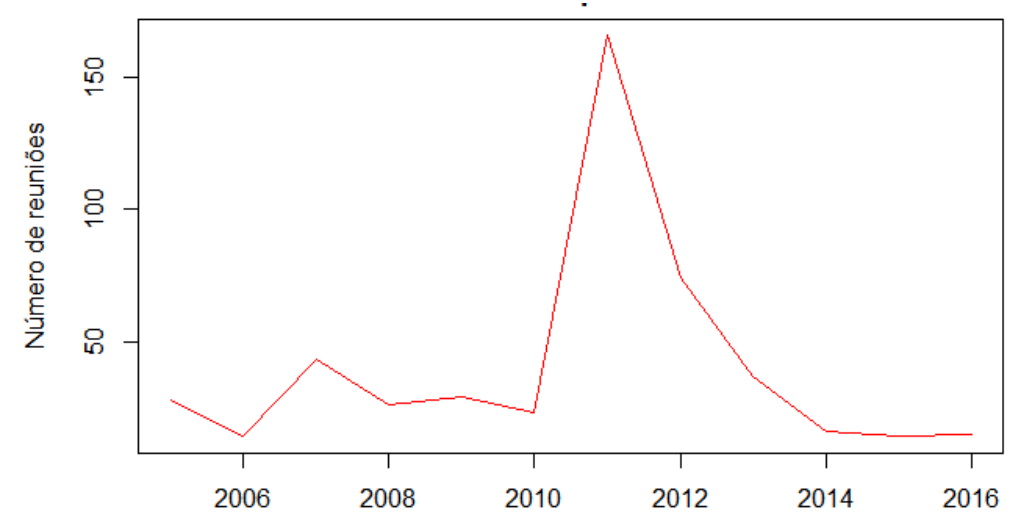

Figura 51: Número de reuniões realizadas por Subcomissões, por ano

Nesta série, observa-se um aumento abrupto do número de reuniões realizadas no ano de 2011. Isso possivelmente ocorreu devido ao interesse dos 
senadores, empossados pela primeira vez, em criar Subcomissões e exercerem funções nelas. Ressalta-se que, no ano em pauta, ocorreu a maior renovação de cadeiras, chegando à porcentagem de quarenta e quatro por cento em relação aos outros anos analisados (em 2007 e 2015, foi de vinte e quatro por cento), podendo ter repercutido, direta ou indiretamente, no aumento do número de reuniões.

Já para explicar a quantidade de reuniões ocorridas, no período de 2003 a 2016, coube analisar a correlação entre o número total de reuniões realizadas pelas Subcomissões, permanentes ou temporárias, com o número de Subcomissões existentes, conforme apresentada na Figura 52.

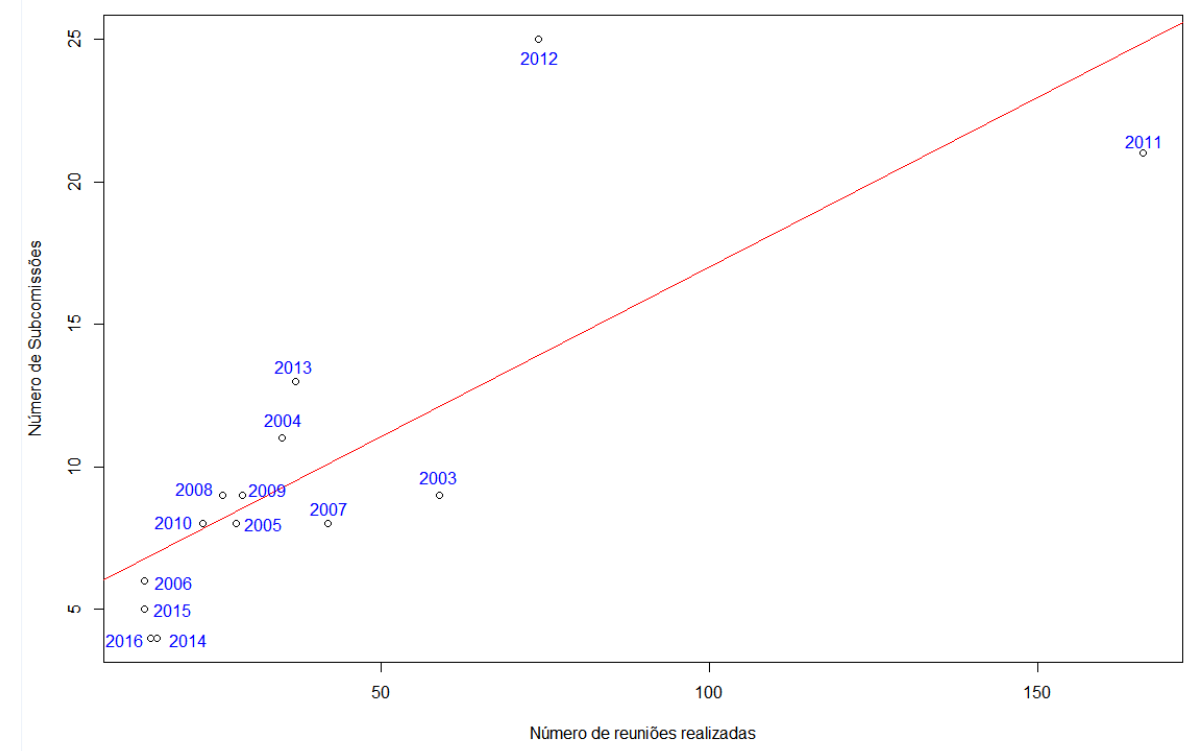

Figura 52: Número de reuniões x Número de Subcomissões

Nota-se a existência de correlação linear forte e positiva entre as variáveis "Número de Subcomissões" e "Número de Reuniões realizadas", com exceção do ponto influente, que se refere ao ano de 2012. A estimativa do coeficiente de correlação ${ }^{2}$ dado por 0,78 , relativamente alto, é outro indício da existência da correlação.

Partindo-se do princípio de que pontos influentes podem interferir na estimativa do coeficiente de correlação, para efeito de avaliação exclui-se da análise o dado referente ao ano de 2012. Realizada a exclusão, obteve-se a nova estimativa de 0,89 , reafirmando a forte correlação existente entre as variáveis.

${ }^{2} \mathrm{O}$ coeficiente de correlação é dado por: $\rho(X, Y)=\frac{\operatorname{Cov}(X, Y)}{\sigma_{X}^{2} \sigma_{Y}^{2}}$ 
Tendo em vista os resultados obtidos pela análise descritiva, também foi elaborado um modelo de regressão, em que a variável resposta foi dada pelo número de reuniões realizadas pelas Subcomissões (reusub) e as variáveis explicativas foram definidas pelo número de Subcomissões existentes (numdesub) e pelo percentual de senadores empossados pela primeira vez (novosperc). A fim de estabilizar a variância dos erros, também foi necessário adicionar, como variável independente, o percentual ao quadrado (novosperc ${ }^{2}$ ). A porcentagem de renovação (novosperc) foi calculada por:

$$
\frac{\text { número de senadores empossados pela primeira vez }}{\text { número total de senadores }} 100
$$

Estimando-se o modelo por MQO, obteve-se a equação 23:

$$
\text { reusub }=0,95+2,94 \text { numdesub }-227,13 \text { novosperc }+1033,35 \text { novosperc }{ }^{2}
$$

Para verificar a adequabilidade do modelo, implementaram-se os mesmos testes propostos no item 4.1. Assim, após a realização do Teste t, pôde-se afirmar que cada variável explicativa realmente influencia na variável resposta, mantendo as outras constantes. Isso pode ser representado na Tabela 9:

Tabela 9: Teste $\mathrm{t}$

\begin{tabular}{l|c|c|c}
\hline Parâmetro & Estatística teste & P-valor & Conclusão \\
\hline$\widehat{\beta}_{\text {numdesub }}$ & 10,58 & 0,0000 & Há evidências para rejeitar $H_{0}$ \\
$\widehat{\beta}_{\text {novosperc }}$ & $-5,59$ & 0,0005 & Há evidências para rejeitar $H_{0}$ \\
$\widehat{\beta}_{\text {novosperc }}{ }^{2}$ & 9,53 & 0,0000 & Há evidências para rejeitar $H_{0}$ \\
\hline
\end{tabular}

Aplicando-se o teste de significância global, concluiu-se que os parâmetros são conjuntamente significantes, uma vez que a estatística de teste equivale a 256,1 e o p-valor foi de aproximadamente zero.

As suposições referentes aos resíduos também foram verificadas. Analisando os gráficos, apresentados na Figura 53, pôde-se observar a dispersão aleatória dos pontos, comprovando que o pressuposto de homocedasticidade não foi violado. 

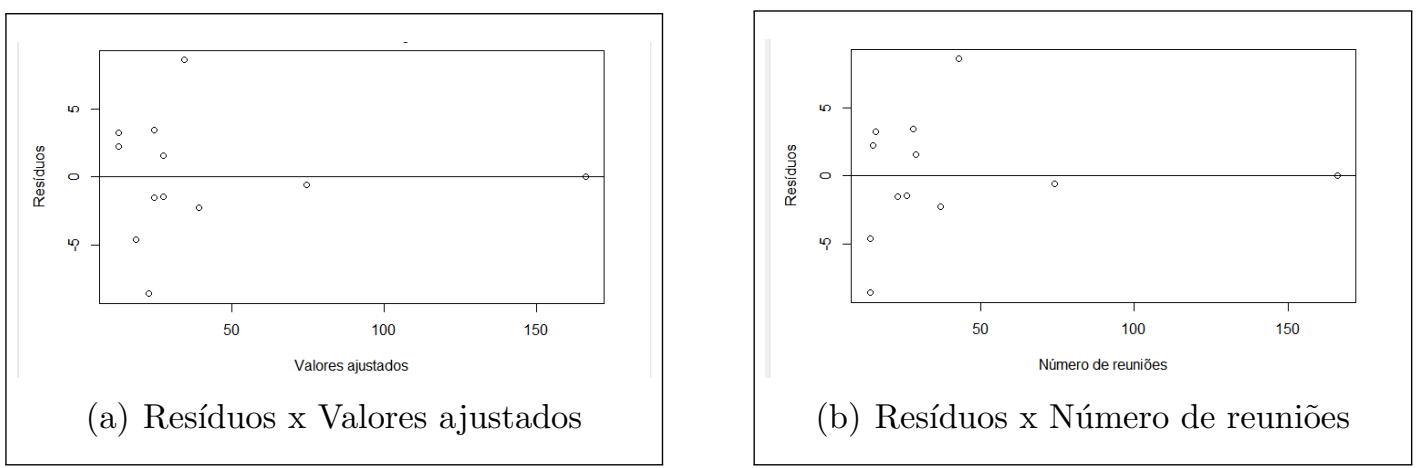

Figura 53: Análise de resíduos - Homocedasticidade

A suposição de normalidade também foi validada, como pode-se notar no Gráfico de Probabilidade Normal dos Resíduos, apresentado na Figura 54. Além disso, tal suposição foi reiterada pelo resultado do teste de ShapiroWilk, exibido na Tabela 10

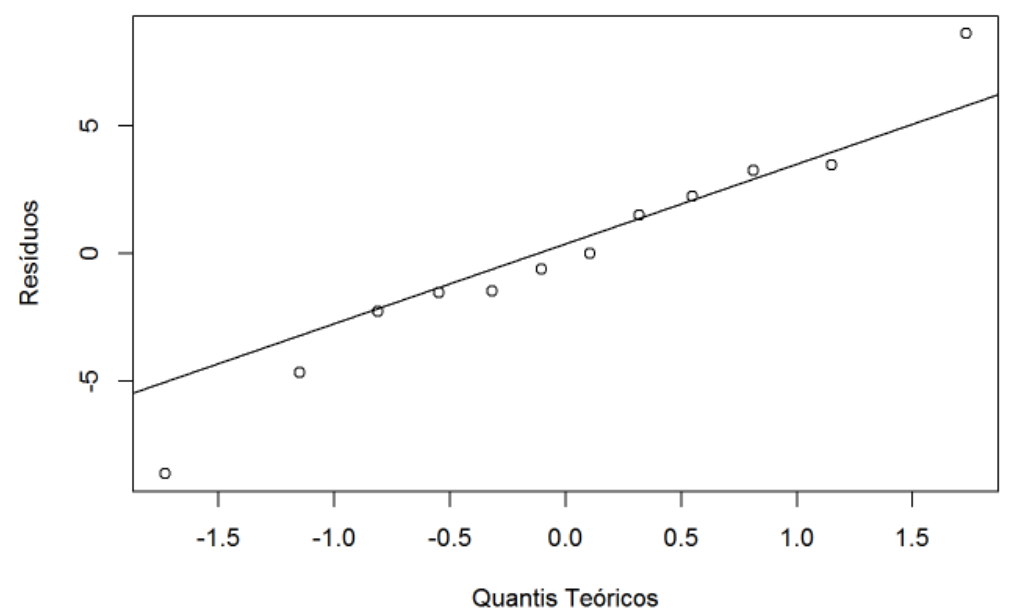

Figura 54: Gráfico de Probabilidade Normal dos Resíduos

Tabela 10: Teste de significância de Shapiro-Wilk

\begin{tabular}{c|c|c}
\hline Estatística teste & P-valor & Conclusão \\
\hline 0,97 & 0,96 & Não há evidências para rejeitar normalidade \\
\hline
\end{tabular}

\subsection{Reuniões realizadas por Comissões Temporárias}

A Tabela 11 apresenta a comparação entre o quantitativo de reuniões registrado no programa Arquimedes e o quantitativo registrado no RAP, no 
período de 2013 a 2016, para as Comissões Temporárias de natureza Jurista, CPI e Temporária.

Tabela 11: Tabela comparativa entre Arquimedes e RAP

\begin{tabular}{l|l|l|l|l|l|l}
\hline \multirow{2}{*}{ Ano } & \multicolumn{3}{|c|}{ Arquimedes } & \multicolumn{3}{c}{ RAP } \\
\cline { 2 - 7 } & Juristas & CPIs & Temporárias & Juristas & CPIs & Temporárias \\
\hline 2013 & 35 & 14 & 62 & 35 & 14 & 62 \\
2014 & 0 & 12 & 14 & 0 & 12 & 14 \\
2015 & 15 & 99 & 58 & 15 & $100^{*}$ & 58 \\
2016 & 15 & 13 & 72 & 15 & $9^{*}$ & 72 \\
\hline
\end{tabular}

${ }^{3}$ OBS.: ${ }^{*}$ Em 2015 e 2016, apareceram divergências no CDC pelo RAP, no que se refere ao quantitativo de reuniões realizadas pelas CPIs. Para garantir a credibilidade da informação, considerou-se o total de reuniões registrado no programa Arquimedes, por ter maior confiabilidade e por ser utilizado como fonte complementar do CDC pelo RAP, já mencionado anteriormente. É oportuno mencionar, que, para suprir tal divergência, o CDC pelo RAP foi corrigido com as informações contidas no programa Arquimedes.

Ao comparar tais informações, observa-se que os números de reuniões realizadas pelas referidas Comissões se equivalem, à exceção dos números destacados com asterisco. Isso fornece a segurança necessária para afirmar que as informações são confiáveis.

Visando a uma análise gráfica mais abrangente, apresenta-se a série temporal referente ao número total de reuniões realizadas pelas Comissões Temporárias, no período de 2003 a 2016;

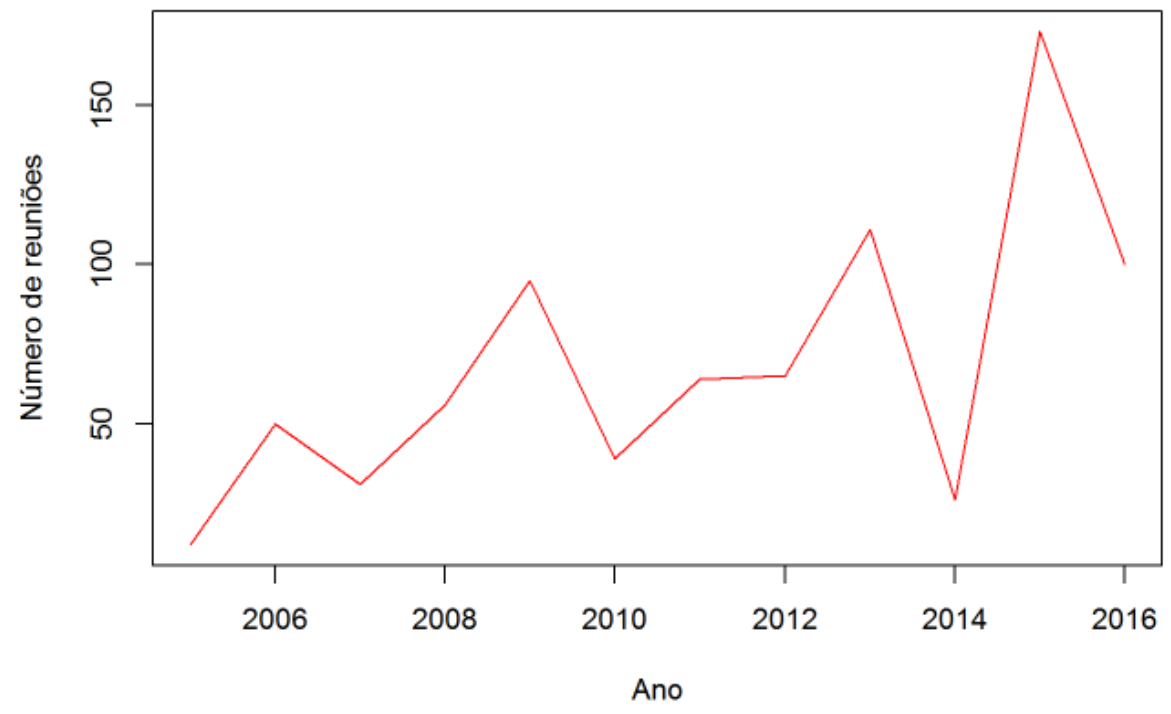

Figura 55: Número de reuniões de Comissões Temporárias realizadas por ano 
A série apresentada só inicia após o ano de 2005 pelo fato de não haver registros de reuniões das Comissões Temporárias no período de 2003 a 2004.

As Comissões Temporárias geralmente são instituídas para atender demandas específicas e possuem a vigência por tempo determinado. Assim, o número de Comissões instauradas varia de acordo com as necessidades do Senado Federal, não sendo possível determinar previamente quantas existirão no ano.

Assim, uma forma proposta para explicar o número de reuniões realizadas pelas Comissões Temporárias, no período referido, foi analisar a correlação do número total de reuniões realizadas com o número de Comissões Temporárias existentes, conforme exposta na Figura 56:

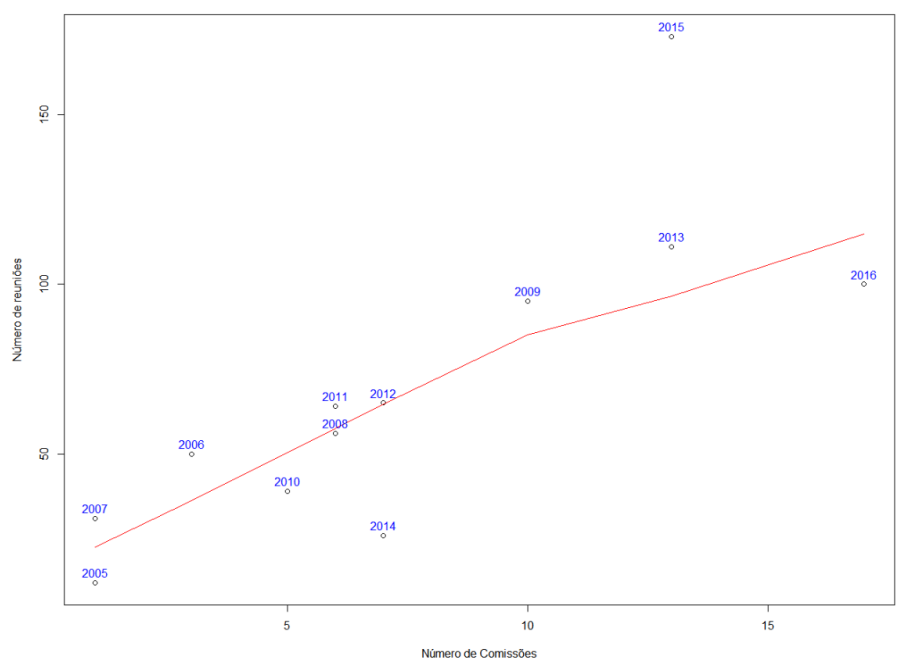

Figura 56: Número de Comissões Temporárias x Número de reuniões

Pode-se notar a existência de correlação linear forte e positiva entre as variáveis "Número de Comissões" e "Número de Reuniões". A estimativa do coeficiente de correlação dado por 0,81, relativamente alto, é outro indício da existência da correlação.

Assim, o primeiro modelo proposto consistiu em relacionar o número de reuniões realizadas por Comissões Temporárias (reutemp) com o número de Comissões Temporárias existentes (comtemp). Porém, ao realizar o teste de Shapiro-Wilk, notou-se que o p-valor estava próximo da região de rejeição da hipótese nula, como evidenciado na Tabela 12. Observando-se também o Gráfico de Probabilidade Normal dos Resíduos, indicado na Figura 57, é possível identificar que $25 \%$ das observações estão afastadas da reta. 
Tabela 12: Teste de significância de Shapiro-Wilk

\begin{tabular}{l|l}
\hline Estatística de Teste & P-valor \\
\hline 0,88 & 0,08 \\
\hline
\end{tabular}

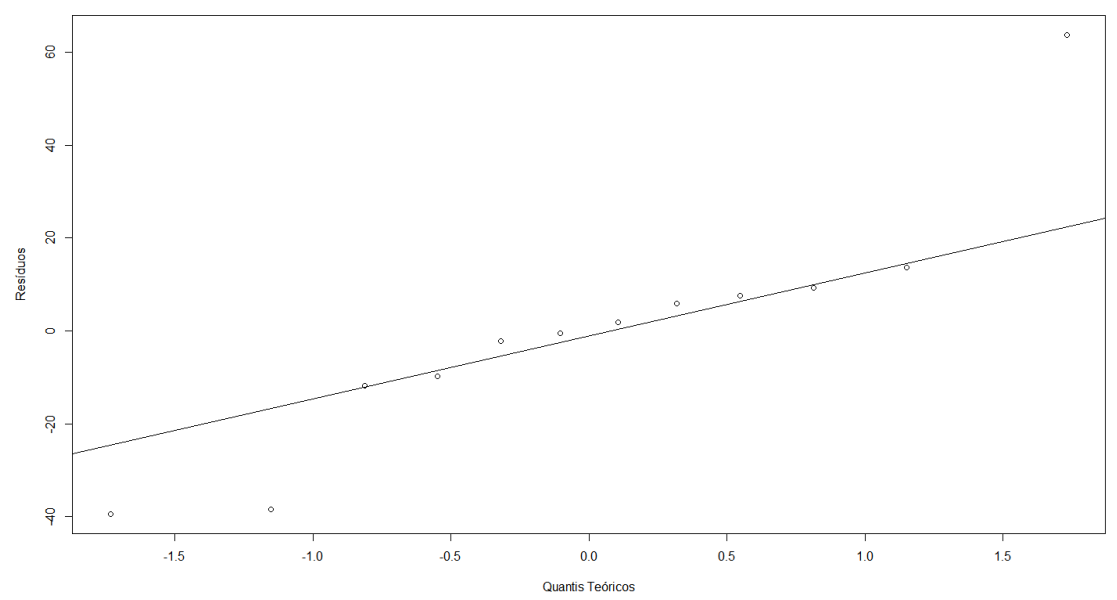

Figura 57: Gráfico de Probabilidade Normal dos Resíduos

Dessa forma, foi necessário aplicar uma transformação numérica na variável resposta reutemp. Foram testadas duas transformações, dadas pela Box-Cox e pela raiz quadrática.

Aplicando-se a Transformação Box-Cox, observou-se que a conversão logarítmica apresentou resultados satisfatórios e a suposição de normalidade não foi violada.

Empregando-se a transformação raiz quadrática na variável resposta, também verificou-se que os resíduos foram normalizados.

Aplicadas as transformações, analisou-se o Erro Quadrático Médio (EQM) dos modelos estimados. Como pode ser visto na Tabela 13, o melhor modelo corresponde à transformação raiz quadrática, pelo fato de possuir o menor EQM.

Tabela 13: Erro Quadrático Médio

\begin{tabular}{l|l}
\hline Transformação & EQM \\
\hline Logarítmica & 5,41 \\
Raiz Quadrática & 2,68 \\
\hline
\end{tabular}

Estimando a regressão por MQO, obteve-se a equação 24: 


$$
\sqrt{\text { reutemp }}=4,56+0,445 \text { comtemp }
$$

Como o modelo enunciado na equação 24 é uma regressão linear simples, o Teste t e o Teste de significância global são equivalentes. Logo, aplicando-se o teste de hipótese, foi possível concluir que o número de Comissões Temporárias realmente influencia no número de reuniões. Isso pode ser representado na Tabela 14:

Tabela 14: Teste $\mathrm{t}$

\begin{tabular}{l|c|c|c}
\hline Parâmetro & Estatística teste & P-valor & Conclusão \\
\hline$\widehat{\beta}_{\text {comtemp }}$ & 21,85 & 0,0008 & Há evidências para rejeitar $H_{0}$ \\
\hline
\end{tabular}

Ao verificar as suposições do modelo, pela análise gráfica dos resíduos, presentes na Figura 58, pode-se concluir que os erros são homocedásticos.

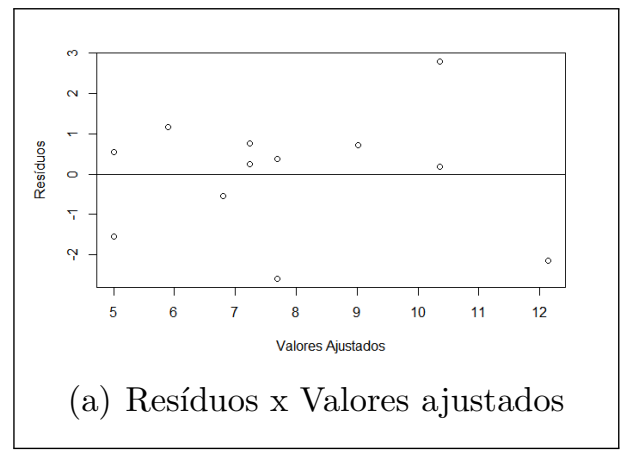

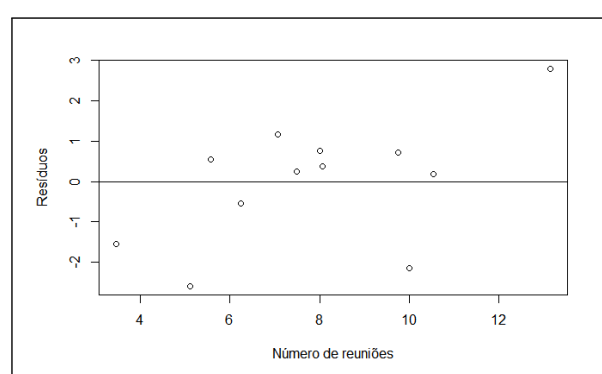

(b) Resíduos x Número de reuniões

Figura 58: Análise de resíduos - Homocedasticidade

Além disso, com a análise do Gráfico de Probabilidade Normal dos Resíduos e com a realização do teste de Shapiro-Wilk, constantes na Figura 59 e na Tabela 15, também pode-se afirmar que a suposição de normalidade não foi violada. 


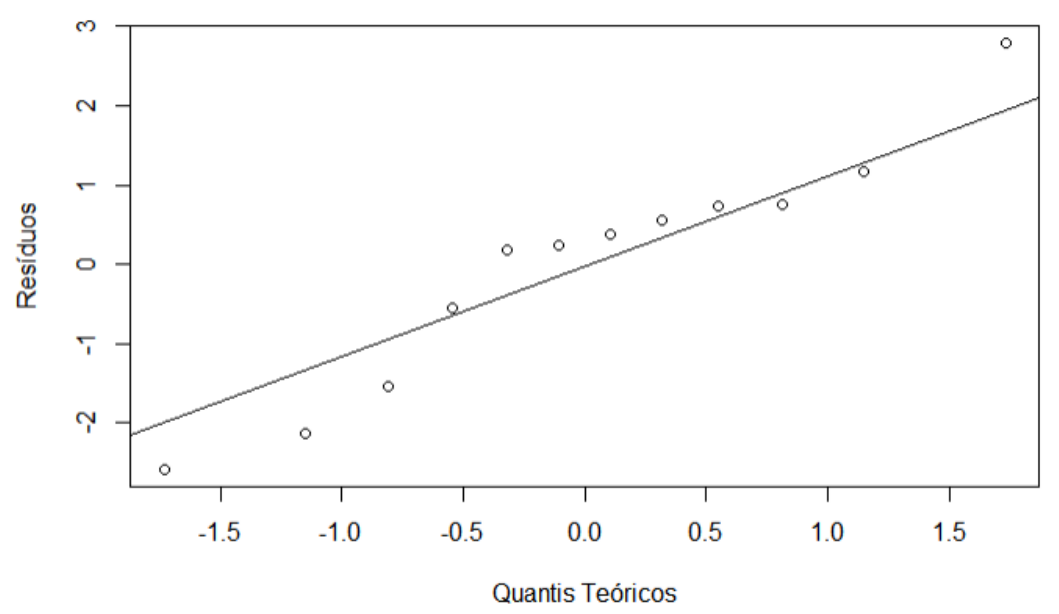

Figura 59: Gráfico de Probabilidade Normal dos Resíduos

Tabela 15: Teste de significância de Shapiro-Wilk

\begin{tabular}{c|c|c}
\hline Estatística teste & P-valor & Conclusão \\
\hline 0,94 & 0,50 & Não há evidências para rejeitar normalidade \\
\hline
\end{tabular}

\subsection{Sessões Plenárias}

A Tabela 16 apresenta a comparação entre o quantitativo de sessões plenárias registradas no RAP e o quantitativo registrado no Diário do Senado Federal. 
Tabela 16: Tabela Comparativa

\begin{tabular}{c|c|c}
\hline Ano & $\begin{array}{c}\text { Número de sessões } \\
\text { plenárias registradas no }\end{array}$ & $\begin{array}{c}\text { Número de sessões } \\
\text { plenárias registradas no }\end{array}$ \\
RAP & DSF \\
\hline 2003 & 215 & $214^{*}$ \\
2004 & 206 & 206 \\
2005 & 225 & 225 \\
2006 & 252 & $251^{*}$ \\
2007 & 243 & 243 \\
2008 & 251 & 251 \\
2009 & 259 & 259 \\
2010 & 217 & 217 \\
2011 & 235 & 235 \\
2012 & 239 & 239 \\
2013 & 231 & 231 \\
2014 & 190 & 190 \\
2015 & 228 & 228 \\
2016 & 197 & 197 \\
\hline
\end{tabular}

${ }^{4}$ OBS.: ${ }^{*}$ Nos anos de 2003 e 2006 , foi observada a diferença entre o número de sessões plenárias extraído do RAP e o número de sessões plenárias obtido do Diário do Senado Federal. Ao se aplicar o processo de validação, utilizando-se as Atas como fonte de consulta, verificou-se que a versão digital do Diário do Senado Federal possuía um registro a menos. Tal discrepância foi corrigida.

Essa tabela pode ser esboçada na série temporal ilustrada na Figura 60: 


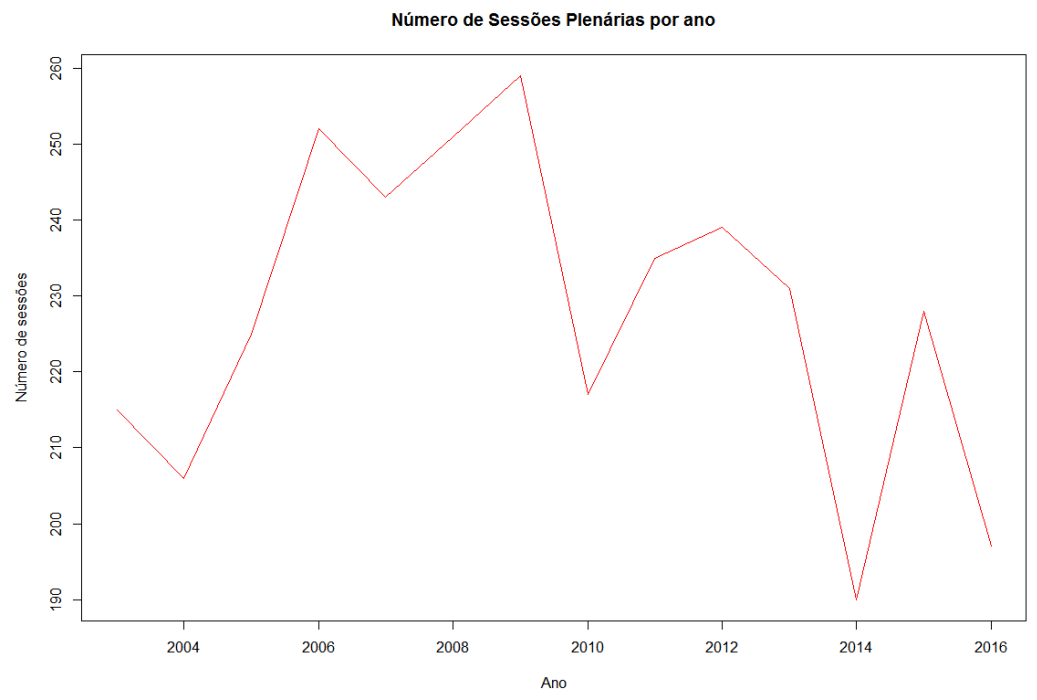

Figura 60: Número de sessões plenárias por ano

É importante ressaltar que até o ano de 2006, ocorriam com frequência convocações de Sessões Legislativas Extraordinárias. Com a entrada em vigor da Emenda Constitucional $n^{\circ} 50$, que alterou o art.57 da Constituição Federal, estas não têm ocorrido, embora continuem previstas no RISF. Logo, para a análise gráfica mais apurada do quantitativo de sessões realizadas pelo Senado Federal, foi considerado somente o período de 2007 a 2016.

Nota-se que a amplitude do gráfico equivale a 69 sessões, no período de 2007 a 2016. Trata-se de uma margem considerável no levantamento do quantitativo de sessões, podendo repercutir diretamente sobre o planejamento orçamentário.

É importante mencionar que uma sessão pode ser prevista, mas, não necessariamente realizada, pelas condições dispostas no art. $154 \S 6^{\circ}$ do Regimento Interno do Senado - RISF.

Há indícios de que o principal motivo da não-realização de uma sessão está relacionado com a falta de quórum, normalmente ocasionado pelas campanhas dos períodos eleitorais.

Vislumbrando correlacionar essas informações, levantou-se o número de sessões plenárias "não-realizadas", que passam a constar na Tabela 17: 
Tabela 17: Número de sessões plenárias não-realizadas

\begin{tabular}{c|c|c}
\hline Ano & Ano eleitoral & $\begin{array}{c}\text { Número de sessões } \\
\text { plenárias não-realizadas }\end{array}$ \\
\hline 2007 & Não & 6 \\
2008 & Sim & 6 \\
2009 & Não & 4 \\
2010 & Sim & 31 \\
2011 & Não & 4 \\
2012 & Sim & 20 \\
2013 & Não & 1 \\
2014 & Sim & 37 \\
2015 & Não & 16 \\
2016 & Sim & 32 \\
\hline
\end{tabular}

Desta, pode-se observar que o número de sessões "não-realizadas" realmente foi maior nos anos eleitorais (com exceção do ano de 2008).

Confrontando-se o número de sessões realizadas por ano, com o número de sessões previstas, observou-se que, nos anos em que ocorreram eleições, a amplitude reduz de 69 para 36 sessões, motivo que ratifica a hipótese de que, em anos eleitorais, a quantidade de sessões realizadas diminui.
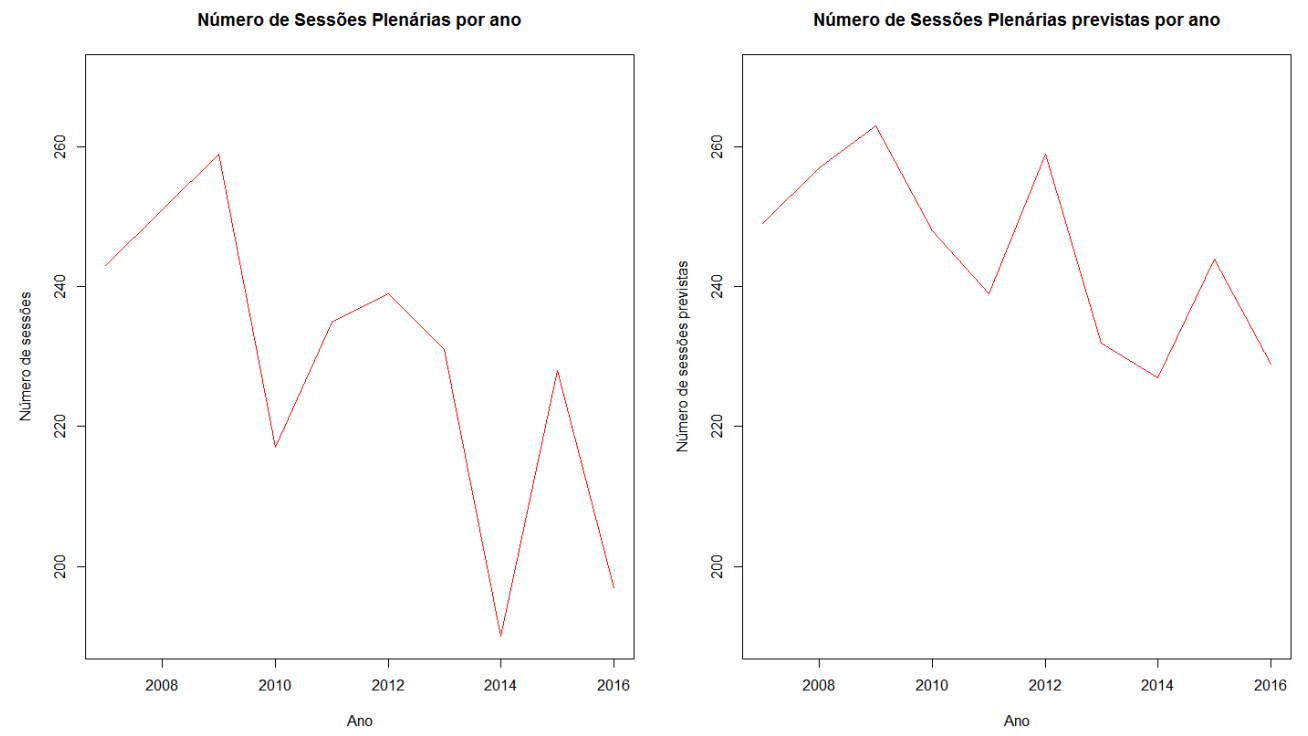

Figura 61: Número de sessões realizadas por ano x número de sessões previstas por ano 
De forma idêntica, o desvio padrão corrobora tal hipótese. Comparandose o desvio padrão estimado para "reuniões realizadas" com o desvio padrão calculado para "reuniões previstas", ele diminui de 22,13 para 12,79 , fato que ratifica o pressuposto de que o quantitativo de sessões diminui em anos eleitorais.

Ainda há de se considerar as sessões deliberativas ordinárias realizadas para discutir as Propostas de Emenda à Constituição (PEC). De acordo com os artigos 358, 362 e 363 do RISF, decorrido o prazo de 30 dias sem que a Comissão de Constituição, Justiça e Cidadania tenha dado seu parecer sobre a PEC, a referida proposta é incluída na Ordem do Dia para discussão, em cinco sessões deliberativas ordinárias, no primeiro turno, e em três sessões deliberativas ordinárias consecutivas, no segundo turno, obedecendo-se o interstício de, no mínimo, cinco dias úteis entre o primeiro e o segundo turno.

Contudo, a aprovação dos "requerimentos de calendário especial de tramitação de PEC"quebra essa formalidade ao permitir que o interstício entre os dois turnos seja reduzido. Logo, os dois turnos, muitas vezes, são realizados no mesmo dia. A título de exemplo, segue a Tabela 18 que demonstra a data da realização, horário de início, tipo, número da sessão e a discussão de uma PEC.

Tabela 18: Sessões plenárias realizadas em 28/10/2009

\begin{tabular}{|c|c|c|c|c|}
\hline Data & $\begin{array}{l}\text { Horário de } \\
\text { início da } \\
\text { Sessão }\end{array}$ & Tipo & $\begin{array}{l}\text { Número da } \\
\text { Sessão }\end{array}$ & Discussão de Emenda \\
\hline $28 / 10 / 09$ & $19: 22$ & $\begin{array}{c}\text { Deliberativa } \\
\text { Extraordinária }\end{array}$ & 192 & $\begin{array}{c}2^{\mathrm{a}} \text { sessão de discussão, } \\
\text { em } 1^{\circ} \text { turno }\end{array}$ \\
\hline $28 / 10 / 09$ & $19: 24$ & $\begin{array}{c}\text { Deliberativa } \\
\text { Extraordinária }\end{array}$ & 193 & $\begin{array}{c}3^{\mathrm{a}} \text { sessão de discussão, } \\
\text { em } 1^{\circ} \text { turno }\end{array}$ \\
\hline $28 / 10 / 09$ & $19: 26$ & $\begin{array}{c}\text { Deliberativa } \\
\text { Extraordinária }\end{array}$ & 194 & $\begin{array}{c}4^{\mathrm{a}} \text { sessão de discussão, } \\
\text { em } 1^{\circ} \text { turno }\end{array}$ \\
\hline $28 / 10 / 09$ & $19: 28$ & $\begin{array}{c}\text { Deliberativa } \\
\text { Extraordinária }\end{array}$ & 195 & $\begin{array}{c}\text { Redação final. } \\
\text { Aprovada em } 1^{\circ} \text { turno }\end{array}$ \\
\hline $28 / 10 / 09$ & $19: 53$ & $\begin{array}{c}\text { Deliberativa } \\
\text { Extraordinária }\end{array}$ & 196 & $\begin{array}{c}1^{\mathrm{a}} \text { sessão de discussão, } \\
\text { em } 2^{\circ} \text { turno }\end{array}$ \\
\hline $28 / 10 / 09$ & $19: 57$ & $\begin{array}{c}\text { Deliberativa } \\
\text { Extraordinária }\end{array}$ & 197 & $\begin{array}{c}2^{\mathrm{a}} \text { sessão de discussão, } \\
\text { em } 2^{\circ} \text { turno }\end{array}$ \\
\hline $28 / 10 / 09$ & $19: 59$ & $\begin{array}{c}\text { Deliberativa } \\
\text { Extraordinária }\end{array}$ & 198 & $\begin{array}{l}\text { Redação final. } \\
\text { Aprovada em } 2^{\circ} \text { turno }\end{array}$ \\
\hline
\end{tabular}


Conforme pode ser visto, uma sessão é aberta logo após a outra, com intervalo máximo de cinco minutos. Da mesma forma, não há o interstício mínimo de cinco dias úteis entre os turnos. Isso poderá ter interferido diretamente na previsão de gastos com a realização das sessões, no ano de 2009, uma vez que o quantitativo de sessões realizadas foi elevado.

Usando os resultados obtidos pela análise descritiva, o modelo preditivo tem como variável resposta o número de sessões plenárias realizadas (sessoesplen) e, como variável independente, o número de sessões plenárias não realizadas (naoreal). Estimando por MQO, obtém-se a Equação 25:

$$
\text { sessoesplen }=250,82-1,38 \text { naoreal }
$$

Ressalta-se que ao inserir a variável explicativa anoeleitoral no modelo de previsão acima, observou-se, ao realizar o Teste t, que tal variável não influiu significativamente no número de sessões plenárias (sessoesplen) realizadas, motivo pelo qual a referida variável não participou do modelo. Já o número de sessões não realizadas, dado pela variável explicativa naoreal, teve influência. Acrescenta-se ainda que, ao empregar a variável naoreal, os anos eleitorais foram indiretamente considerados. Assim, para aferir a previsão, desconsiderou-se a variável anoeleitoral e introduziu-se a variável indicadora naoreal.

Assim como ocorreu no modelo da Equação 24, o Teste t e o Teste de significância global são equivalentes. Conforme pode ser notado na Tabela 19, há evidências para rejeitar a hipótese nula, ratificando a significância da variável naoreal.

Tabela 19: Teste t

\begin{tabular}{l|c|c|c}
\hline Parâmetro & Estatística teste & P-valor & Conclusão \\
\hline$\widehat{\beta}_{\text {naoreal }}$ & 20,83 & 0,002 & Há evidências para rejeitar $H_{0}$ \\
\hline
\end{tabular}

Realizando a análise gráfica dos resíduos, pode-se verificar, na Figura 62, que os erros são homocedásticos, uma vez que não possuem tendência aparente. 

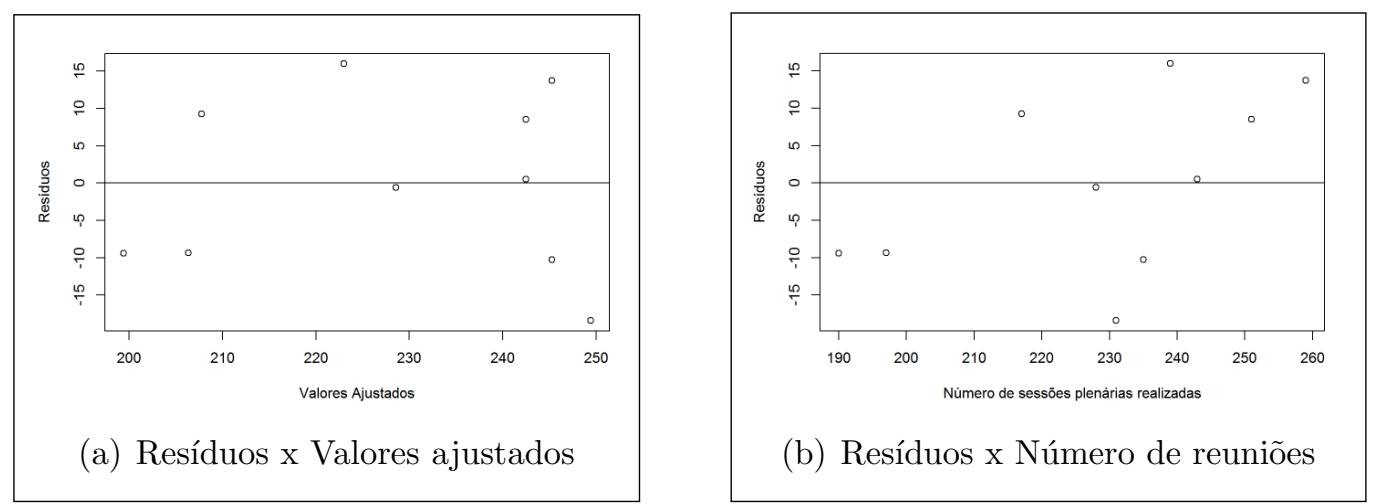

Figura 62: Análise de resíduos - Homocedasticidade

O Gráfico de Probabilidade Normal dos resíduos e o teste de ShapiroWilk também indicam normalidade nos resíduos, como apresentado, respectivamente, na Figura 63 e na Tabela 20.

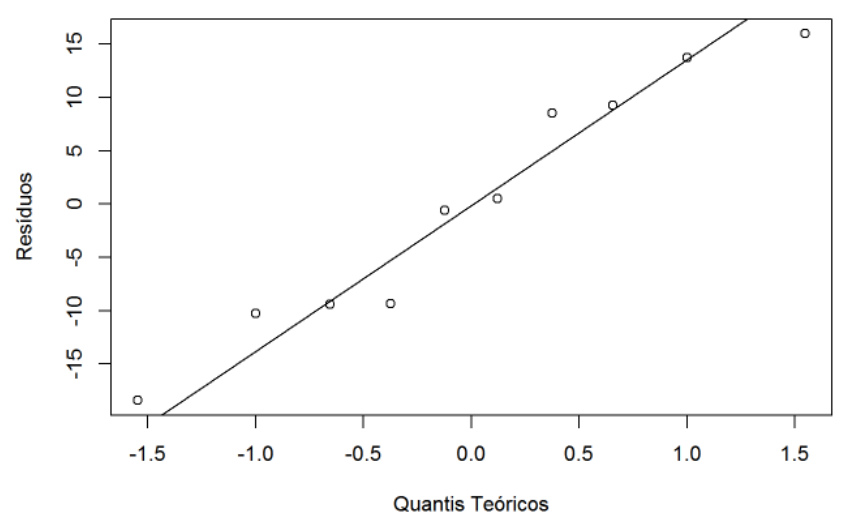

Figura 63: Gráfico de Probabilidade Normal dos resíduos

Tabela 20: Teste de significância de Shapiro-Wilk

\begin{tabular}{c|c|c}
\hline Estatística teste & P-valor & Conclusão \\
\hline 0,93 & 0,52 & Não há evidências para rejeitar normalidade \\
\hline
\end{tabular}

\subsection{Sessões Conjuntas}

A análise gráfica da série temporal referente ao número de sessões realizadas anualmente, o estudo da FAC e da FACP, a identificação pelo critério de Informação Bayesiano e a utilização do algoritmo de Stepwise tornaram 
possível e confiável a eleição do modelo de Médias Móveis como o mais indicado para prever o número de sessões conjuntas realizadas pelo Congresso Nacional.

A série temporal apresentada na Figura 64, participou do estudo, oferecendo subsídios para a interpretação e seleção do referido modelo. Vale ressaltar que o comportamento da série não possui causa aparente, ou seja, não há variáveis que se implicam diretamente no número de sessões conjuntas.

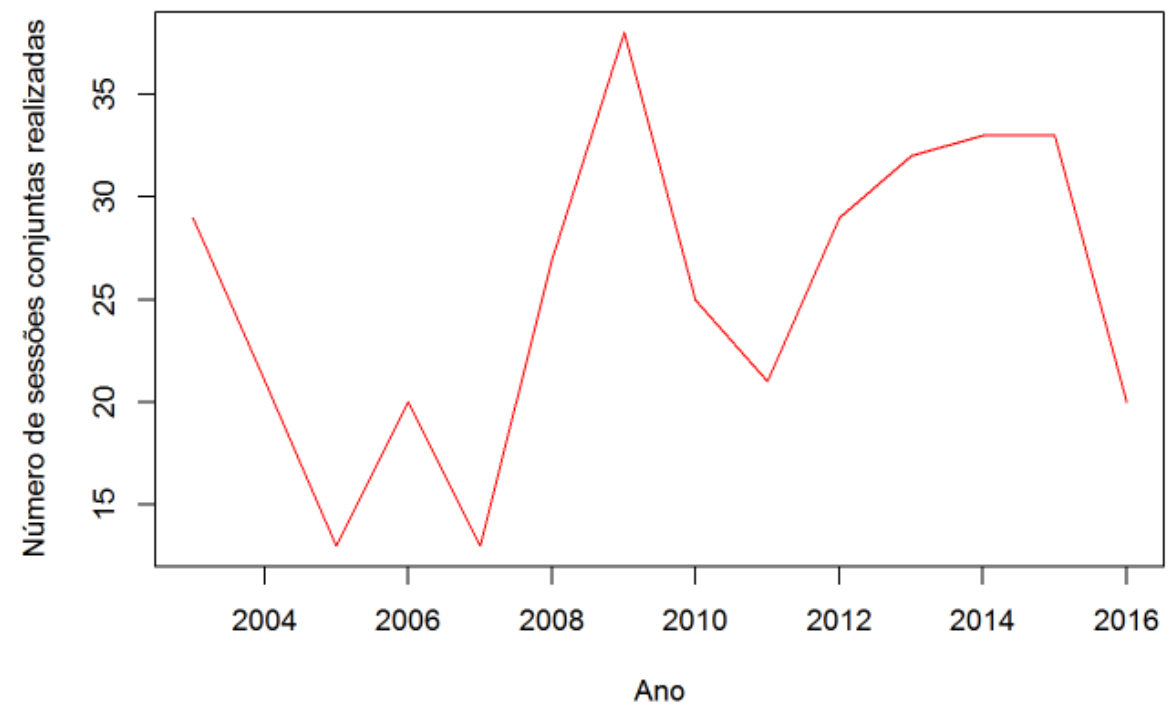

Figura 64: Sessões Conjuntas

Ao observar o gráfico, nota-se que a série não aparenta ter tendência ou sazonalidade. Sendo assim, parte-se da suposição de que a série é fracamente estacionária, não sendo necessário realizar transformações numéricas na amostra.

Com a verificação da FAC e a FACP do processo, representadas na Figura 65, constata-se que todas as autocorrelações estimadas encontram-se dentro do intervalo de confiança; logo, nenhuma autocorrelação é estatisticamente significante, e o pressuposto de a série ser fracamente estacionária é confirmado. 

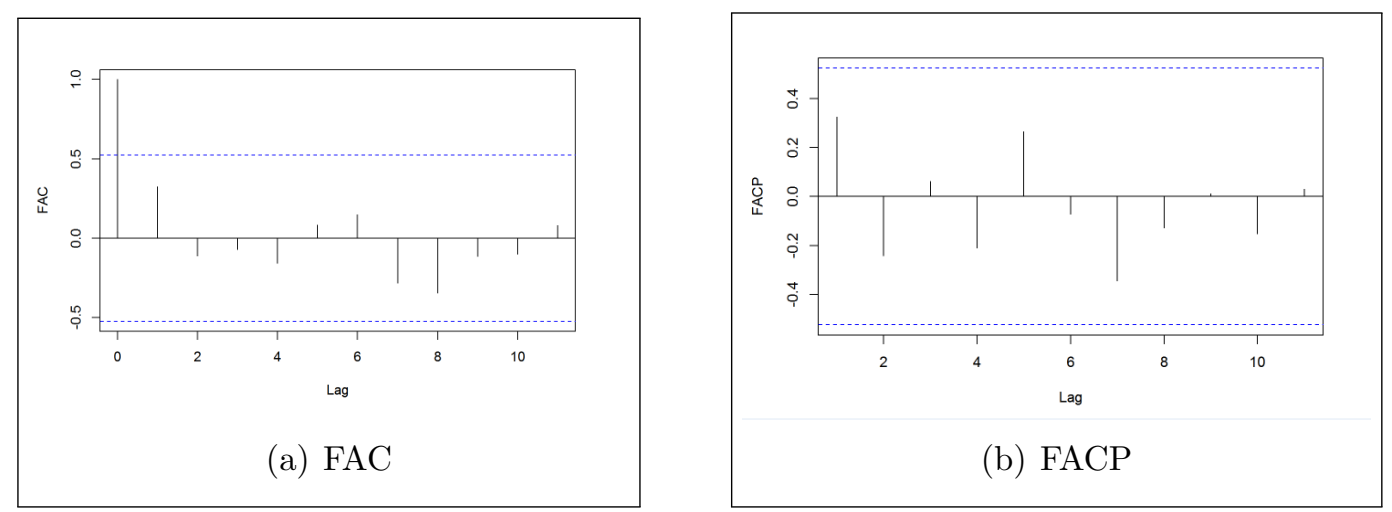

Figura 65: FAC e FACP do processo

Isso, de certa forma, dificulta a escolha de um modelo propício para a previsão. Assim, foi adotado outro critério de identificação do modelo, baseado no critério de Informação Bayesiano de modelos pré-definidos.

Com a finalidade de reduzir possíveis distorções na identificação do modelo eleito, foi utilizado o algoritmo de Stepwise ${ }^{1}$ e selecionado o modelo de menor BIC. Foi aplicado o teste KPSS, sendo verificada a estacionariedade da série.

Assim, chegou-se ao modelo de Médias Móveis de ordem 1 (MA(1)) representado na equação 26, onde a variável resposta sessoesconj representa o número de sessões conjuntas realizadas.

$$
\text { sessoesconj }=25,41+0,67 a_{t-1}+\varepsilon_{t}
$$

Definido o modelo para o número de sessões conjuntas realizadas, foi necessário realizar o diagnóstico dos resíduos, ou seja, analisar se os resíduos da regressão são não autocorrelacionados e se são normalmente distribuídos.

Para verificar se há ausência de autocorrelação entre os resíduos, aplicouse o teste Box-Pierce, cuja estatística de teste foi equivalente a 0,06 e o p-valor igual a 0,8, não havendo evidências para rejeitar a hipótese nula. Dessa forma, a suposição não foi violada. Tal afirmação também pode ser comprovada por meio da análise gráfica da FAC e da FACP dos resíduos, disposta na Figura 66:

\footnotetext{
${ }^{1}$ Algoritmo Stepwise é um método interativo que adiciona e remove variáveis, a partir de um critério de seleção. No trabalho, foi adotado o BIC.
} 


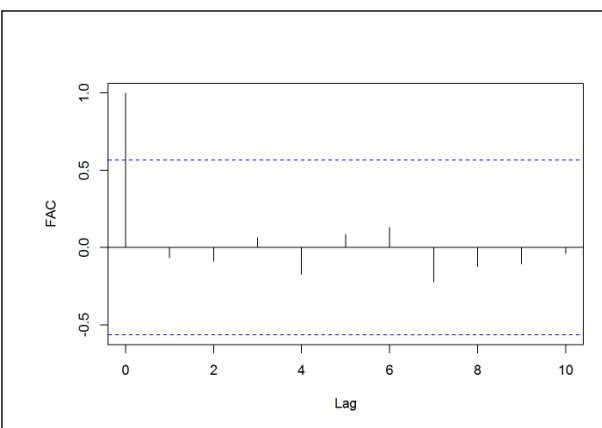

(a) FAC

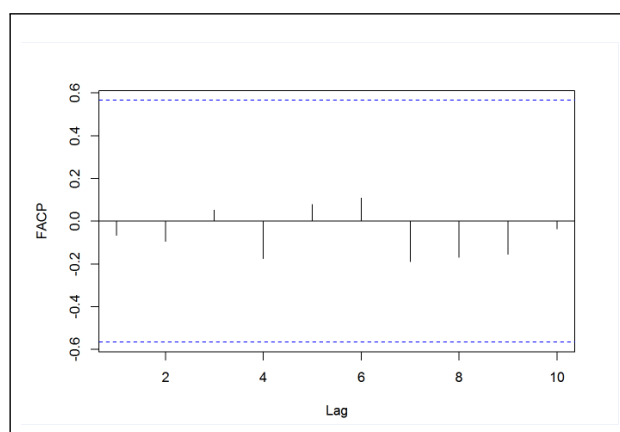

(b) FACP

Figura 66: Análise de resíduos - Correlograma

Para testar a hipótese de normalidade, foi aplicado o teste de ShapiroWilk, que confirmou não haver evidências para rejeitar a hipótese nula, uma vez que a estatística teste equivale a 0,96 e o p-valor a 0,80. Dessa forma, afirma-se que os erros assumem normalidade.

Empregando a Equação 26, calculou-se o número de sessões conjuntas previstas para os anos de 2015 e 2016, a fim de confrontá-las com os valores reais dos respectivos anos e analisar se o modelo selecionado produz boas previsões.

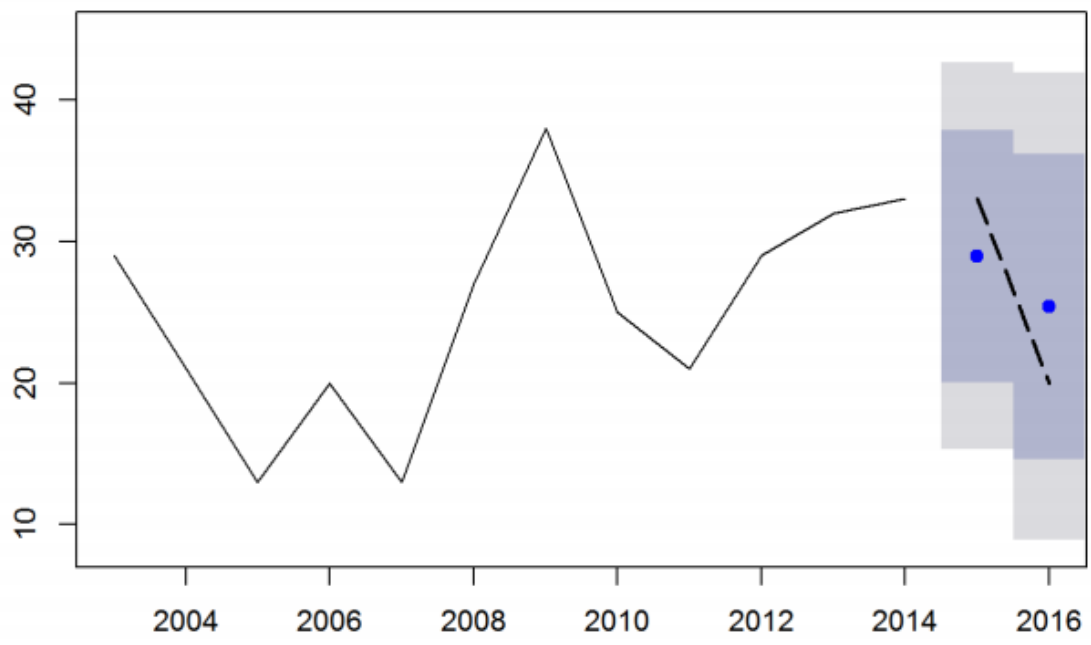

Figura 67: Previsão para 2015 e 2016 x Valores reais de 2015 e 2016

Como pode ser observado na Figura 67, as previsões se adequam bem à realidade. 


\subsection{Modelo Final}

Um dos objetivos deste trabalho foi propor um modelo de previsão para aferir a estimativa do quantitativo de sessões e reuniões realizadas pelo Senado Federal e de sessões conjuntas realizadas pelo Congresso Nacional.

Para isso, utilizaram-se recursos estatísticos que criaram os modelos parciais reunidos na Tabela 21, onde cada qual tem a função de estimar o quantitativo de sessões ou reuniões segundo seus propósitos. Obtem-se, assim, os resultados parciais, que expressam valores específicos, referentes a eventos analisados individualmente.

Tabela 21: Modelos Parciais

\begin{tabular}{|c|c|}
\hline Evento & Modelo Estimado \\
\hline Comissões Permanentes & reuperm $=510,88-172,31$ anoeleitoral $+144,91 t v$ \\
\hline Subcomissões & reusub $=0,95+2,94$ numdesub-227, 13novosperc $+1033,35$ novosperc ${ }^{2}$ \\
\hline Comissões Temporárias & $\sqrt{\text { reutemp }}=4,56+0,445$ comtemp \\
\hline Sessões Plenárias & sessoesplen $=250,82-1,38$ naoreal \\
\hline Sessões Conjuntas & sessoesconj $=25,41+0,67 a_{t-1}+\varepsilon_{t}$ \\
\hline \multicolumn{2}{|l|}{ 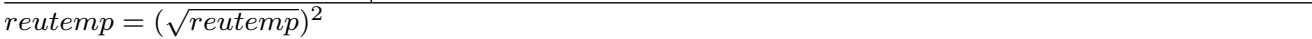 } \\
\hline \multirow{3}{*}{\multicolumn{2}{|c|}{$\begin{array}{l}\text { numdesub - média simples do número de Subcomissões dos anos anteriores. } \\
\text { comtemp - média simples do número de Comissões existentes nos anos anteriores. } \\
\text { naoreal }=\left\{\begin{array}{l}\text { média simples de sessões não realizadas em anos eleitorais, se o ano é eleitoral } \\
\text { média simples de sessões não realizadas em anos não eleitorais, caso contrário }\end{array}\right.\end{array}$}} \\
\hline & \\
\hline & \\
\hline \multicolumn{2}{|c|}{ novosperct $=\left\{\begin{array}{c}\text { média simples do percentual de renovação de } 1 / 3, \text { se no ano houve renovação de } 1 / 3 \\
\text { média simples do percentual de renovação de } 2 / 3, \text { se no ano houve renovaça de } 2 / 3 \\
0, \text { caso contrário }\end{array}\right.$} \\
\hline
\end{tabular}

O modelo de previsão final corresponde ao somatório dos resultados parciais, de forma a prever, em um único resultado, o número total de sessões e reuniões realizadas pelos órgãos mencionados. Segue a representação do modelo de previsão final (somatot):

$$
\text { somatot }=\text { reuperm }+ \text { reusub }+ \text { reutemp }+ \text { sessoesplen }+ \text { sessoesconj }
$$

Para verificar a precisão do modelo final, analisou-se a porcentagem de resíduos relacionados com o número total de reuniões e sessões realizadas no período de 2009 a 2016. Este período foi selecionado pelo fato de os Conjuntos de Dados Consolidados somente possuírem informações relativas a todas as categorias (Comissões Permanentes, Comissões Temporárias, Subcomissões, sessões Plenárias e Conjuntas) a partir do ano de 2009.

A Figura 68 apresenta o gráfico do percentual de resíduos do modelo final (somatot), onde se pode constatar que o referido modelo é mais preciso nos anos não-eleitorais do que nos anos eleitorais, pois o maior valor absoluto residual entre os anos não-eleitorais foi de 7,5\%, que se refere ao ano de 2011, enquanto que entre os anos eleitorais foi de $16,4 \%$, que se refere ao ano de 2014 . 


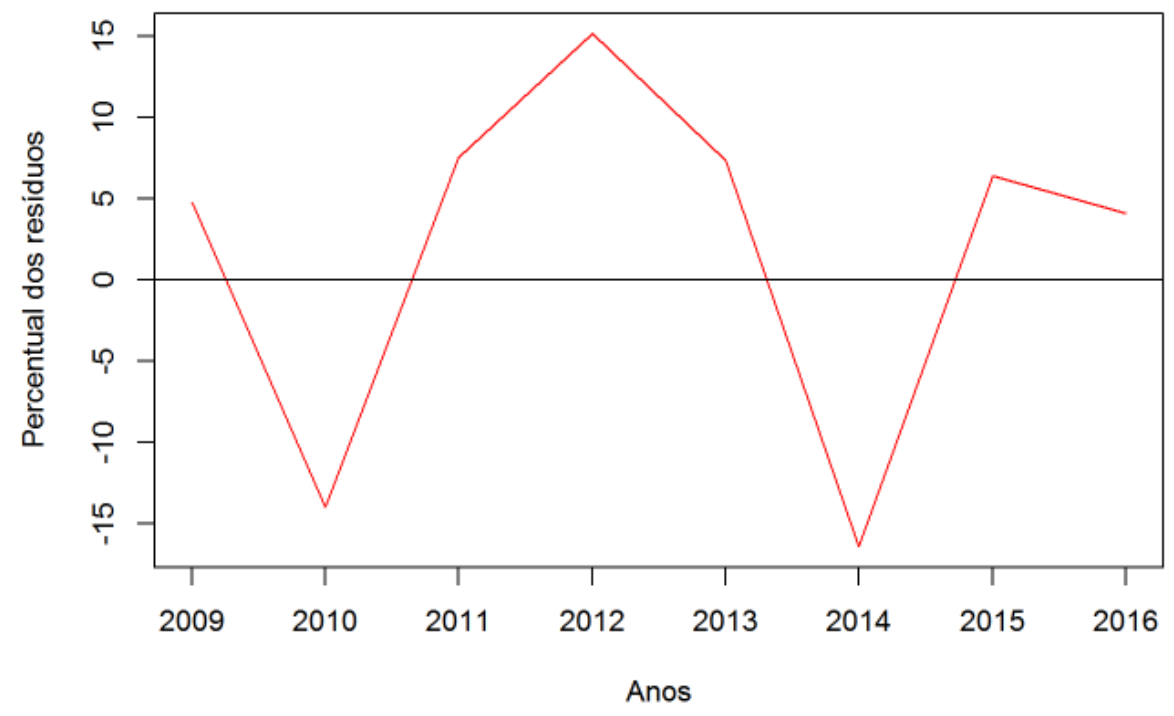

Figura 68: Anos x Percentual dos resíduos

Cita-se ainda que os modelos estimados para Subcomissões (reusub) e para as Comissões Temporárias (reutemp) foram os que apresentaram maior resíduo. Isto porque o primeiro possui a variável independente "número de subcomissões" (numdesub) que muda a cada ano para atender necessidades específicas. De forma semelhante, a variável "novos percentuais" (novoperc), pertencente ao mesmo modelo, não pode ser pré-definida nos anos em que ocorre a renovação da Casa, devido aos resultados eleitorais. Já o segundo modelo, reutemp, possui a variável "número de comissões temporárias" (comtemp), que também não pode ser pré-definida porque se modifica anualmente em função das necessidades do Senado.

Logo, como o resultado de ambos os modelos parciais (reusub, reutemp) influi no resultado do modelo final, a imprevisão é transmitida para o resultado final, podendo explicar a imprecisão do referido modelo. Contudo, ressalta-se que tal imprevisão não interferiu no resultado final do modelo.

Frisa-se também que os feriados oficiais não interferiram estatisticamente nos resulados dos modelos parciais. 


\section{CONCLUSÃO}

Anualmente, a Secretaria-Geral da Mesa (SGM) do Senado Federal fornece ao setor de Coordenação de Planejamento e Acompanhamento Orçamentário a previsão do número de sessões e reuniões realizadas pelo Senado Federal e pelo Congresso Nacional no decorrer do ano. Os custos estimados com a realização desses eventos constam da dotação orçamentária do Senado Federal, estabelecida na Lei Orçamentária Anual, com base no parágrafo $5^{\circ}$ do artigo 165 da Constituição da República Federativa do Brasil de 1988. A Coordenação de Estatística, Pesquisa e Relatórios Legislativos (COER) é o setor responsável, junto à SGM, pelo levantamento desses valores. Por se tratar de uma previsão, torna-se necessário adotar critérios com embasamento estatístico para aproximar a previsão da situação real.

Visando a esse propósito, este trabalho procurou criar modelos capazes de prever o quantitativo de sessões e reuniões a serem realizadas pelos referidos órgãos no decorrer do ano. Uma vez quantificadas, setores interessados podem prever seus custos, a fim de inserir tais valores na dotação orçamentária do Senado federal.

Para isso, criaram-se conjuntos de dados com informações pertinentes, extraídas de fontes de consultas oficiais, no período de 2003 a 2016, como os Diários do Senado Federal, os Relatórios da Presidência, os Relatórios Mensais da Atividade Legislativa, as Atas e as Pautas de reuniões, disponibilizadas pela Secretaria de Comissões, e o programa Arquimedes, de acesso restrito aos servidores do Senado. Para garantir a lisura das informações, os dados foram submetidos ao processo de confrontamento e validação, sendo selecionados somente aqueles que realmente demonstraram veracidade e relevância, chegando-se, assim, ao primeiro objetivo do trabalho.

Uma vez quantificado o número de reuniões realizadas por Comissões Permanentes e suas Subcomissões, por Comissões Temporárias e o número de sessões Plenárias e Conjuntas, realizou-se a análise descritiva de cada categoria de reunião e sessão, para identificar e descobrir prováveis causas relacionadas às informações coletadas. Nessa fase do trabalho, utilizaram-se as medidas de posição, dispersão e análise gráfica.

Depois, passou-se ao esforço de predição. Para prever o número de reuniões realizadas, durante o ano, pelas Comissões Permanentes e suas Subcomissões, Comissões Temporárias juntamente com o número de sessões Plenárias, utilizou-se o método de Regressão Linear. Para estimar o número de sessões Conjuntas do CN, realizadas durante o ano, empregou-se o método de Séries Temporais.

Durante a aplicação do método de análise de Regressão Linear, utilizando- 
se Mínimo Quadrado Ordinário (MQO), foram realizados testes de Hipóteses para verificar as significâncias estatísticas das variáveis, de forma individual e conjunta, assim como foram analisadas as suposições de homocedasticidade e normalidade dos resíduos.

Já durante o emprego das Séries Temporais, verificaram-se a estacionariedade do modelo, as funções de Autocorrelação (FAC) e de Autocorrelação Parcial (FACP), que auxiliaram na identificação do modelo mais adequado. Essa tarefa foi complementada pelo Critério de Informação Bayesiano (BIC), em que selecionou-se o modelo de Médias Móveis. Selecionado o modelo, passou-se à análise dos resíduos, a fim de averiguar se eram independentes e assumiam padrões de normalidade condizentes. Mesmo assim, ainda era possível de o modelo identificado se ajustar bem aos dados usados, mas não produzir boas previsões. Logo, a amostra foi fracionada em dois grupos, um de controle e outro de teste, para dirimir eventuais dúvidas.

Assim, foi criado um modelo individual de previsão para cada categoria. Esses modelos geraram resultados parciais. O somatório desses resultados parciais deu origem ao modelo final capaz de prever, em um único resultado, o número total de sessões e reuniões realizadas anualmente pelos órgãos citados.

Para verificar a precisão do modelo final, analisou-se a porcentagem de resíduos relacionados com o número total de reuniões e sessões realizadas no período de 2009 a 2016. Constatou-se que o modelo é mais preciso para os anos não-eleitorais do que para os anos eleitorais, fato que não impede sua aplicação pelo motivo de gerar resultados satisfatórios. Assim, chegou-se ao segundo e último objetivo deste trabalho. 


\section{REFERÊNCIAS}

WOOLDRIDGE, Jeffrey M. Introdução à econometria: uma abordagem moderna. 3 ed. Cengage, 2005. 684 p.

CHARNET, R et al. Análise de modelos de regressão linear: Com aplicações. 2 ed. UNICAMP, 1999. 368 p.

MORETIN, P. A.; TOLOI, C. Análise de Séries Temporais. 2 ed. Blucher, 1969. $564 \mathrm{p}$.

THODE JR., H.C. Testing for Normality. Marcel Dekker, New York. 2002.

SAMOHYL, R. W. Controle Estatístico de Qualidade. 1 ed. Elsevier, 2009. 288 p.

SENADO FEDERAL. Relatório da Presidência. Disponível em:

<http://www25.senado.leg.br/web/atividade/relatorio-da-presidencia/1999em-diante >. Acesso em: 20 mar. 2017

SENADO FEDERAL. Regimento Interno. Disponível em:

$<$ https://www25.senado.leg.br/web/atividade/regimento-interno>. Acesso em: 20 mar. 2017

SENADO FEDERAL. Relatório Mensal da Atividade Legislativa. Disponível em:

<http://www25.senado.leg.br/web/atividade/relatorios-mensais >. Acesso em: 30 mar. 2017

R Core Team (2015). R: A language and environment for statistical computing. R Foundation for Statistical Computing, Vienna, Austria. URL https://www.R-project.org/ 


\section{GLOSSÁRIO}

Arquimedes - é o nome fantasia para um sistema de inteligência de negócios (Business Intelligence - BI) organizado sobre uma base de dados legislativos, implementada em um armazém de dados (DataWarehouse - DW). O DW extrai informações de variados sistemas legislativos. O Senado não tem um único sistema para planejar, operar e registrar os procedimentos legislativos. São diversos sistemas especializados; por exemplo, um controla as proposições (projetos e propostas); outro mantém as informações associadas ao mandato parlamentar; outro para registro das sessões plenárias e mais um para registro das reuniões das comissões. Há muita informação legislativa, porém sua dispersão por diversos sistemas, com tecnologias distintas e organização própria, torna difícil a consulta. O armazém de dados contorna o problema ao consolidar a informação de modo homogêneo, conhecido e, na medida do possível, simplificado. O uso do Arquimedes consiste na construção de consultas sobre o DW e apresentação para impressão, produção de arquivo PDF ou publicação em página web. É utilizado para produção de publicações estatísticas periódicas; atendimento ao usuário do processo legislativo, quando se trata de pesquisa legislativa; produção de documentos de controle operacional por diversos setores da Secretaria Geral da Mesa; elaboração de relatórios para assessoramento superior.

Ata - É um documento que registra resumidamente e com clareza as ocorrências, deliberações, resoluções e decisões de reuniões ou sessões.

Comissões - A Constituição Federal de 1988, no seu artigo 58, prevê o funcionamento de comissões permanentes e temporárias, no âmbito do Poder Legislativo, "constituídas na forma e com as atribuições previstas no respectivo regimento ou no ato de que resultar sua criação". As comissões decorrem do aprimoramento das atividades parlamentares; a elas cabe realizar uma análise mais aprofundada e especializada das matérias apresentadas ao Parlamento, assumindo papel relevante no processo legislativo.

Comissões Externas - As Comissões Externas são convocadas para lidar com assunto específico que esteja situado fora da sede da respectiva Casa Legislativa. (RAP)

Comissões Internas - As Comissões Internas são compostas para emitir pareceres acerca de proposições legislativas em situações especiais e/ou oferecem estudos mais aprofundados sobre temas específicos, recebendo especi- 
alistas no assunto para o debate.

Comissão Parlamentar de Inquérito - constitucionalmente prevista no $\S 3^{\circ}$ do art.58, é um importante instrumento para cumprir a função de fiscalização e de investigação de fatos determinados. Atua no controle da Administração Pública e na defesa dos interesses da coletividade.

Comissão Permanente - As comissões permanentes são as de caráter técnicolegislativo ou especializado, integrantes da estrutura institucional da Casa, copartícipes do processo legiferante, e têm por finalidade "estudar e emitir parecer sobre os assuntos ou proposições submetidos ao seu exame" (RISF, art. 97) e sobre eles deliberar, assim como exercer o acompanhamento dos planos e programas governamentais e a fiscalização orçamentária da União, no âmbito dos respectivos campos temáticos.

As comissões permanentes, além da Comissão Diretora, são as seguintes:

I - Comissão de Assuntos Econômicos (CAE);

II - Comissão de Assuntos Sociais (CAS);

III - Comissão de Constituição, Justiça e Cidadania (CCJ);

IV - Comissão de Educação, Cultura e Esporte (CE);

V - Comissão de Transparência, Governança, Fiscalização e Controle e Defesa do Consumidor (CTFC); (Redação dada pela Resolução nº 3, de 2017)

VI - Comissão de Direitos Humanos e Legislação Participativa (CDH);

VII - Comissão de Relações Exteriores e Defesa Nacional (CRE);

VIII - Comissão de Serviços de Infraestrutura (CI);

IX - Comissão de Desenvolvimento Regional e Turismo (CDR);

X - Comissão de Agricultura e Reforma Agrária (CRA);

XI - Comissão de Ciência, Tecnologia, Inovação, Comunicação e Informática $(\mathrm{CCT})$;

XII - Comissão Senado do Futuro.

XIII - Comissão de Meio Ambiente (CMA). (Redação dada pela Resolução $\mathrm{n}^{\circ} 3$, de 2017)

Comissão Temporária - As Comissões Temporárias são órgãos técnicos, formados por parlamentares, que possuem um período definido de existência, sendo extintas pela conclusão de sua tarefa, ao término do respectivo prazo ou ao término da sessão legislativa ordinária. Subdividem-se em internas, externas e parlamentares de inquérito (RISF, arts. 74 e 76).

Diário do Senado Federal - É um veículo oficial do Parlamento, no qual são publicadas as atas circunstanciadas de cada sessão - contendo, entre outros, os incidentes, debates, declarações da Presidência, listas de presença e 
votações, texto das matérias lidas ou votadas e os discursos - além de atas de comissões, normas promulgadas, atos administrativos e outros documentos que demandam publicação oficial. O Diário é publicado diariamente, durante as Sessões Legislativas Ordinárias e Extraordinárias, e, eventualmente, nos períodos de recesso, sempre que houver matéria para publicação.

Legislatura - Compreende o período de quatro Sessões Legislativas, a contar do ano seguinte ao das eleições parlamentares.

Pauta - A pauta é uma espécie de documento onde se encontram os tópicos que devem ser abordados durante a determinada reunião.

Reuniões - nome denominado às assembleias das Comissões

Relatório da Presidência - Previsto no art. 269, I, do Regimento Interno do Senado, o Relatório da Presidência (RAP) é publicado anualmente. De responsabilidade da Presidência, trata-se de um repositório de informações sobre o Processo Legislativo e a atuação dos parlamentares ao longo da Sessão Legislativa, englobando o funcionamento do Senado Federal e do Congresso Nacional, tanto em Plenário quanto no âmbito das comissões e demais colegiados. As informações apresentadas no Relatório contêm, dentre outras, a representação por Unidades da Federação, Partidos e Blocos Parlamentares e a tramitação das matérias e proposições ao longo da Sessão Legislativa.

Relatório mensal da Atividade Legislativa - O relatório mensal da Atividade Legislativa consolida informações referentes a sessões e reuniões plenárias, matérias legislativas deliberadas e atuação das comissões, entre outros, no âmbito do Senado Federal e do Congresso Nacional.

Sessão Conjunta - reunião da Câmara dos Deputados e do Senado Federal em caráter solene, para inaugurar a sessão legislativa, dar posse ao Presidente e ao Vice-Presidente da República eleitos, promulgar emendas à Constituição Federal, homenagear Chefes de Estado estrangeiros e comemorar datas nacionais. Em sessão conjunta, compete também ao Congresso Nacional discutir e votar o Orçamento, conhecer de matéria vetada e sobre ela deliberar $\left(\mathrm{CF}\right.$, art. $57, \S 3^{\circ}$ e $\mathrm{RCCN}$, arts. $1^{\circ}$ e $\left.3^{\circ}\right)$.

Sessão deliberativa ordinária - Sessões, para os efeitos do art. 55, III, da Constituição Federal, realizadas de segunda a quinta-feira às quatorze horas e às sextas-feiras às nove horas, quando houver Ordem do Dia previamente designada. (RISF, art.154) 
Sessão deliberativa não ordinária - Sessões, com Ordem do Dia própria, realizadas em horário diverso do fixado para sessão ordinária, ressalvado o disposto no $\S 3^{\circ}$. O Presidente poderá convocar, para qualquer tempo, sessão extraordinária quando, a seu juízo e ouvidas as lideranças partidárias, as circunstâncias o recomendarem ou haja necessidade de deliberação urgente. (RISF, art.154)

Sessão especial - Possui natureza honorífica e destina-se a comemorações, homenagens ou recepção de autoridades (RISF, art. $154, \S 5^{\circ}$ ). Durante sua realização, usam da palavra oradores previamente designados pelo Presidente do Senado ou pelas lideranças partidárias ou de blocos parlamentares (RISF, art. 200, caput).

Sessão Legislativa Extraordinária - Compreende o trabalho realizado durante o recesso parlamentar, mediante convocação. Cada período de convocação constitui uma Sessão Legislativa Extraordinária.

Sessão Legislativa Ordinária - Período de atividade normal do Congresso Nacional a cada ano, de 2 de fevereiro a 17 de julho e de $1^{\circ}$ de agosto a 22 de dezembro

Sessão não-deliberativa - Sessão destinada a discursos, comunicações, leitura de proposições e outros assuntos de interesse político e parlamentar, e realizar-se-á sem Ordem do Dia. (RISF, art.154)

Sessão Plenária - Corresponde à instância máxima de discussão, deliberação, pronunciamento e homenagens do Poder Legislativo. São classificadas como deliberativas ordinárias, deliberativas não-ordinárias, extraordinárias, não deliberativas e especiais. (RISF, art.154)

Subcomissões - Criadas pelas Comissões Permanentes objetivando uma análise mais específica sobre um determinado tema. 